\title{
ADVANCING CRAFT A TRANSLATION TO MODERN TECTONICS
}
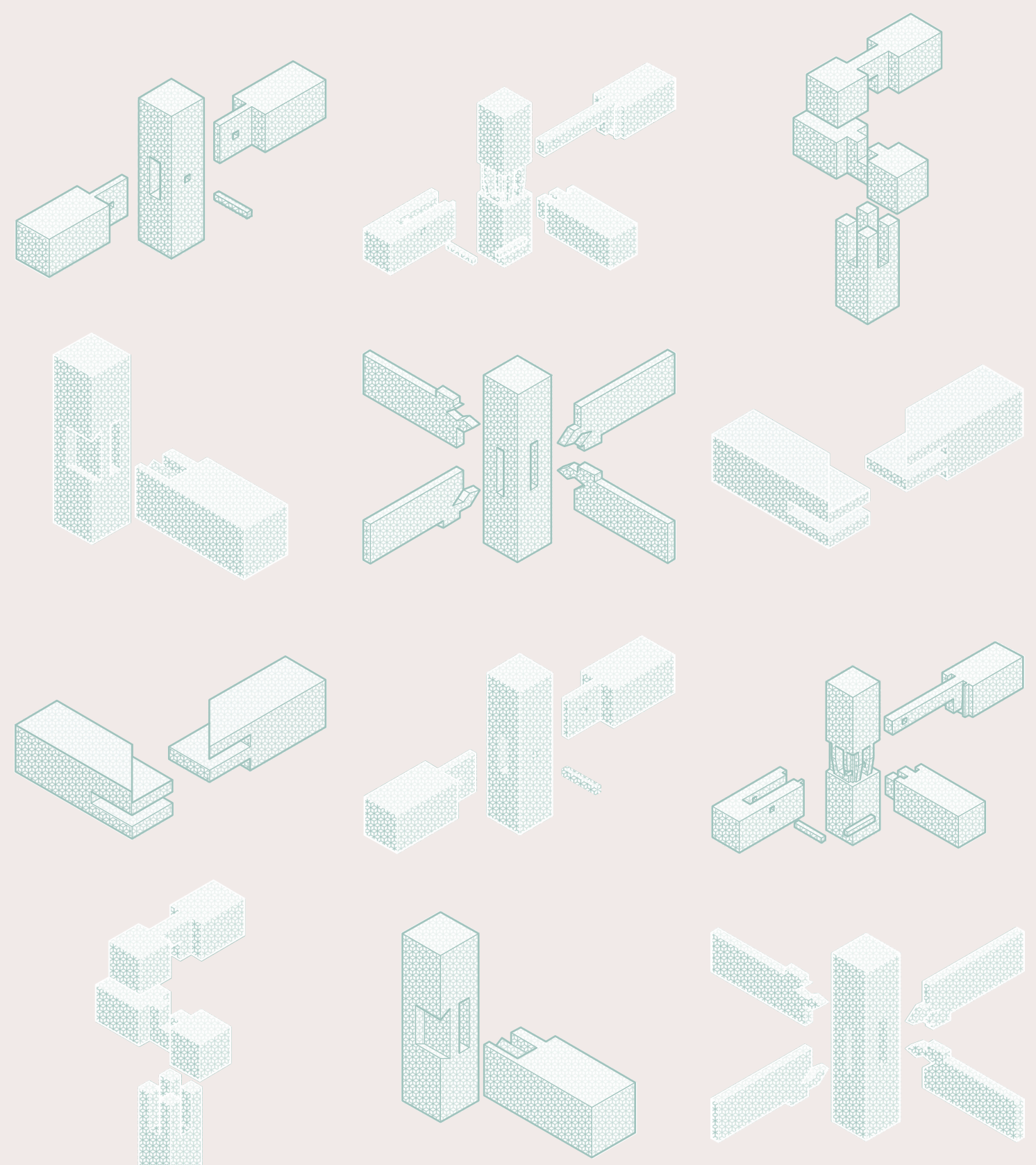

A 120 point thesis submitted in fulfillment of the requirements for the degree of Master of Architecture (Professional)

Victoria University of Wellington, School of Architecture Jasmine Tran

2020 


\section{ACKNOWLEDGMENTS}

First, I would like to express my deepest gratitude to the following people.

Natasha Perkins, supervisor and friend who supported our stream throughout the rollercoaster of a year.

Alice Harland for her encouragement.

Lizzie, Maria, Pam, and Renee, a great stream to work with.

Graeme, Phil, and the workshop team, who were always there to help.

Paul Tozer and Isaac Graham for their knowledge.

Degree of Freedom and Kengo Kuma and Associates for their assistance.

My family, who always believed in me. Without their love and support, I would not have had this opportunity.

To my friends who kept the stressful times fun.

Griffin and his family for looking out for me.

Thank you. 


\section{ABSTRACT}

Well-made joinery can be pricey, no matter if it is hand-crafted or prefabricated. This thesis attempts to understand all available tectonics used to fabricate joints and find a potential alternative to generate well-made joints in a more accessible manner. Specifically looking at traditional Japanese carpentry, Japanese joinery is a crucial precedent for examining due to its prestigious nature for withstanding the test of time and earthquakes. Here following the crafting of traditional joints is necessary to understand the hand-tool tectonic, allowing for an understanding to then iterate joints in the other tectonics with machine-tools and information-tools. Retrofitting provides for the opportunity for owners to add additional components to their existing properties. The standard residential home is commonly retrofitted by the owners to follow the 'trend' and 'personalise' their home. The want for retrofitting is usually due to the basic nature of cookie-cutter homes that are common to the New Zealand suburbs. By studying ways to construct joints, methods of fabricating joinery can assist the DIY culture in New Zealand, whether through prefabrication on the CNC router that is sold as kitsets or machine jigs that can be made onsite. 


\section{TABLE OF CONTENTS}

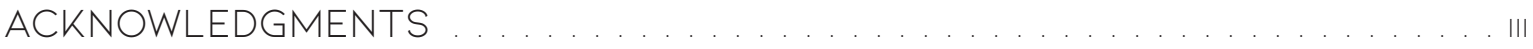

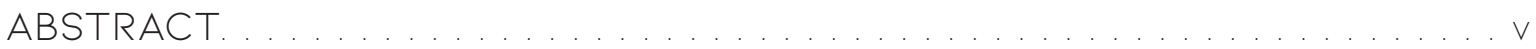

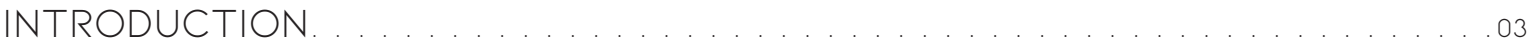

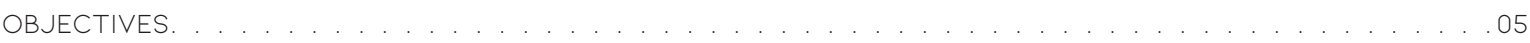

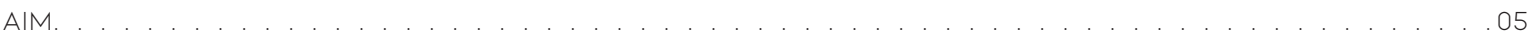

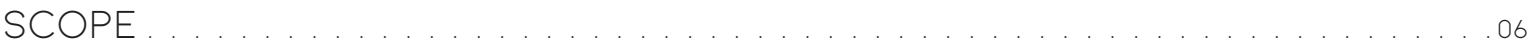

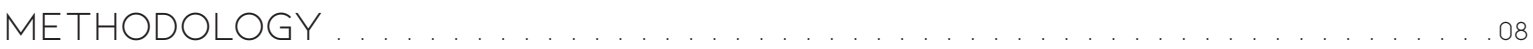

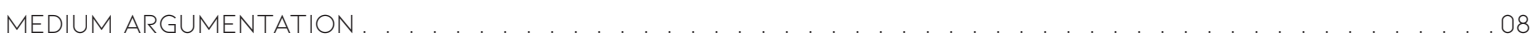

DOUBLE DIAMOND METHODOLOGY . . . . . . . . . . . . . . . . . . . . . . . . . . . . . . . . . . . . . . . . . .

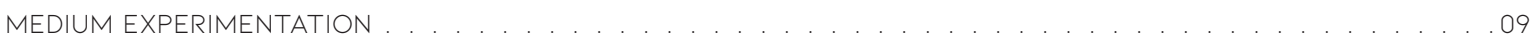

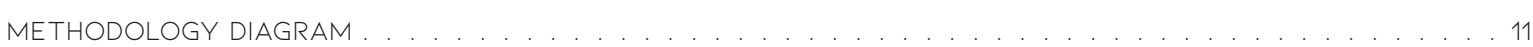

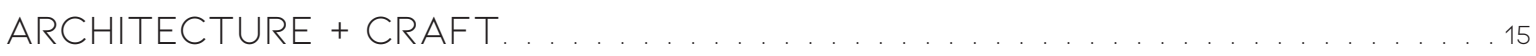

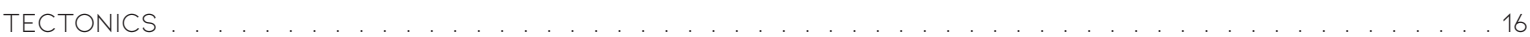

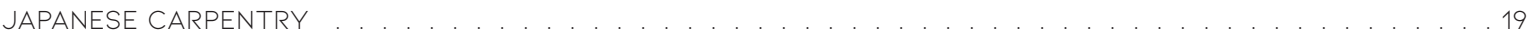

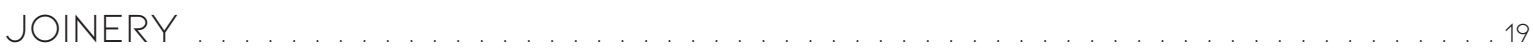

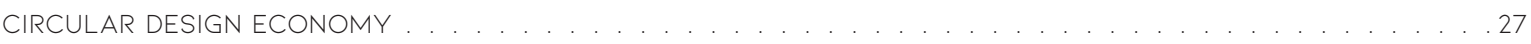

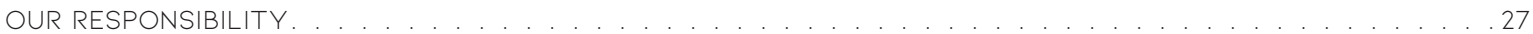

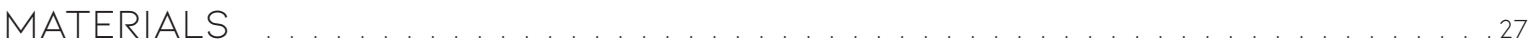

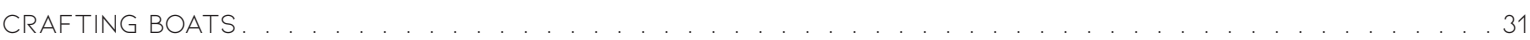

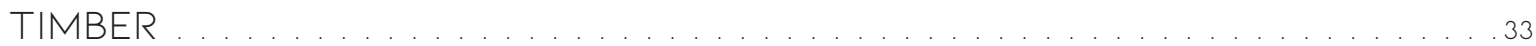

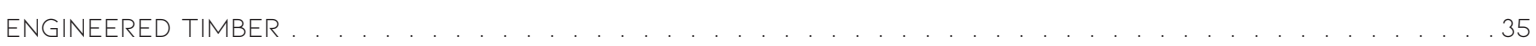

HEAT-TREATED NATURAL WOODS $\ldots \ldots \ldots \ldots \ldots$

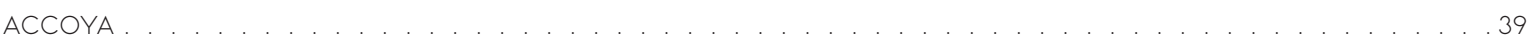

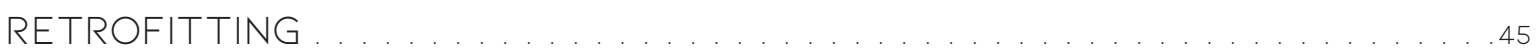

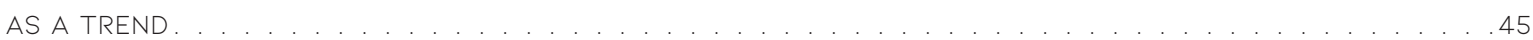

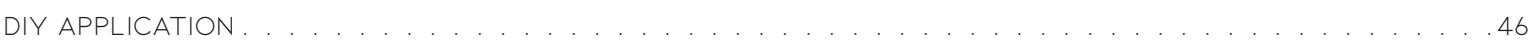




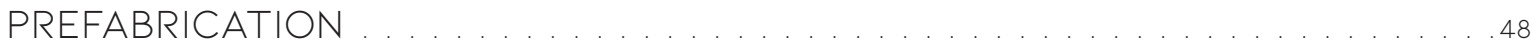

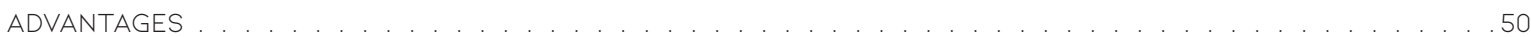

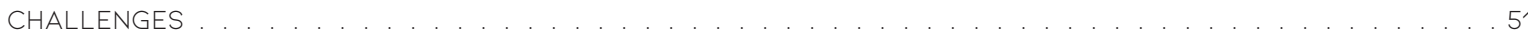

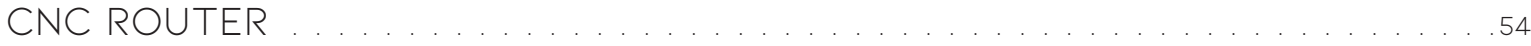

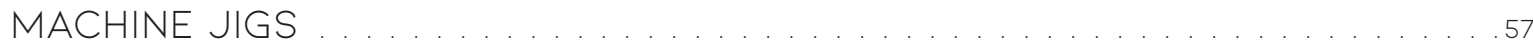

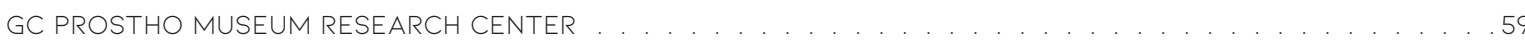

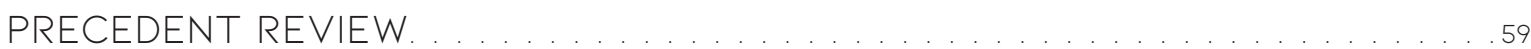

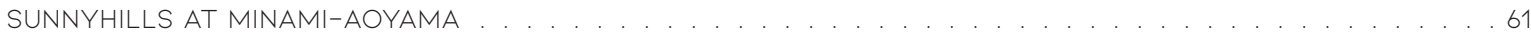

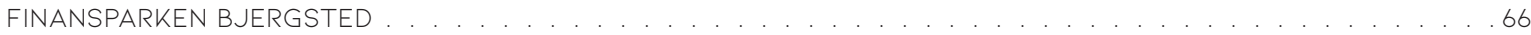

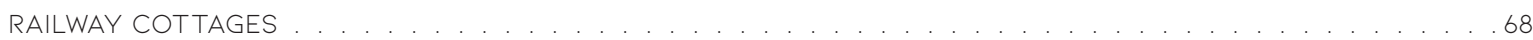

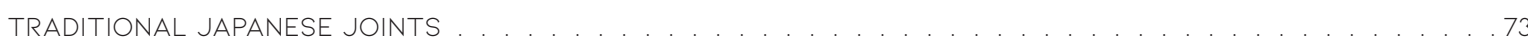

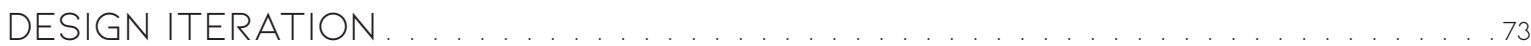

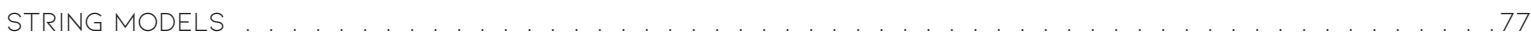

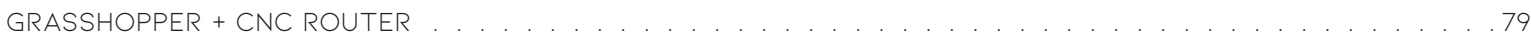

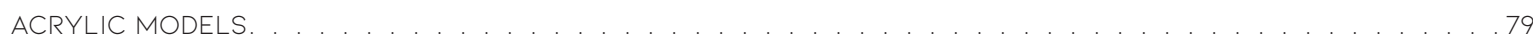

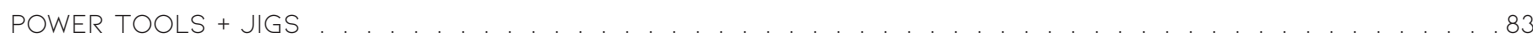

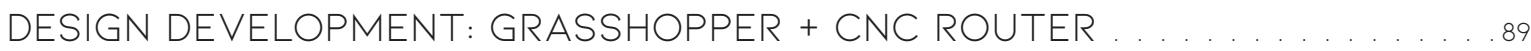

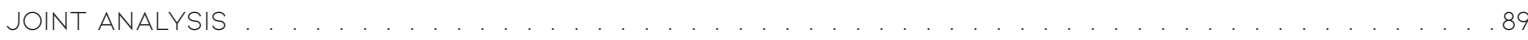

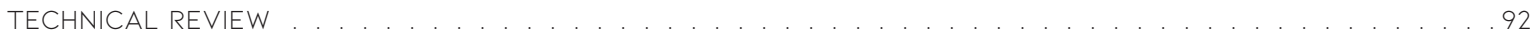

DESIGN DEVELOPMENT: POWER TOOLS + JIGS . . . . . . . . . . 95

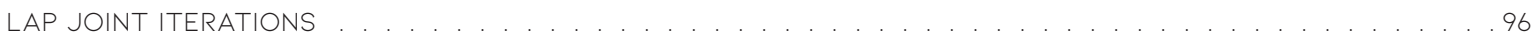

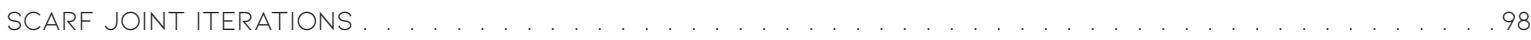

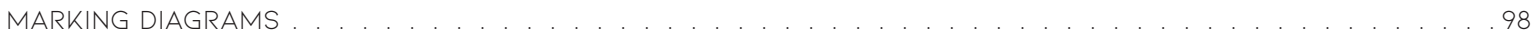


SPLICING JOINTS

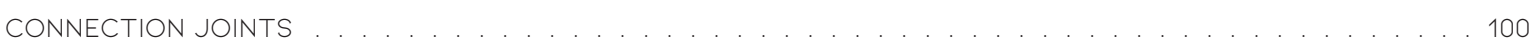

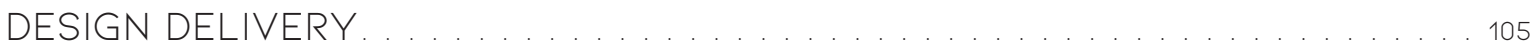

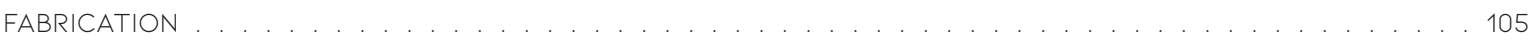

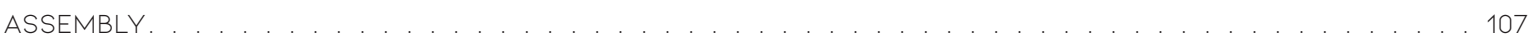

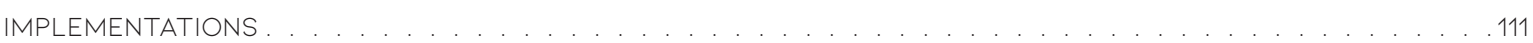

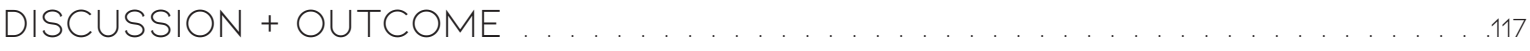

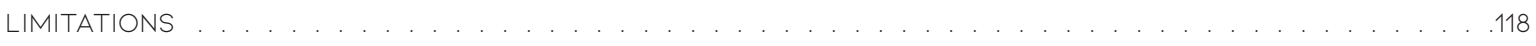

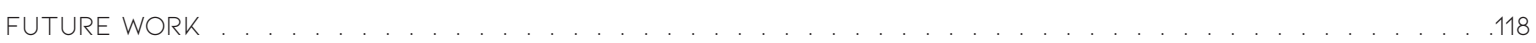

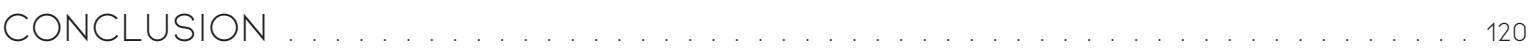

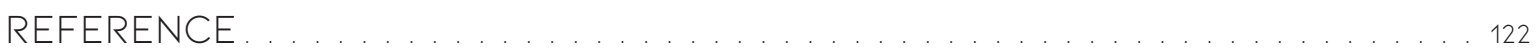

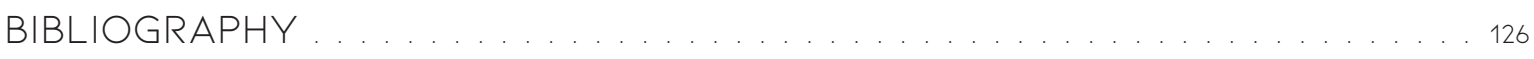

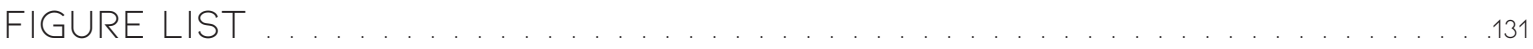

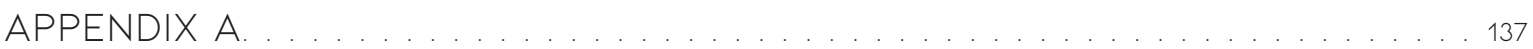

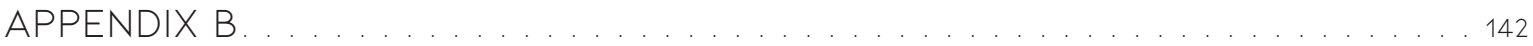



- 1 (1) a C.P. $<\div \div$ -

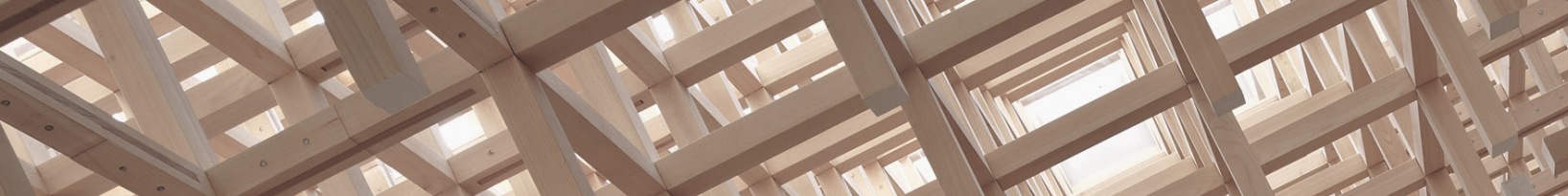

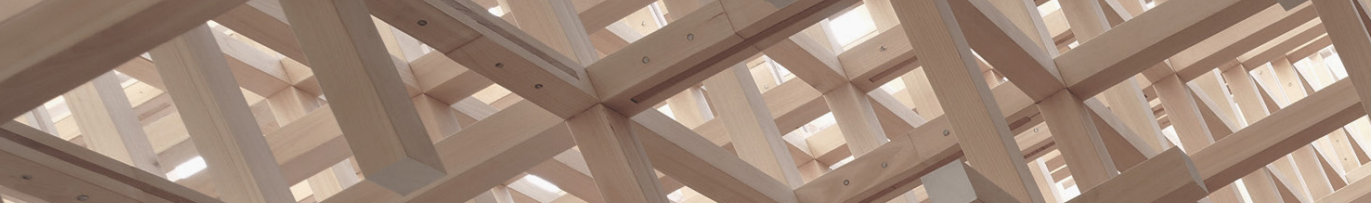

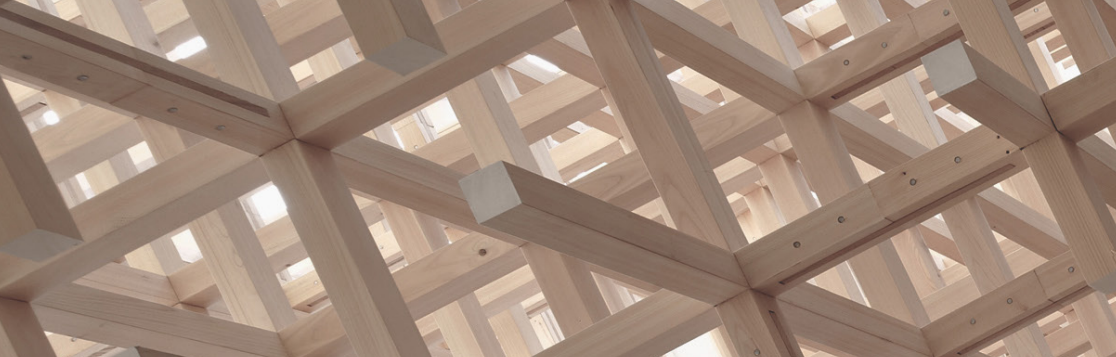
r

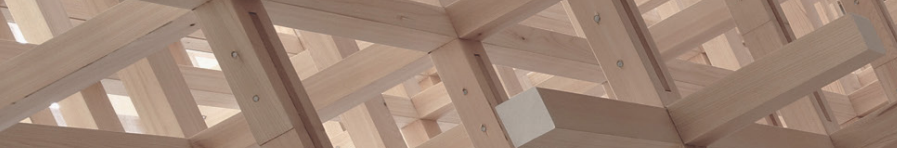




\section{DISCOVER + DEFINE}

INTRODUCTION AIMS + OBJECTIVES

SCOPE

METHODOLOGY

MEDIUM ARGUMENTATION

MEDIUM EXPERIMENTATIONS

DOUBLE DIAMOND METHODOLOGY

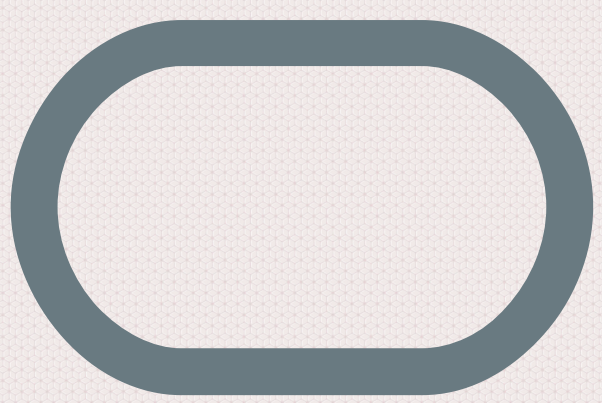





\section{INTRODUCTION}

This research aims to find a solution to craft that has the capability for easy production in the residential and light industrial scale. Wellmade joinery is expensive, no matter which tectonic is used. This thesis attempts to understand all tectonics used to create joints, searching for a potential alternative to form well-made joints in a more accessible manner.

Craft plays a role across different disciplines; however, with the advancement of technology, traditional crafts in architecture has lost its importance. In recent times, there has been a resurgence in architectural craft that does not follow the traditional tectonic of manual craftsmanship and tradespeople. Craft in architecture now sits between art and technology, using toolpaths and parametric modelling, where it allows for the availability for uniqueness and individualism. This thesis looks at some possible tectonics for constructing timber joinery in order to reintroduce craft in a more accessible method. By researching and analysing the wooden, industrial, and digital tectonic, this thesis explores the capability of each tectonic for easy production in the residential and light industrial scale.

This research looks specifically at traditional Japanese carpentry. Japanese joinery is a crucial precedent for examining due to the environmental variables being very similar to New Zealand. One of the objectives for this thesis is to take into consideration the material qualities of the joinery and where it will end up. The methodology designed for the joints must take into account the circular design economy, allowing for the ability to be disassemble for reusing, repairing and recycling.

Timber joinery can be used in retrofitting, which is an excellent method for the preservation of existing buildings that may be outdated, bland, 
or not up to the building standard for occupation. Homes are a place where identity is expressed through personalisation and décor. DIY (Do It Yourself) plays an active role in New Zealand culture that ties the person to their home by allowing for their identity to be materialised. This thesis will concentrate on the methodology of joinery production with the intent of DIY and the potentials of structural retrofitting. Exploring the use of the CNC router creates an opportunity for the possibilities to prefabricate. It is a method of construction that has the potential to be cheaper, faster and more sustainable, therefore more accessible to the wider audience. Machine jigs are a tool that makes crafting timber relatively simpler and quicker, consequently is useful when processes need to be repeated. If a system for jigs is produced and allows for joints to be made quickly while making the set up easy, they can assist in the DIY culture New Zealand upholds.

This thesis discusses the aims and objectives, along with the methodology and scope in Chapter 1.1. Chapter 2.1 reviews the existing perceptions of craft and the types of tectonics used in timber architecture, which continues through to analysing Japanese carpentry. Chapter 2.2 examines materials, and as designers, how to utilise the products. The materials explored in this chapter explains the importance of sustainable timber and the types of products that can be produced from low-grade wood. Chapter 2.3 discusses how the product can be applied through the use of retrofitting and how the joints can be potentially produced with prefabrication and how it can be fabricated. Precedent reviews are reviewed to understand the way joints have been applied to existing buildings. Chapter 3.1 examines design iterations of hand-tool technology, machine-tool technology and information-tool technology to conclude the most effective method of fabrication. Chapter 4.1 refines the method of fabrication, and chapter 5.1 summarises the research findings. 
How can we simplify timber crafts in architecture sustainably, and allow for easy construction at a residential and light industrial scale that is readily available?

\begin{abstract}
AIM
To create a method of timber construction that has the sense of craft and capability for easy production in the residential and light industrial scale that is readily available.
\end{abstract}

\title{
OBJECTIVES
}

Analyse traditional Japanese joinery through experimentation and model making to understand the process. Fijian kauri is used for the mock models, as it has allowed for an understanding of how the process of the joinery and how the design can be simplified.

Interviewing craftsmen to understand what craft means, and how craft can be advanced alongside technology. This will provide an outside perspective from architecture on how technology and craft intertwine. Identify sustainable construction strategies and a viable solution for the New Zealand market.

Develop a joinery design that can be prefabricated and mass-produced. The design will be the outcome from researching Japanese joinery with influences from other methods of design.

Test parametric modelling and scripting to automatically generate joints for milling with a $\mathrm{CNC}$ router.

Develop and test jig designs that can allow for on-site construction.

Produce a kit set and process of the different options of joinery design.

Test and produce a hypothetical design. 


\section{SCOPE}

This thesis is to explore architectural tectonics through the fabrication of timber joinery. Aiming to find a methodology that can produce wellmade timber joints in a more accessible manner, the outcome will be achieved through three primary stages: the exploration of tectonics, design of process, and physical fabrication.

First, the research was conducted through the analysis of traditional Japanese joinery. Beginning with the testing of traditional tectonic, hand-tools were used to reproduce timber joints with Fijian Kauri. Fijian Kauri is an easily sourced material in Wellington and is the closest material to what is commonly used in Japan. Reproducing these joints provided an insight as to how joinery was cut, leading to the testing of how joinery can be translated for fabrication with information-tools and power-tools. Rhino, grasshopper and Rhino CAM are used as information-tools to control the geometry and sizes for the joints, where it will be fabricated on a CNC router. The CNC router has been selected due to its availability, other tools like the robot arm are not within this scope as they have a high cost, leading to limited accessibility. There are many other machine-tools like the circular tool, oscillating tool, and 
hand router that are commonly used for onsite construction. To test power tools, the mitre saw has been selected as it is fixed, hence has more control over cutting depth and angles. After analysing the handtool tectonic, the testing of power-tools and information tools begins. The goal is to find a tectonic most suited to achieving quick production of joinery in an accessible way. The third step is to fabricate the iterations of joints using the selected method physically. Physical prototyping was essential to refine the process.

Japanese carpentry is a crucial precedent for examining as it is known to withstand the test of time and lateral loads such as earthquakes. Other forms of joinery will not be looked at in-depth as they are outside of the scope. The intention of these joints is for them to integrate into existing properties as retrofitting elements to enhance identity in the space. There is a limitation of knowing the structural integrity and seismic resilience of the joints. It is not possible to test the strength in this research; therefore, it will be outside of this scope. The information based on the strength of the joints will be dependent on the research conducted throughout the years by Japanese carpenters. This research does not involve constructing a full-scale prototype, but only conceptual scaled models due to the time constraint. 


\section{METHODOLOGY}

Various methods can be used to conduct research, with different approaches leading to different types of methodologies. Typically architectural research is done through design-led research or researchled design. These research methods use at least one of the seven conventional research methods defined by Groat and Wang: historical research, qualitative research, correlational research, experimental research, simulation research, logical argumentation, and case studies + combined studies (Groat \& Wang, 2013). This thesis is conducted through a research-led design process that uses primarily logical argumentation, case studies + combined studies, and experimental research, with the assistance of historical research (fig. 02). The research looks closely at the intricate traditional timber joinery and reviews the traditional method to find a substitute that allows for easy fabrication.

\section{MEDIUM ARGUMENTATION}

Beginning with the technical review, the research will focus on cases in context to the tradition, craft, material, and precedent. Case studies have been undertaken to understand existing construction techniques. Understanding how these techniques have been utilised in the past is fundamental to this thesis. Historical research is used to understand the narrative created by the cultural shift from traditional to industrial, and

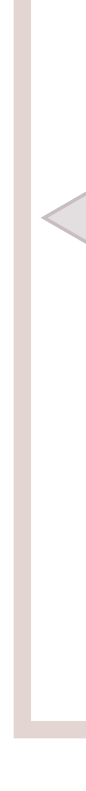
then to digital design. This is crucial to the progression of timber crafts, to explain links between the tradition, craft, material, and precedent. Interviews have been conducted with logical argumentation to interpret the information against the research. This provides a paradigmatic innovation on the process and deductive argumentation through logic.

Fig. 02 Research Method diagram adapted from Groat and Wang's Architectural research methods "a conceptual framework for methods". 


\section{MEDIUMEXPERIMENTATION}

Recreating timber joints through experimental research with traditional mediums and digital mediums of Japanese timber joints tend to be tedious and very difficult to craft. This experimentation assists in understanding how to simplify traditional techniques, applying them to prefabricated timber joints. This will then allow for the exploration of form, digital modelling, and jigs.

\section{DOUBLE DIAMOND METHODOLOGY}

The double diamond methodology is not a linear process, but instead depicts the converging and diverging nature of research (fig. 03).

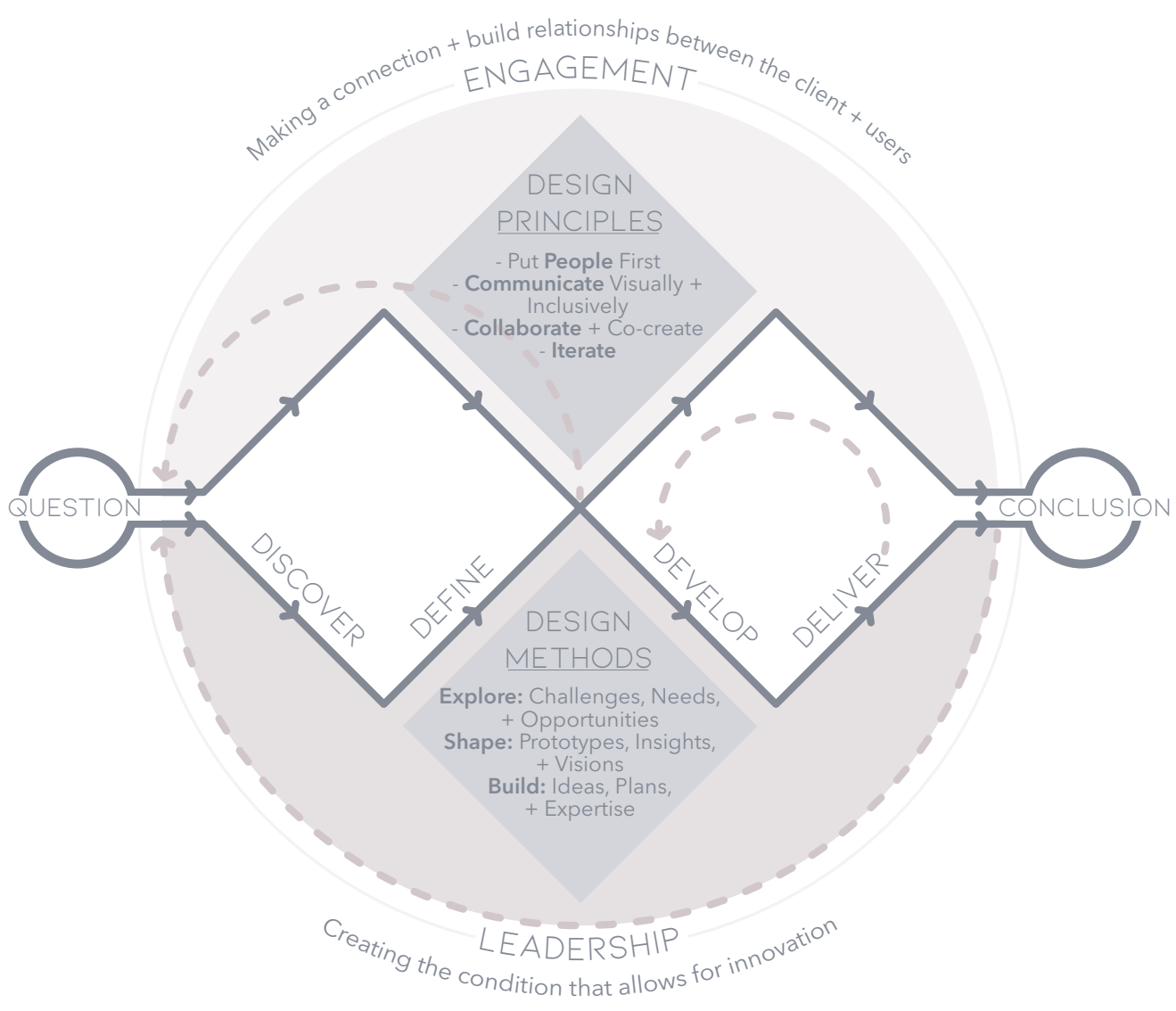

Fig.03 Diagram adapted from Design Council's "Framework for Innovation" diagram. 
This methodology can be broken down into four key phases that include fundamental design principles:

Discover: the designer is to understand the problem and affected issues, with the intention to put people first.

Define: using the information from the discovery phase, the designer is to define the scope and challenges, communicating visually and inclusively the problems and ideas.

Develop: encourages collaborate, co-create, and iteration.

Deliver: the testing of solutions, iterating, and improving.

To create a culture of success using the double diamond methodology, there is a need for leadership and engagement. Leadership encourages innovation, allowing for the ability to enhance skills through learning and experimentation. Engagement with the user allows for the designer to have a greater understanding of the user and their needs (Design Council, 2019).

The outcome requires critical reflection at each stage for improvement and refinement; therefore, criteria for the joints must be established based on practicality, availability, and aesthetic. The final product must have the ability for easy production for residential properties and light industrial buildings, allowing the craft to be readily accessible. 
METHODOLOGY DIAGRAM

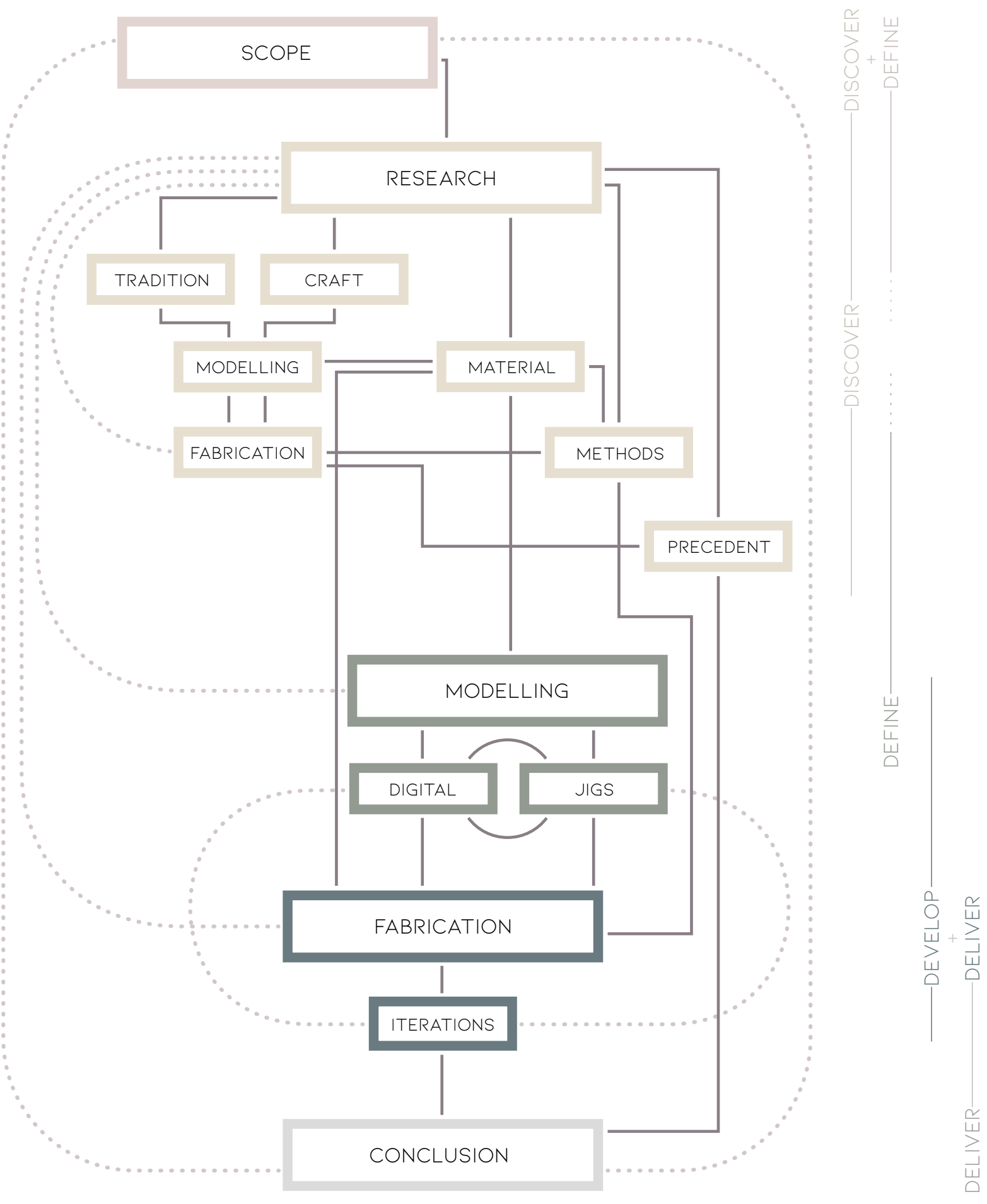

LEGEND 
To reinvigorate new and existing homes, the integration of craft is crucial. Craft evokes identity as it provides an experience; by manipulating how a material is used, we can begin to enhance social identity and place. The definition of craft is the requirement of skill and knowledge to produce a product. Traditional joinery in Japan is an excellent example of craft in architecture. Japan faces comparable environmental challenges to New Zealand and therefore uses the same vernacular building material of timber. Taking on the characteristics of Japanese joinery can help craft in New Zealand to celebrate imperfections, turning them into perfections. This links to Chapter 2.2, which discusses materials, and furthers the discussion of our responsibility as designers and architects and how that affects the circular design economy.

\section{DISCOVER}

ARCHITECTURE + CRAFT

TECTONICS

JOINERY

JAPANESE CARPENTRY
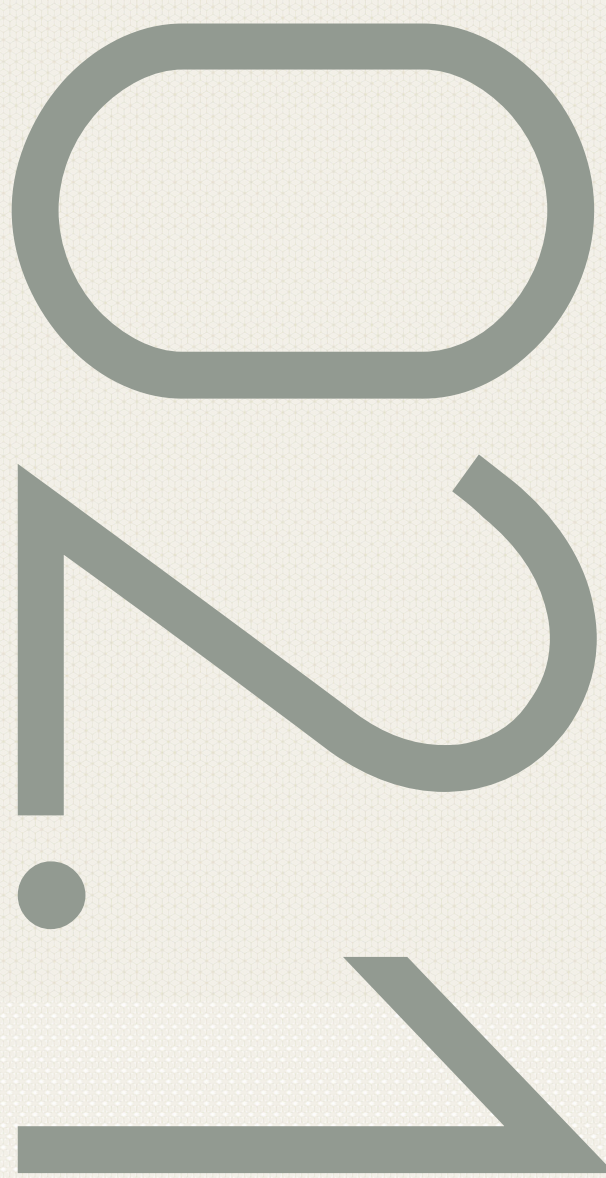



\section{ARCHITECTURE + CRAFT}

Craft plays a role across many disciplines; however, with the advancement of technology, traditional crafts has lost its importance in design. The term 'craft' derives from the Old English word cræft. Cræft is an combination of knowledge, power, and skill, with "an extended definition where a sense of 'wisdom' and 'resourcefulness' surpass in importance the notion of 'physical skill'" (Langlands, 2018, p. 9). Cræft was a way of thinking and the relationship between material and people. The industrialisation has allowed for faster and cheaper production of goods; however, it loses 'craft'. As stated by Langlands "the concept of craft as a form of art emerged - as a self-conscious counterpoint to factory-made goods. Craft became defined in opposition to industrial manufacture" (Langlands, 2018, p. 12). There is a resurgence in craft in architecture, not through the traditional tectonic of manual labour and tradespeople, but through a new notion of craft that uses toolpaths and parametric modelling. The new generation of craftsmen will be "trained in a completely virtual environment" (Garber, 2014, p. 130). As technology has advanced, the potentials to produce craft quickly and at a large scale has increased. 


\section{TECTONICS}

Tectonics derives from the Greek terminology tekton, which refers to a builder, carpenter, woodworker, or a master in any art. Tectonics can be understood as "construction technology's potential for poetic expression" (Weinand \& Buri, 2011, p.56). Tectonics does not necessarily favour any particular style; however, "in conjunction with site and type, serve to counter the present tendency for architecture to derive its legitimacy from some other discourse" (Frampton, 1995, p.2). Three key factors outline a building's tectonics: the material, the tools, and the design. The advancement of technology further defines phases of evolution that the tectonics have undergone throughout history. Looking at timber buildings, there are three tectonic phases: the wooden - the use of hand-tool technology, the industrial - the use of machine-tool technology, and the digital - where information-tool technology is used. 


\section{THE WOODEN}
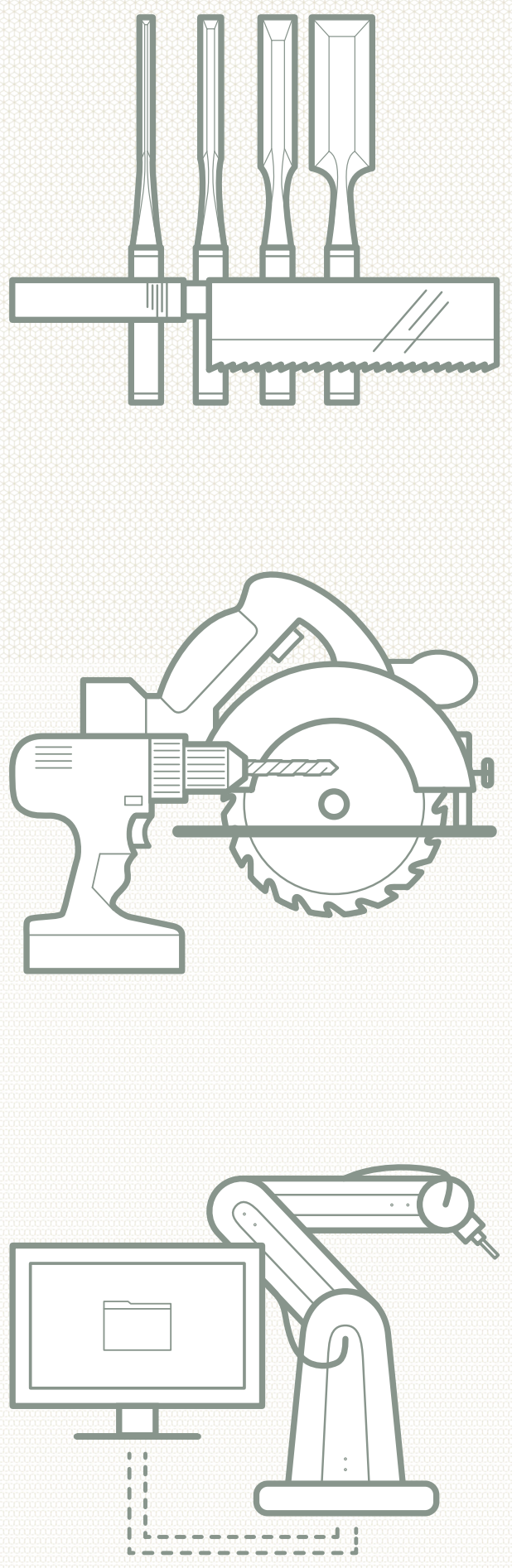

The traditional method of craft was through the use of hand-tool technology. Carpenter were "in charge of both execution and planning" (Weinand \& Buri, 2011, p.56), dealing with the drawings and construction. The carpenter would take into account the specific properties of timber in their planning and execution, leaving traces of individuality and personalisation in their finished product.

\section{THE INDUSTRIAL}

Industrialisation created more specialisation amongst the tradesmen. Carpenters now are commonly in charge of execution, with the "design and technical planning were in the hands of the architect and the engineer" (Weinand \& Buri, 2011, p.57). Under human control, the management of the tool and workpiece was transferred to machines, known as machine-tool technology. The industrial age brought standardisation and specialisation.

\section{THE DIGITAL}

Unlike the industrial age, the use of information-tool technology has brought back the strong tenancy of individualisation, while still having speed in production. The ability to control machines through the use of computer coding and scripting eliminates the need for serial production. With the use of machine-tool technology, the operator would often use a one-time machine setting. In contrast, now the information dictating the form of a workpiece is directly integrated into the machine (Weinand \& Buri, 2011). 

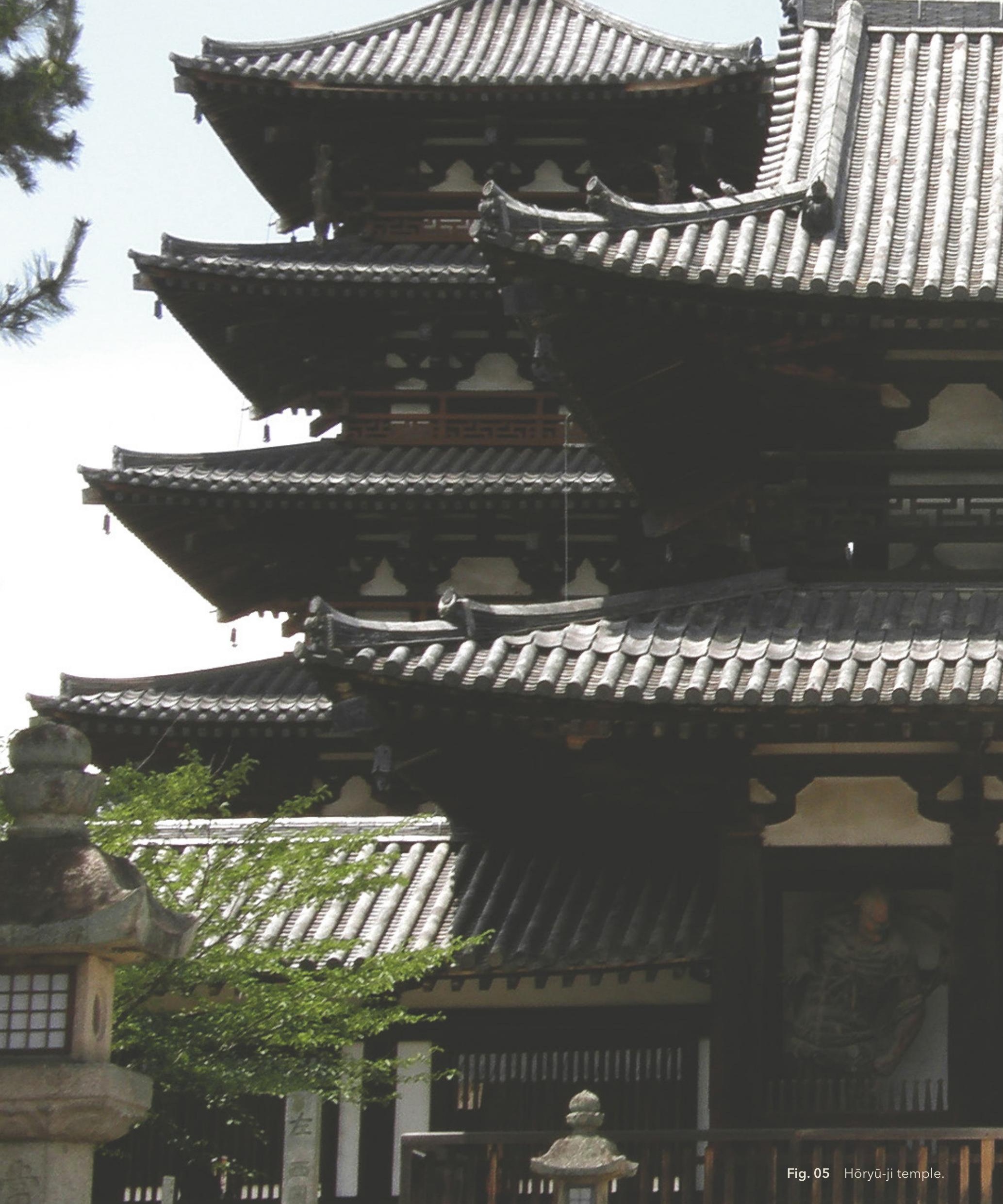


\section{JOINERY}

Joinery is a crucial component of woodworking and is the method of connecting two or more pieces of timber. There are many types of joints which fall into a few basic categories, fundamentally joints follow simple ideologies. It is found in furniture, cabinetry, and architecture, and can be crafted with all the tectonics discussed in the previous section. Traditional carpenters primarily tend to use hand-tools and power-tools, whereas industrial companies tend to produce joinery through powertools and information-tool technology. Well-made joinery is expensive, no matter which tectonic is used, this thesis attempts to understand all tectonics used to create timber joints, searching for a potential alternative to creating well-made joints in a more accessible manner.

\section{JAPANESE CARPENTRY}

A particularly well-resolved form of traditional joinery is Japanese carpentry. Japanese carpentry is renowned for its hand-built timber joinery that does not require any nails, screws, or glue to hold the separate timber members together. Historically in Japan, the carpenters were the craftsman, the architects and the engineer. It is a difficult skill to become proficient, requiring a lot of time and investment to master the techniques of Japanese carpentry. Every traditional carpenter would use tools they made, as tools "are not only a part of his craft but a part of him" (Seike, 1977, p. 10). Some power tools are evident in contemporary workshops; however, they are only used as a tool for roughing out the joint, the craft would still be done through traditional means.

Japanese carpenters would generally specialise and master their craft. There are four categories:

Miyadaiku, the practice in the construction of Shinto shrines, and Buddhist temples.

Sukiya-daiku, the practice in the construction of teahouses and residential.

Tateguya, the practice in the construction of interior finishes. 
Sashimono-shi, the practice in the construction of furniture.

This section will look at the history of Japanese carpentry and will be reviewed as a system. Japanese joinery is a crucial precedent for examining as the environmental variables are similar to New Zealand, such as an island nation, climate, and earthquakes. The information gathered will be analysed and integrated into a design system.

DEVELOPMENT OF THE TRADE

The earliest evidence of carpentry in Japan is of primitive pit dwellings scattered across the country dating from Ancient Japan (fig. 06). During the Yayoi period (200 BCE - CE 250), there came the first significant revolution in Japanese architecture, metal tools from Korea were introduced, leading to a shift in construction. Metal tools allowed for the beginning of woodworking, shifting from structure made from lashings with ropes and vines to log cabins. These were created with either whole logs or dressed planks, where the early outputs acted as storehouses. At the end of the Yayoi period, this was possibly the beginning of specialised architecture, where carpenters began "forming the first rudimentary family guilds" (Seike, 1977, p. 9). These guilds established carpentry techniques and were protect as a secret, often specialising in the construction of shrines, temples, or dwellings. During this time, diplomatic contact with the Chinese court is made, which would later have influential effects in Japan.

The next crucial change was the shift in political power, leading to the unification of the Japanese architectural style. During the Tumulus period (250 - 552 CE) Japan became unified as a whole, where the "political consolidation was to have a lasting impact on carpentry and architecture" (Seike, 1977, p. 8). Contacts with mainland Asia has increased, leading to the loose influences from South Korea. During this time, carpenters from Korea migrated to Japan to "join a hereditary corporation, or family guild" (Seike, 1977, p. 8). These immigrants may have brought new technology and techniques; however, they seemed to have little influence on the established indigenous architectural style. 


\section{DEVELOPMENT OF ARCHITECTURAL TECHNOLOGY}

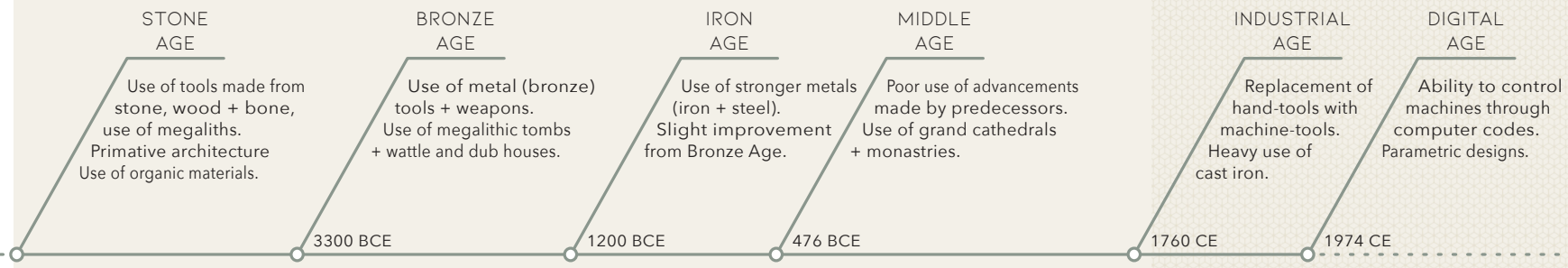

DEVELOPMENT OF JAPANESE ARCHITECTURAL TECHNOLOGY
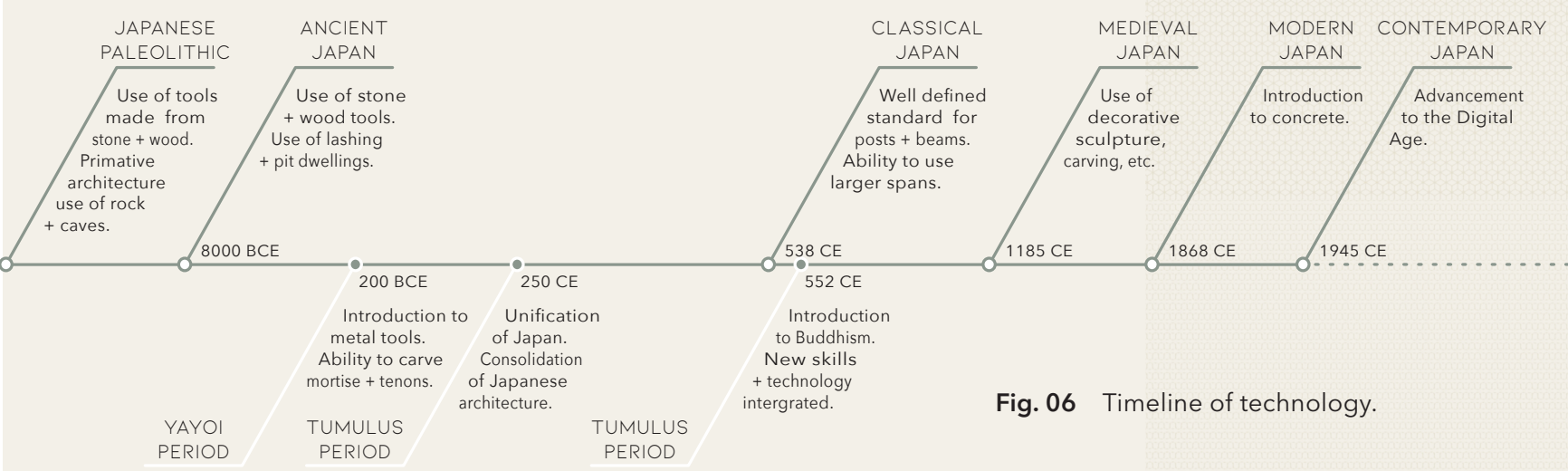

Fig. 06 Timeline of technology.

During the Asuka period (552 - 646 CE) the contact with mainland Asia has expanded with the introduction to Buddhism, and Buddhist carpenters. The Japanese carpenters quickly assimilated and adapted the new techniques which led to the great Buddhist temple Hōryū-ji (fig.05). The temple is located the town Ikaruga and is known to have the oldest surviving wooden structure in the world, the Golden Hall (679 $\mathrm{CE}$ ) and the Pagoda (693 CE). These two structures prove that if a timber structure is well maintained, it can survive Centuries.

The Japanese developed a proportion system, known as kiwari, meaning "determined construction proportions" and the literal meaning "dividing wood" (Seike, 1977, p. 14). Unlike the ancient Greeks experimentation 
with symmetry, proportions, and development of the Doric, lonic and Corinthian orders, kiwari is more of a general term. Kiwari is used to identify the concept of determined construction proportions and does not refer to a specific set of ideals. Acknowledging that kiwari is the governing principle of Japanese carpentry, examples of kiwari can be seen as early as the Nara period (646 - 794 CE), but the term did not come into use until the early seventeenth century.

As the forests in Japan become exhausted of good timber, there came a need for the development of numerous splicing and connection joints. Japanese joints fall into two categories, either tsugite (splicing joint) or shiguchi (connecting joint). Both joint categories should "contribute to both the strength and the beauty of a structure" (Seike, 1977, p. 20), where most joint must be reinforced. Contemporary methods of strengthening splicing joints include the use of high polymer adhesives, iron or steel plates, bolts, or they are nailed together. Before the development of high polymer adhesives, Japanese carpenters only had access to adhesives made of either rice, lacquer, resin or animal hide, which is not reliable for construction. It was desirable to use metal reinforcement in construction during ancient Japan; however, they were "difficult to come by, and hence expensive" (Seike, 1977, p. 95). The lack of metal led to the development of joints that didn't require any adhesive, plate, bolt or nail. Now in modern times, it is more efficient cost and timewise to use adhesives, metal plates, straps, nails and bolts to reinforce splicing and connection joints, rather than the complex and labour intensive traditional joinery. However, this may not be as efficient in the sustainable sense and will be discussed in Chapter 2.2. 


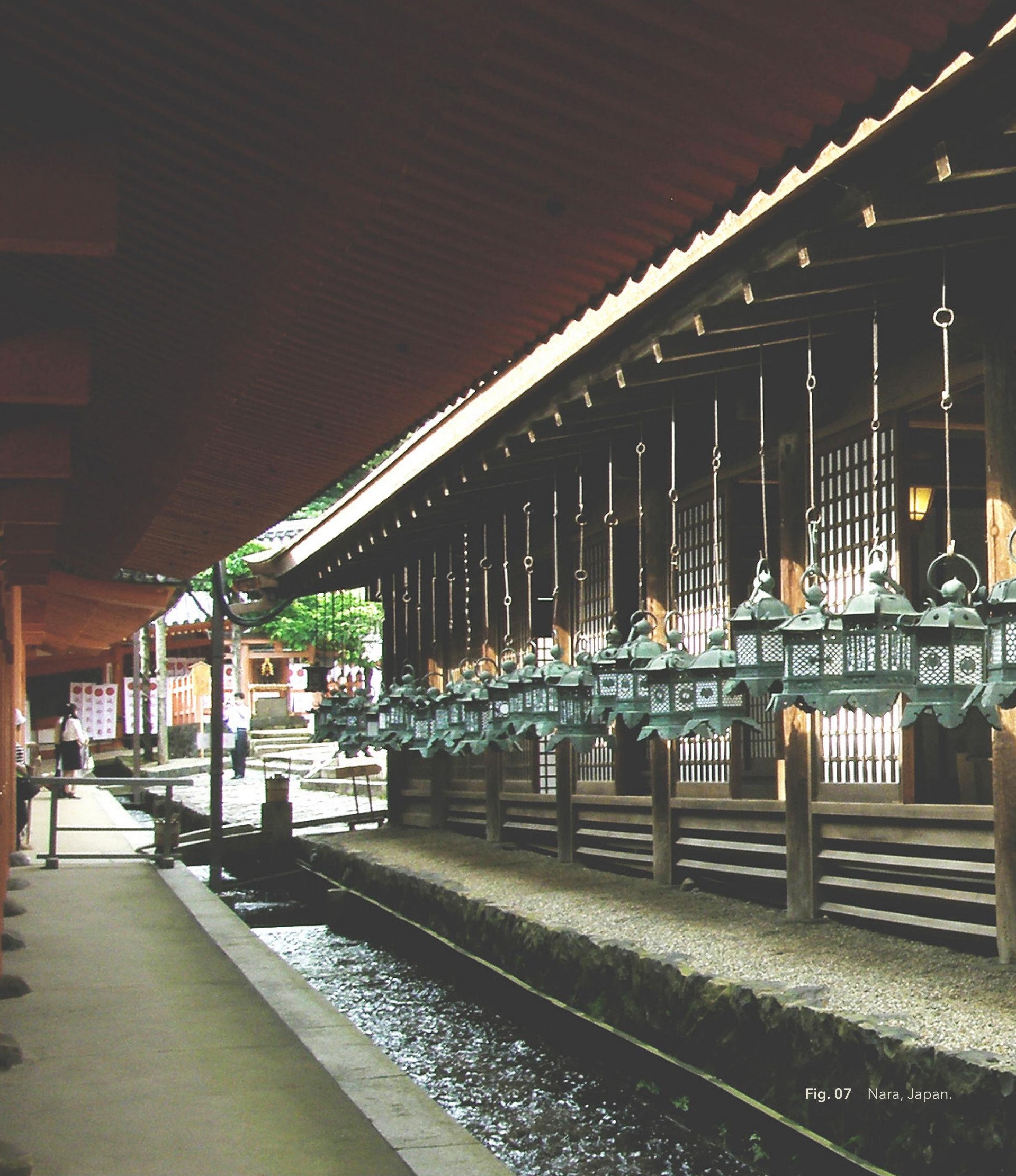



This section explains the importance of material selection and how this will impact the environment. As designers and architects, there is an importance in understanding material properties, and how to design in a way that allows for reuse of material. A consideration of how that will affect the environment in the long run leads to a push for sustainable material, which can only be achieved through innovative engineering and development. Timber construction is one of the standard methods in New Zealand and has been for centuries, therefor it has been selected for analysis in this thesis.

Discussion points on our responsibility as designers, circular design economy, and craft in boats have been made to emphasise the importance of sustainability. Timber, Heat treated natural woods, Accoya, and engineered timber is reflected as an option to assist sustainability. The following section, Chapter 2.3, explores retrofitting, methods of prefabrication and existing builds. This furthers the discussion on how the material will be implemented in architecture.

\section{DISCOVER}

MATERIALS

OUR RESPONSIBILITY

CIRCULAR DESIGN ECONOMY

CRAFTING BOATS

TIMBER

ENGINEERED TIMBER

HEAT-TREATED NATURAL WOODS

ACCOYA ${ }^{\circledR}$ 



\section{MATERIALS}

\section{OUR RESPONSIBILITY}

Designers and architects as creative professionals, have undertaken a responsibility between client and manufacturers. They as a profession are an influencer for the material selection, development, and output; encouraging "the creation of new materials and production methods" (Peters, 2011, p.12). As professionals, it is our responsibility to preserve the remaining rare and raw materials that are limited, seeking for an alternative solution. We must work towards material innovations and development to form an alternative material that is more natural and more sustainable. The aim to produce materials that have the same functional qualities as the raw materials has never been more critical to protect the remaining scarce resources for the next generations to come (Peters, 2011).

\section{CIRCULAR DESIGN ECONOMY}

Circular design considers what will happen to the product when it breaks or served its purpose. As a society, the linear system (fig. 09) has been the trend where the product is produced, distributed, used, and disposed of. Circular design (fig. 10) breaks this chain with the help of designers finding a method that creates a cycle where the product can be repaired, reused and recycled.

For the last six decades since the 1950s and 1960s, the throw-away culture has been advertised as 'the lifestyle'. Style obsolescence is a major issue and has been around since post-Second World War consumerist America. Products have been designed to be used and thrown away, even in perfect working condition (Whiteley, 1987). With the increase in global population, this the linear economy based trend is not sustainable, especially with the overexploitation of natural recourses and toxic waste it produces (Accsys Technologies, 2017). To design with 
minimal waste in mind, circular design takes into consideration where the product could end up in the future.

Roughly $80 \%$ of the environmental impacts are determined within the design phase. The choice of materiality, method of construction, and way it is consumed plays a huge role in what will happen to the product once it has served its purpose. The circular economy fundamentally designs out waste and futureproofs the products by allowing for the ability to be repaired, reused, and recycled. Integrating this cycle during the design phase allows for future natural resources and systems to regenerate after years of pillaging (Ellen MacArthur Foundation, 2017).

To protect the depleting resources, circular design must be considered when designing. As architects and designers, there is a responsibility to ensure that the output of the design contributes back to the economy, whether that product is reused, repaired or recycled for the circular economy to begin again.

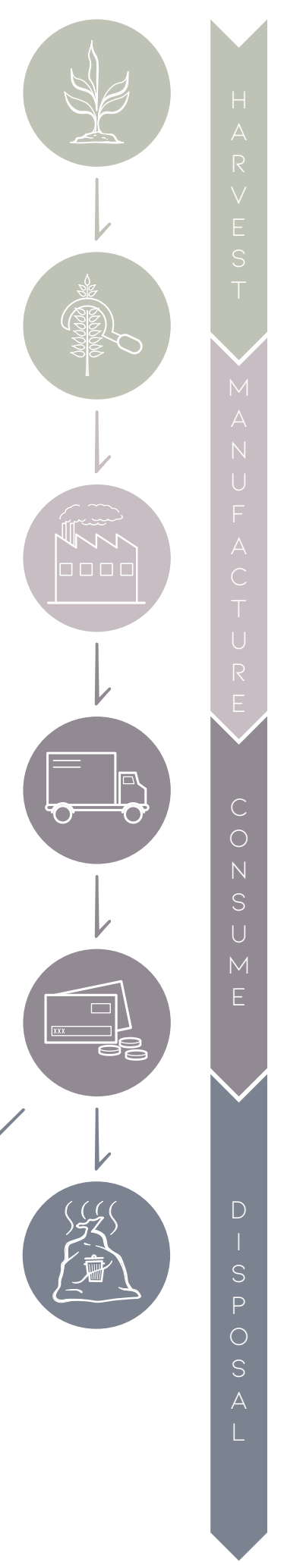

Fig. 09 Linear economy diagram adapted from Ellen 
"Design is integral in the shift to the circular economy. There's only so much we can do with products, services and systems based on the 'take, make, dispose' model. By re-thinking and re-designing, we can accelerate the transition to a new model that doesn't just' eke out resources a bit longer', but is restorative and regenerative by design."

(Ellen MacArthur Foundation, 2017)

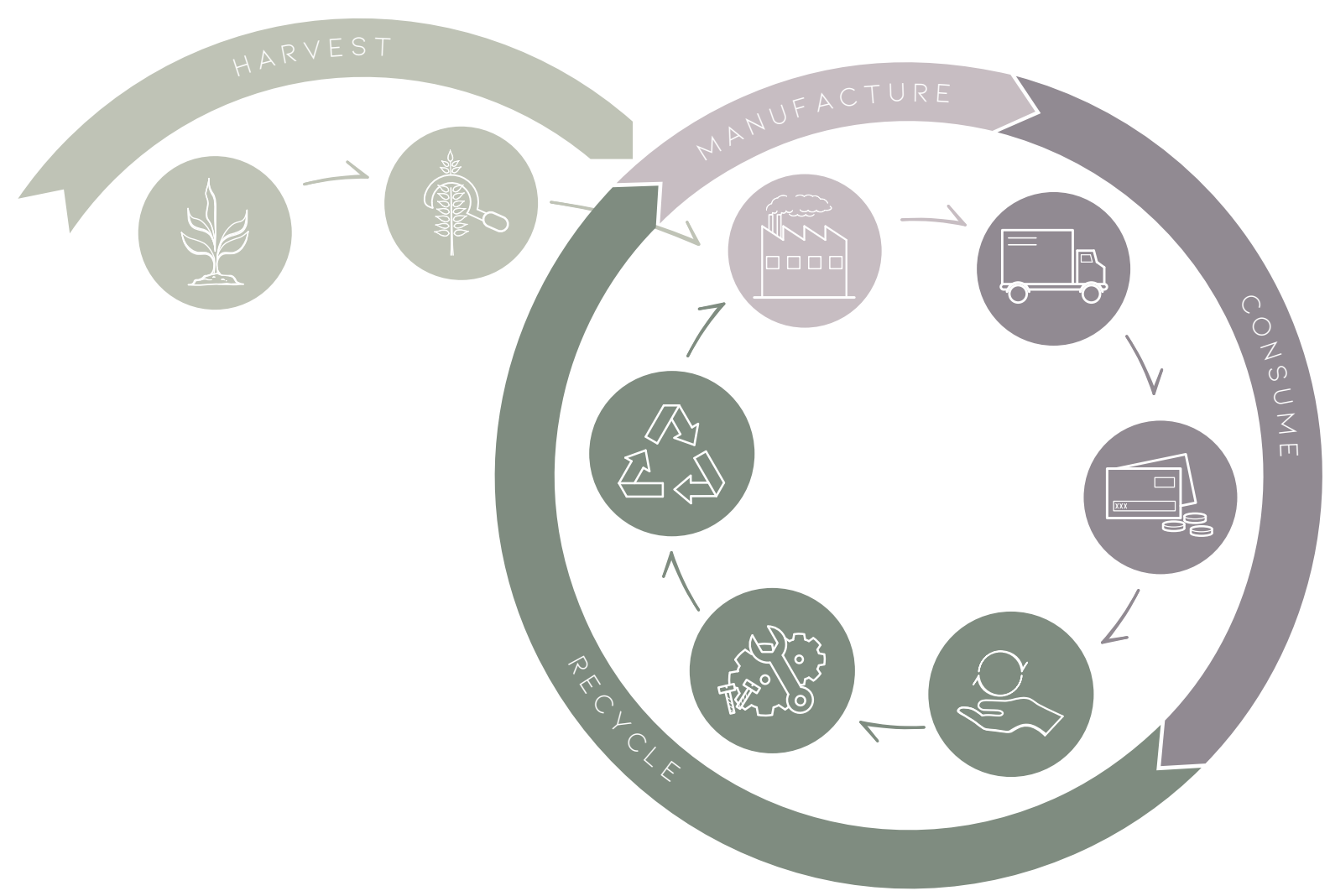

Fig. 10 Circular economy diagram adapted from Ellen MacArthur Foundation. 


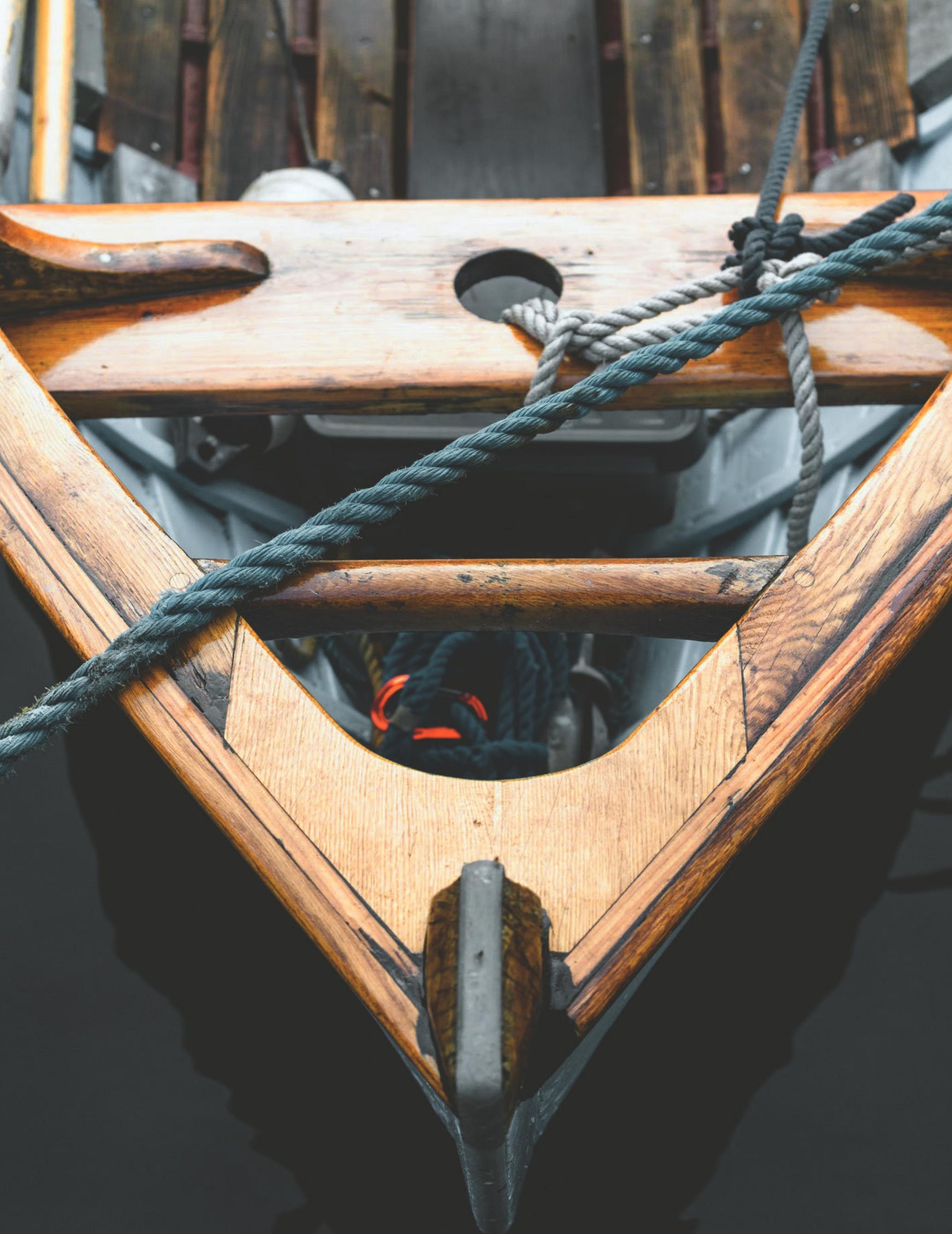

Fig. 11 Ropes tied on brown wooden boat on water. 


\section{CRAFTING BOATS}

[ Transcript summary located in appendix A ]

As an example of circular design, traditional boat building has been studied in this section. Boat building is a craft which requires years to master, from drawing scaled plans to assembly. The process would usually consist of drawing a scaled plan, a 1:1 scale plan, taking patterns off the drawing, cutting, bending, and assembling the pieces. Apprenticeships for boat building currently requires the apprentice to learn and master one element of boat building, such as laying fibreglass or internal joinery. Compared to the contemporary method of boat building, Paul Tozer, a traditional boat builder, began his apprenticeship in 1964 where the job required an expertise in all fields except the electrical. He learnt how to woodwork, produce technical drawings, how to install motors, and plumbing. Traditionally an adze is used to cut and shape the wood; however, most contemporary workshops use power tools to assist in cutting the material. Machines have decreased manual labour, making the production of tradition boats easier and faster.

Like traditional Japanese carpenters, Tozer makes a lot of his tools. He would often make custom tools from scratch or would grind down tools to fit uncommon sizes. The creation of unique tools is essential as the craft of boatmaking requires specific tools for specific jobs. The traditional tools Tozer has owned since 1964, dating back to multiple generations. These tools are the same as those found in the English museum of the Cutty Sark, built-in 1869. For Tozer, the treatment of his tools is essential; they have continuously been repaired and reused, emphasising the importance of circular design.

Material selection for timber boats is crucial to the lifespan. For example, the restoration of the 1911 steel framed Halswell Junction boat done by Tozer was in a state of disrepair. The traditionally, copper bolts are used to fix the timber on a boat. However, the Halswell Junction boat had a steel frame and bolts. The steel rusted away from the corrosion of the ocean, leading to rot in the timber. If the traditional method had been 
used, the copper would have oxidised, and deterioration would not have been as prominent. Material selection is crucial, as circular design is essential for preserving the product for future repair and reuse.

Mass-produced fibreglass boats have influenced the boatmaking industry in a positive yet negative way. It has made the production of boats a lot less labour intensive, therefore faster, more manageable, and ultimately cheaper to produce. It makes it easier for people to own boats, and there is less maintenance; however, this has led to the loss of craftsmanship in boat making. Traditional boats currently cannot be mass-produced as a lot of the shaping must be done by hand or with a power tool. The process of building a wooden and steel boat requires a full-scale drawing which a template can be taken off. Each piece is unique from the treatment, whether it is rolling the steel or steam bending the timber. Traditional boats are preferred for the look and aesthetic, which costs a lot of money to build and maintain. Maintenance is an important factor for timber boats otherwise they will deteriorate in look and quality. Boatbuilding is a dying craft; however, Tozer says "I think it will always continue, but very limited. Some guys just really like old wooden boats."

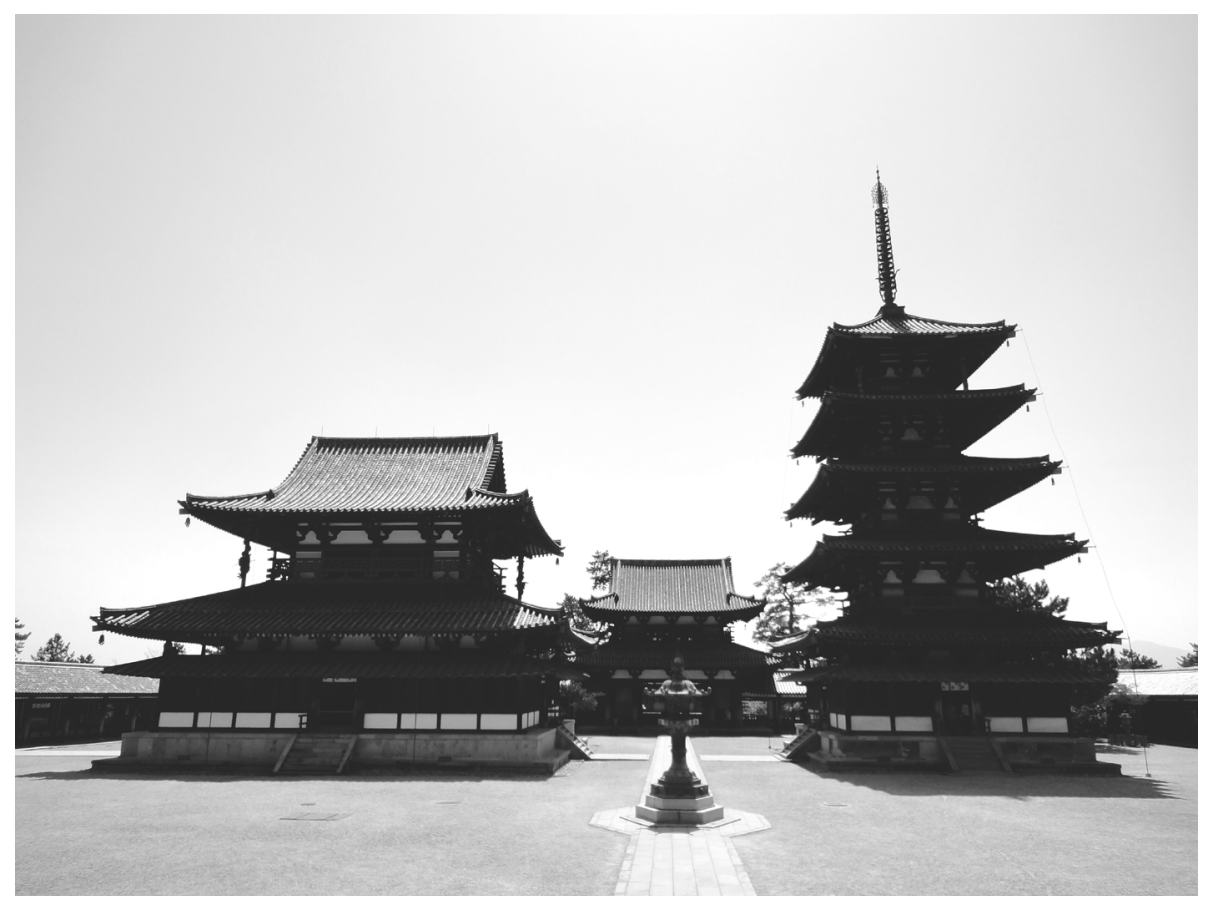

Fig. 12 "Hōryū-ji, Nara, Japan", the Golden Hall and the Pagoda. 


\section{TIMBER}

Timber is a sustainable material when used and treated correctly. Timber is a common material used in New Zealand as a standard construction method in residential and even light industrial buildings. We can begin to adapt other timber construction from around the world to New Zealand buildings by carefully examining existing structures.

There is a common notion to believe timber is not as strong as steel or concrete. Timber is thought of an inferior product due to its flammable qualities, weakness against bending motions, insects, and rot. The measured strength of timber varies depending on the species and defects, which makes materials like metal alloys more appealing as they are uniform in strength and appearance. Timber has a "natural resistance to axial stress, tension stress, and compression stress" (Seike, 1977, p. 96); however, it is weak against bending motions, which can be combated through the use of bracing. When timber is compared by its strength to its volume weight, it is comparable to metal alloys and concrete. For example, white cedar is considered a weaker timber; however, it has about four times the tensile strength of steel and about six times the compressive resistance of concrete (Seike, 1977).

The idea of timber being inferior to steel and concrete due to its combustible nature is a misconception. Timber is a poor conductor of heat, the surface will char until the temperature reaches the burning point around $300^{\circ} \mathrm{C}$. Metal alloys are great conductors of heat, steel begins to fail once it has reached $600^{\circ} \mathrm{C}$. For example, a steel staircase in a fire would immediately become too hot for someone to step on, and it is difficult to cool down quickly with water. In comparison, a wooden staircase would have charred on the surface and can be efficiently cooled down with water as it is a poor heat conductor (Seike, 1977).

In regards to Japanese timber buildings, these structures are some of the longest surviving wooden structures. Examining buildings such as the Hōryūji Temple (fig. 05 and fig. 12) shows with simple maintenance well-crafted structure can survive for Centuries. The Hōryūji Temple 
allowed the mature timber to be truthful to its nature, there was no use of chemicals to prevent decay like the modern methods of treating timber. By using chemicals to preserve the timber, it becomes challenging to recycle and is commonly disposed of in landfills. Waste from untreated timber (offcuts, shavings and sawdust) can be recycled back into other wood-based products or used as an energy source.

Timber has the property to change according to environmental influences. Certain timber from the tropics in particular experience less swelling when exposed to moisture, compared to some varieties of European wood. Protection of the tropical forest is vital as the rate of deforestation has had a tremendous impact on the environment. Increasing the quality of fast-growing low-grade timber, such as radiata pine, can act as a substitute for high-grade timber (Peters, 2011). 


\section{ENGINEERED TIMBER}

Engineered Wood Products (EWP) is a composite material that is manufactured by binding lower quality timber elements, such as fibres, particles, profiles, and veneers with an adhesive. The decreasing access to high-quality timber is a pressing factors, and the "industry commitments to better utilisation of harvests" (Williams, 2018, p.6) has become the motivation for the development of EWPs.

The introduction and the eventual domination of concrete and steel came about due to a combination of factors. Concrete and steel are now the standardised construction materials in the commercial industry, with this method of construction and aesthetic bleeding into the designs of residential housings. In the past wood products "dominated the light commercial market before the Second World War" (Williams, 2018, p.6). As a part of the international style, it became a common notion to use concrete and steel, especially in Japan, to "emulate the United States - the country that had won the war" (Aline \& Kuma, 2006, p.16). Using Japan as an example, Kengo Kuma states "building in rough and heavy concrete have overwhelmed delicate Japanese sensitivities, leading to a state of even more conflict with the natural environment" (Aline \& Kuma, 2006, p.16). To evoke identity with the natural environment in Japan, Kengo Kuma has substituted concrete and steel with the vernacular material timber. Following the example Kuma, the use of wood in New Zealand architecture should be encouraged to evoke identity in the community.

There are many types of engineered timber; however, not all are structural or are commonly used in New Zealand. Some structural products that are processed and produced in New Zealand are Glue Laminated timber, Laminated Veneer Lumber, and Cross Laminated Timber. These products are often used in residential and light industrial construction. 
Known to be stronger than steel, glulam is manufactured to strict standards. Defined as a structural timber member composed by glueing multiple pieces of timber profiles side by side, the material grading is based on the stiffness rating of the individual laminations.

\section{LAMINATED VENEER LUMBER (LVL)}

LVL is manufactured by aligning selected veneers, commonly with the grains oriented in a single direction. It can be fabricated from lower grades of trees by laminating the product to produce a uniform, high strength material. LVL is established as a high strength beam and header component. Due to the manufacturing method, LVL can utilise the log up to $35 \%$ more effectively than is possible with solid lumber (Williams, 2018), and can have twice the strength to weight ratio of steel (Sturgeon, 2011).

\section{CROSS LAMINATED TIMBER (CLT)}

Constructed with a minimum of three layers, CLT consists of sawn softwood stacked on top of one another at a right angle to the previous level and glued together. CLT has shown competency in and can be comparable to both concrete and steel (Ramage et al., 2017).
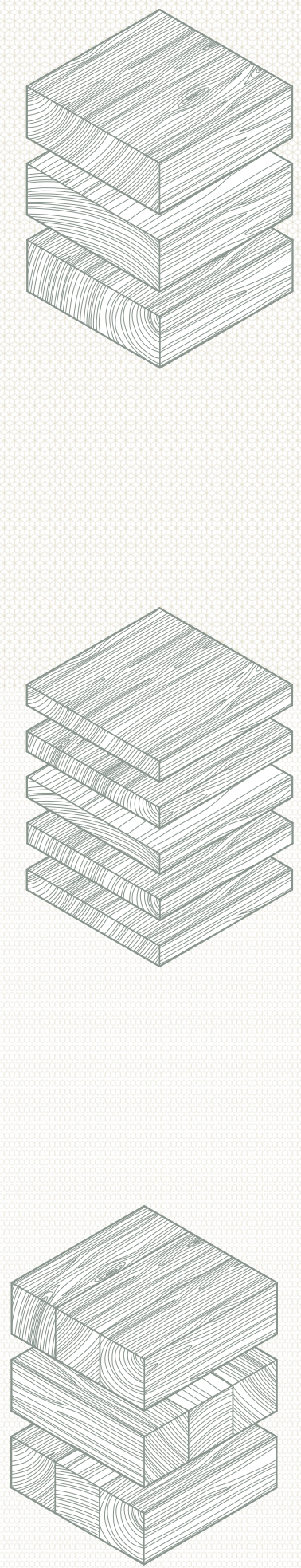


\section{HEAT-TREATED NATURAL WOODS}

Five prominent commercial treatments emerged in the 1990s and early 2000s throughout Europe to satisfy the demand for sustainable building materials. Thermowood from Finland, Plato Wood in Holland, OHT-Oil Heat Treatment in Germany, and two in France, Les Bois Perdure and Rectification (Esteves \& Pereira, 2009). Accsys Technologies was founded in the United Kingdom in 2005, using acetylation, a chemical reaction to develop Accoya timber.

Heat-treated timber is a non-toxic material that comes from a renewable source, making its application ideal for architecture. Traditionally, burning of the surface of timber is known to increase its durability

BEFORE KILN DRYING

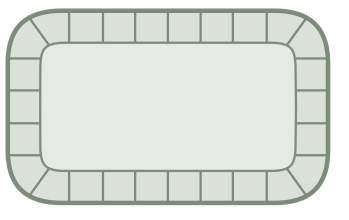

Water held inside of entire cell Ability to store water

AFTER KILN DRYING

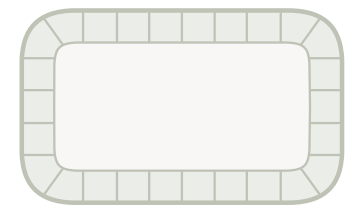

Some water held in cell walls Some ability to store water AFTER THERMAL MODIFICATION

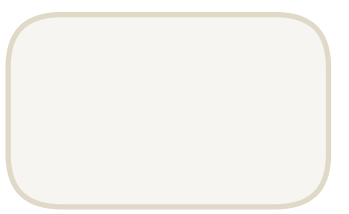

Cell walls collapse and fuse together

Reduced ability to store water against the exterior elements. Known as thermal modification, this technique was commonly used by Vikings. Thermal modification is now a controlled process carried out in specified high-temperature kiln that allows for the timber to be saturated in an organic substance while maintained at a specific temperature. Heat-treated natural woods were scientifically studied in the USA and Germany between the 1930s-1940s, with the research carried out until the 1970s. Thermal modification successfully became a commercialised method of modifying timber after it grew in popularity during the 1990s, with research carried out in the Netherlands, Finland, and France (Tunnicliffe Timber Company Ltd, 2016). Heattreated timber has exceptional dimensional stability and rot-resistance due to the change in the cellular structure of the timber from the treatment. This process causes the cellular structure to change, significantly reducing the amount of water able to be absorbed and pass through the material, resulting in the material

Fig. 13 Diagram of timber cells after modification, adapted from Abodo Wood Ltd "What is Thermal Modification". 
being more water-resistant than untreated timber (fig. 13). The sugar content in the cells is also reduced during this process, minimising the food source for fungus, mould and insects. These two changes in the timber cells result in a product that is stable and durable enough for exterior applications (Hardwoods Incorporated, 2016).

ThermoWood ${ }^{\circledR}$ (fig. 14) uses a method that requires steam and high temperatures of $100-190^{\circ} \mathrm{C}$. This modification process requires a "purpose-built computer-controlled kiln" (Abodo Wood Ltd, 2014) that keeps the timber uniform in its properties and quality. This process slightly changes the properties of the timber. As a result, the properties of lowgrade timbers like radiata pine are increased to be equivalent to treated hazard class rating H3 timber. ThermoWood ${ }^{\circledR}$ have a 30-year life expectancy in above-ground applications, and has an increase of approximately $20 \%$ in thermal insulation properties. However, due to the compromise of strength for durability through the low quantity of moisture, it is not suitable for structural uses as of now. It is only used in window and door framing, cladding, and decking.

Oil Heat Treatment (OHT) (fig. 15) woods is a product that uses a process where the timber is loaded into a vat, which the air is then removed and replaced with hot oil ranging between

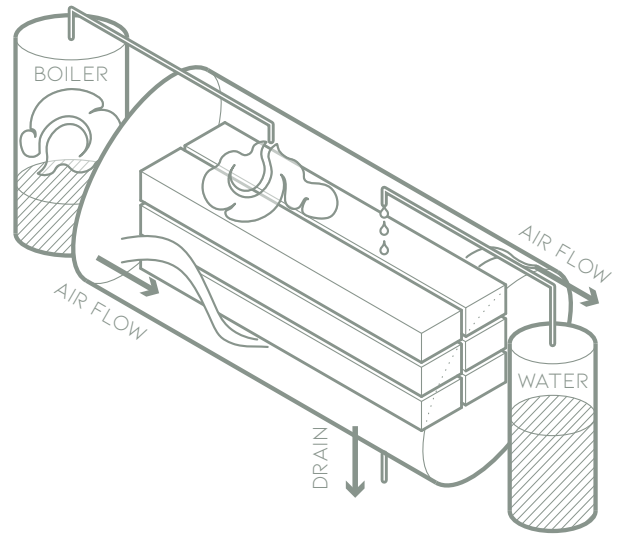

Fig.14 Diagram of thermal modification adapted from "Strength and Colour Response of Solid Wood to Heat Treatment".

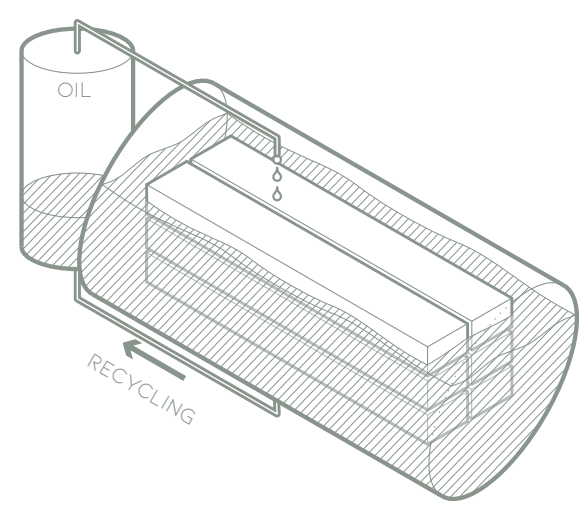

Fig. 15 Diagram of thermal modification adapted from WTT Wood Treatment Technology. 
the temperatures of $170-250^{\circ} \mathrm{C}$. This procedure can take between 24 - 48 hours, during this process, the cells in the timber begin to change to such an extent that the "water absorption and the moisture content equilibrium are significantly lowered" (Peters, 2011, p.48). The oil used consists of natural plant oils such as linseed oil and rapeseed oil, where the hot oil can be recycled for "subsequent treatments" (Dubey, 2010, p.189). This process achieves a "dark homogenous coloured wood with a tropical flavour for specific markets" (Dubey, 2010, p.189). Standard timbers often used in OHT are pine, spruce, birch, and aspen. Pine is generally used for outdoor construction; however, the problem in treating pine using $\mathrm{OHT}$ is the resin that excretes during treatment. Resin causes problems with the equipment if it is not cleaned between fillings and makes planing the surface difficult (Rapp, 2001). This thesis will not focus on OHT timbers, as there is no demand for OHT timber in the New Zealand market as of yet, even though New Zealand's radiata pine wood is suitable for oil heat treatment.

\section{$\mathrm{ACCOYA}^{\circledR}$}

\begin{tabular}{|l|l|}
\hline \multicolumn{1}{|c|}{ APPLICATIONS } & \multicolumn{1}{|c|}{ CHARACTERISTICS } \\
\hline $\begin{array}{l}\text { Window framing, doors, decking, } \\
\text { public infrastructure, bridges, } \\
\text { walkways, structural elements, } \\
\text { damp external conditions. }\end{array}$ & $\begin{array}{l}\text { Natural UV resistance, } \\
\text { dimensional stability, durability, } \\
\text { rot proof improved insulation, } \\
\text { longer lasting coatings. }\end{array}$ \\
\hline
\end{tabular}

Accoya ${ }^{\circledR}$ timber is a heat modified wood that goes through a non-toxic process that involves heat, pressure, and acetic anhydride (fig. 16). This method causes a chemical reaction called acetylation, which is essentially a pickling process. Acetylation involves the substitution of an acetyl

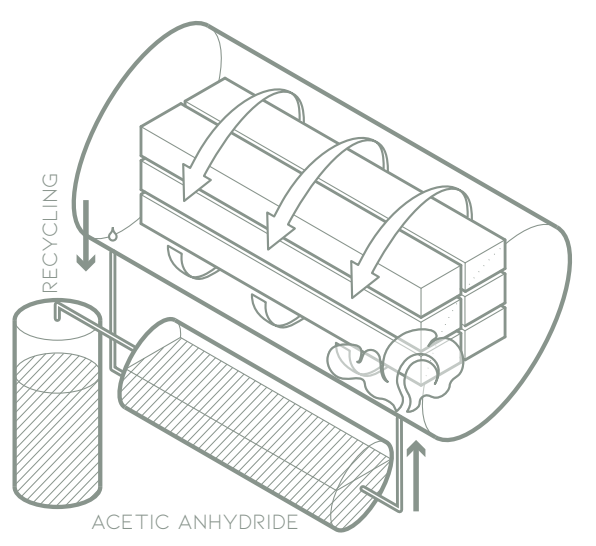

Fig. 16 Diagram of thermal modification adapted from Accoya. 
group for an active hydrogen atom. Acetic anhydride is a natural acid that is commonly used as an acetylating agent, for example, acetic anhydride is used for the production of aspirin. Timber species such as radiata pine, which are a fast-growing renewable source are favourably used to create Accoya (Accsys Technologies, 2018).

Accoya is dimensionally stable, with at least $75 \%$ less swelling and shrinkage of the material, which is great for outdoor application. Accoya is highly durable and is guaranteed to last 50 years above ground and 25 years in the ground or freshwater. It is indigestible to insects, microorganisms, and fungi, making it virtually rot-proof. Like ThermoWood, Accoya has an increase in natural insulation. Accoya also allows stains and oils to coat easier, therefore less product is needed during application, with the coating requiring less sanding and lasts longer. With less splintering, Accoya timber is easy to machine and process, with no special tools required. Accoya wood can be fixed with plates and bolts in the same way as other commonly used softwood species; however, Accoya contains a small amount of acid, and therefore must be attached with corrosion-resistant fixings such as stainless steel. Accoya wood can be glue-laminated, which allow for the product to be structurally sound and applied in structural situations (Accsys Technologies, 2012). Examples of this can be seen on the Wooden Bridge in Sneek, by OAK Architecture, and the Moses Bridge by RO\&AD Architecten.

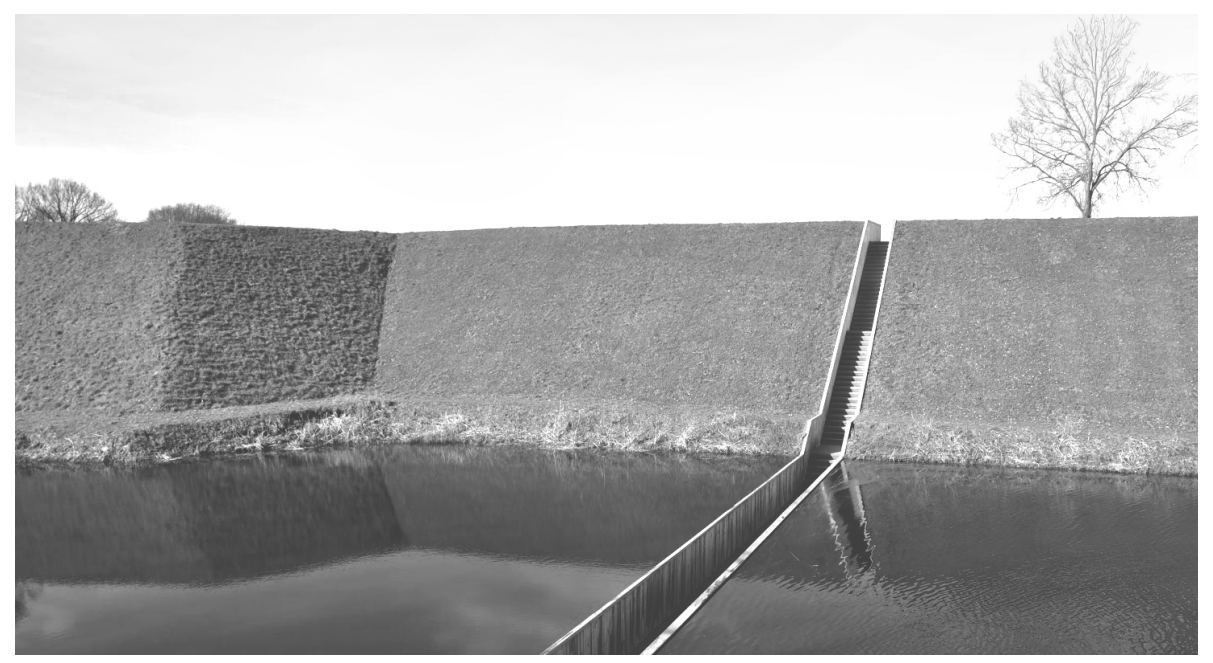

Fig. 17 RO\&AD Architecten - Moses Bridge. 


This section explores the potential strategies to apply and produce joints for existing buildings in New Zealand. This research will be focusing more on the trend of retrofitting, which is an excellent method of preserving buildings. With this in mind, timber joints can assist in refurbishing existing buildings, both aesthetically and seismically. Prefabrication using the CNC router is a technique that can be used to produce timber joinery. Prefabrication has the potential to be cheaper, faster and more sustainable, therefore more accessible. Machine jigs are a different method of fabricating joints, where it provides the opportunity to cut joints onsite, assisting the DIY culture New Zealand has. Precedents of buildings are examined to understand the application of joints and the tectonic strategies used. This links to chapter 3.1, where design iterations explore the methods of construction.

\section{DISCOVER}

RETROFITTING

AS A TREND

DIY APPLICATION

SEISMIC RETROFIT

PREFABRICATION

MACHINE JIGS

CNC ROUTER

THE ROBOT

PRECEDENT REVIEW

SUNNYHILLS AT MINAMI-AOYAMA

FINANSPARKEN BJERGSTED 


\section{RETROFITTING}

Retrofitting allows for the opportunity to add additional accessories or components to existing properties. Retrofitting is excellent for preserving existing buildings that may be plain, old, or not up to code seismically or thermally. The standard residential home is commonly retrofitted by the owners to follow the 'trend' or to 'personalise' their home. This is usually due to the basic and minimal nature of cookiecutter homes that are common to the New Zealand suburbs. Seismic retrofitting is a way to strengthen the buildings capability to withstand seismic activity and environmental loads that can affect the structure. This thesis will concentrate on joinery and briefly touching on structural retrofitting.

\section{AS A TREND}

Consumers want things that are brand new, trendy, improved and different. Homes are a place where identity can be expressed through personalisation and décor. The role of the kitchen has changed from a place that was kept separate to isolate the food smells to being a social aspect to the home, where people can host friends and families. Retrofitting kitchens are common to create a sense of achievement and adequacy.

A lot of kitchens in New Zealand homes currently uses plastic-coated MDF (medium-density fibreboard) box system joinery. Cheap plastic laminate and melamine boards became a popular choice in 2009 and are considered "one of the most practical and cheapest materials for facing kitchen worktops" (Baden-Powell, 2005, p. 156). Plastic laminate and melamine boards are not a sustainable material as the life cycle is commonly less than ten years. Using these materials may secure "on-going work for designers, fabricators and installers. However, the present pattern of repeated remodelling is wasteful and polluting" (MacKay, 2010, p. 1). As designers, there must be a consideration for the end life of the product. Looking at the circular economy, designers 
should refer back to how kitchens were originally designed. During the early 20th Century kitchens were made of wood. The bench-top was "typically unfinished kauri, scrubbed with sand-soap to a velvet finish" (Mackay, 2010, p. 4). When bench-top became worn down, they would be repaired or replaced, and the old bench-top would commonly be repurposed or disposed of as it has naturally biodegraded. Taking into consideration as to how kitchens were designed historically, we can then begin to produce a product that allows for the ability to be natural, durable, and reusable.

\section{DIY APPLICATION}

DIY (Do It Yourself) is an act that ties the person to their home by continually materialising identity in the home and is a strong part of New Zealand culture (Morrison, 2012). In New Zealand, it is "common for people to live in a constant state of renovation" that can continue for years, and "more often than not, DIY projects are never completely finished" (Morrison, 2012, p. 124), leading to a crudely finished product.

A common application for DIY is on outdoor living space of homes to enhance the social aspect between the indoor-outdoor flow. It is common to add pergolas, gazebos, and verandas as an extension to a property. These are often kit sets from the local hardware shop and provide no personalisation. There is an opportunity to for design and identity to be utilised; however, this chance is often not taken as is often thought of as difficult and time-consuming. There is an opportunity for jigs to assist the DIY culture, making timber crafts more readily accessible, which is discussed further under the Machine Jigs section.
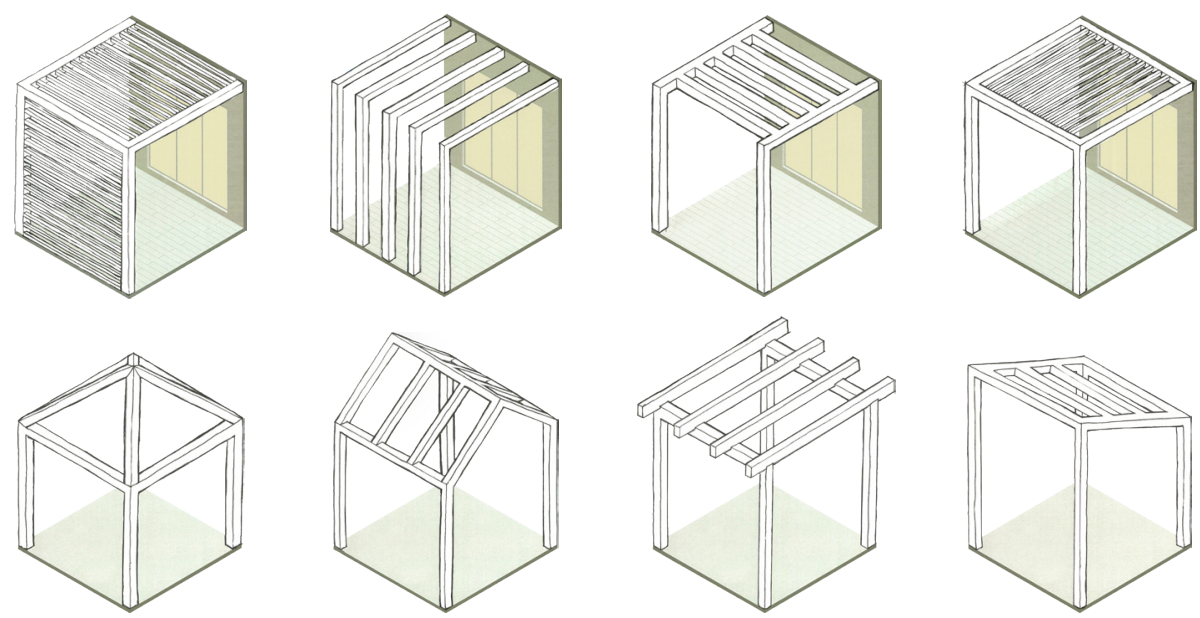


\section{SEISMIC RETROFIT}

New Zealand as an earthquake-prone country requires seismic retrofitting to a lot of their older buildings. Not all existing structures are up to the building code for seismic resilience as a result of the "material degradation due to aging" or "structural inadequacies" (Gorai, 2016, p. 6). Structural retrofitting is needed in order to prevent earthquakes and environmental loads from causing damage to the structure and people. It also needs to be "strong enough, resilient enough, and flexible enough to have a long life" (Southcombe \& Charleson, 2014, p. 98) as the requirements for seismic retrofits are assessed and altered.

Traditional Japanese timber structures are resistant to earthquake damage. The resilience of a Japanese timber building is achieved through the "deflection and friction in its joints, a wooden house absorbs the high-amplitude energy occurring at the beginning of an earthquake" (Seike, 1977, p. 91). This usually results in minimal damage to the structure as "much of the energy of an earthquake is absorbed in these noisy joints" (Seike, 1977, p. 91). Taking this into consideration, timber joinery could be an excellent system for retrofitting seismic elements.

Commonly retrofitting is done through steel or concrete work which can be very clunky. There could be an opportunity to use timber; however, it is not suitable for all methods of seismic retrofitting. Methods of retrofitting with timber include:

Shear walls and diaphragms with structural plywood or CLT Moment frames with Glulam or LVL
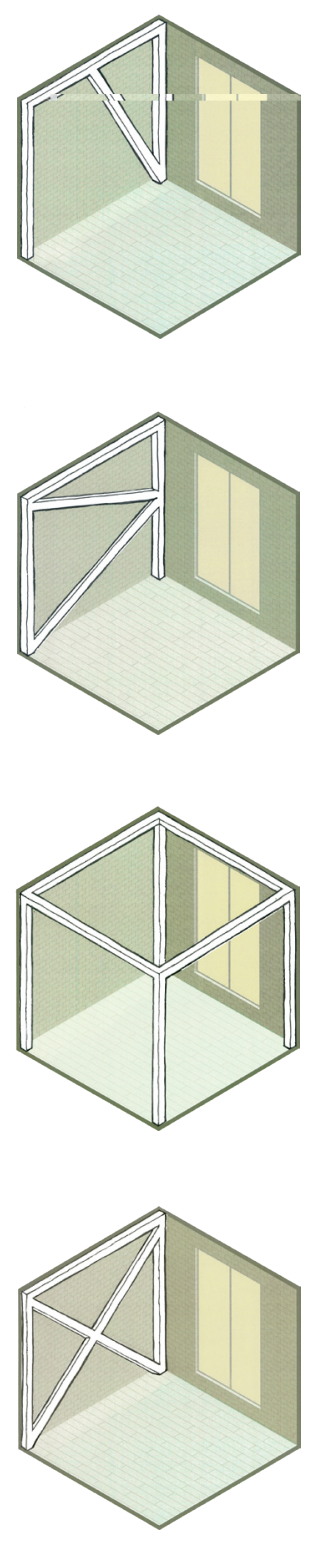

Concentric bracing with Glulam or LVL

Eccentric bracing with Glulam or LVL

These methods would suit well for residential and even light industrial buildings. Using timber to retrofit buildings allows for the opportunity to evoke emotions to the building. As timber joints have the ability to be adapted for retrofitting, there is a limitation of the need for steel connections to the base of the structure to

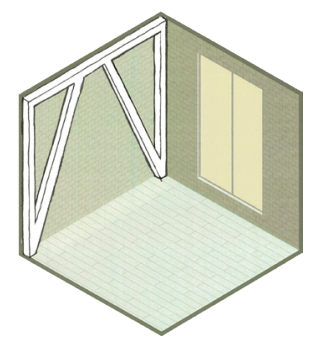
the building. 


\section{PREFABRICATION}

There is a shortage of skilful carpenters and other specialised building workers as the art of traditional carpentry is slowly phasing out. The absence of experienced carpenters has led to the demand for further developing prefabrication "where fast and simple erection on site is a primary goal" (Ramstad \& Hallquist, 1980, p. 414). The term prefabrication, often shortened to prefab, can be interchangeable with 'offsite construction'. Prefabrication is the assembly of a building or building components at a different location from the building site. There is a social misperception about prefab buildings and is often thought of as cheap and poorly constructed buildings that all look the same, despite these accusations not being applicable to all prefabricated buildings.

There are many types of prefabricated buildings as defined by Bell. They can be permanent, temporary, cheap or expensive, with five common ways to prefabricate a structure. 

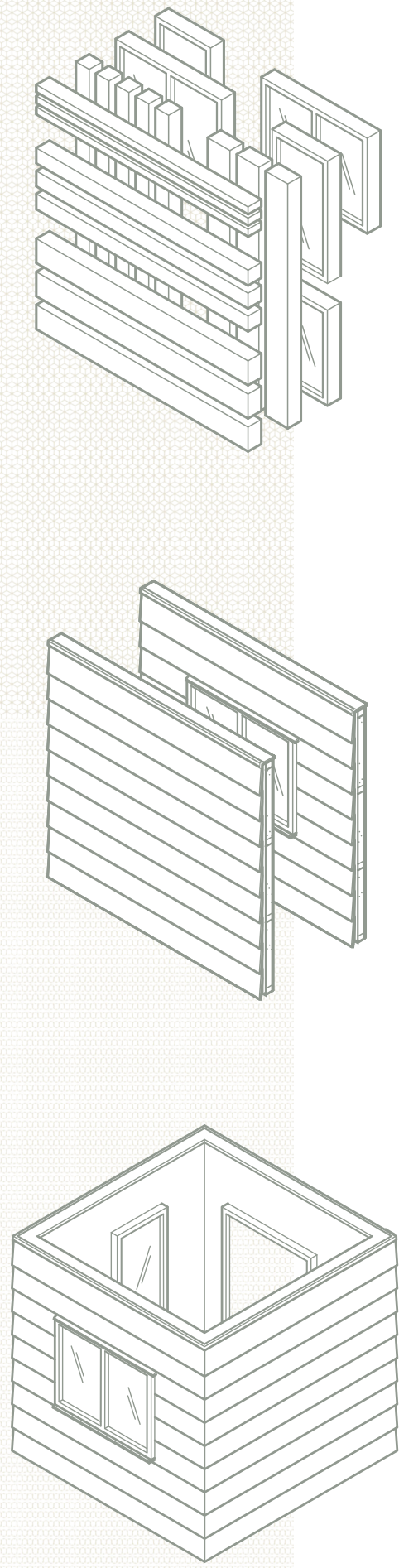

Component Prefabrication - the creation of components to increase the speed of assembly. Also known as stick and subassembly, the stick refers to the length of the member and subassembly refers to the fixtures such as doors (Bell \& Southcombe, 2012; Burgess et al., 2013).

Panelised Prefabrication - twodimensional and nonvolumetric method. This is the creation of flatpack panels that consist of cladding, framework, and sometimes insulation with plumbing and electricals (Bell \& Southcombe, 2012; Burgess et al., 2013).

Modular Prefabrication - modules of volumetric or three-dimensional structure created offsite and combined with multiple modular units together onsite to form a whole dwelling (Bell \& Southcombe, 2012; Burgess et al., 2013). 


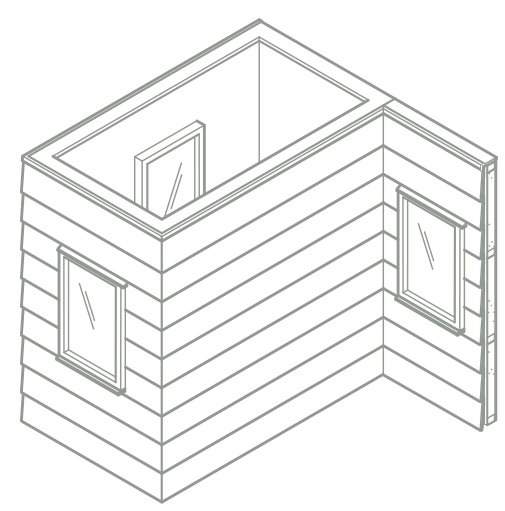

Hybrid Prefabrication - a combination of other prefabricated systems or a combination of a prefabricated method with traditional construction (Bell \& Southcombe, 2012; Burgess et al., 2013).

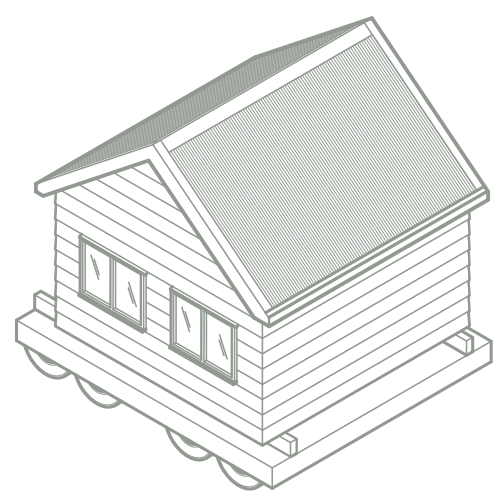

Complete Buildings - a whole building, commonly known as transportable buildings, portable buildings, or mobile buildings, which all have subtle differences between them based on size and number of times moved. It is a type of volumetric prefabrication where a whole building is manufactured offsite and transported to site, where it is attached to a permanent foundation (Bell \& Southcombe, 2012; Burgess et al., 2013).

\section{ADVANTAGES}

Prefabrication has great merits as it provides an opportunity to offer more for less. Prefab can potentially offer more quality for less time onsite, a more secure outcome, less unforeseen circumstances, and an opportunity for a more energy-efficient product.

\section{QUALITY + TECHNICAL MERITS}

The main advantage is the increase of control over the manufacturing and construction conditions. There is an opportunity to "test systems and 
prototypes within a controlled factor environment" (Bell \& Southcombe, 2012 , p. 39). The quality of the product can be assessed before the product leaves the prefabrication premise, allowing for a higher quality end product and minimal mistakes, reducing the need for remedial work post-occupancy.

\section{SPEED + ECONOMICAL MERITS}

With prefabrication, there is no longer a dependency of the weather and for the preparations on-site, such as the foundation. This increases the speed of delivery as it reduces the programme "between $30-60 \%$ " (Bell \& Southcombe, 2012, p. 38) compared to traditional construction processes. Fast delivery is cost-effective for the manufacturer and consumer; this is the result of prior planning with the fabricators where no changes can be made once fabrication initiates.

\section{SUSTAINABILITY MERITS}

The construction and demolition of buildings contribute significantly to the energy consumption, waste, and $\mathrm{CO} 2$ emission in New Zealand. Prefabrication can provide an opportunity for a reduction in all of these factors (Burgess et al., 2013, p. 12). Prefabrication reduces material waste through "efficient ordering, indoor construction protection, preplanning and cutting" (Bell \& Southcombe, 2012, p. 39). However, one sustainability shortcoming with prefabrication is the over engineering and additional materials used. These excessive components are for bracing the volumetric prefabrications for transportation, which is not necessarily needed when set together on site.

\section{CHALLENGES}

There are constant challenges for designers to design around site conditions and transportation limitation; however, these are minor compared to the problem of overcoming the misperception of prefabrication. Buildings that are prefabricated are often though as repetitive and are associated with standardisation. This assumption is a perception New Zealanders have of prefabricated buildings, which 
steam from a historical point of view. Schools in New Zealand would commonly use "temporary prefab classrooms that remained permanently in place, mass-produce kit set homes and transportable baches" (Bell \& Southcombe, 2012, p. 41). Prefab buildings are seen as investments rather than a consumer good due to its low-cost. They are perceived as low-quality, and not well built despite them being over engineered to withstand transportation.

As technology shifts from hand-tools to digital information-tools, there is a shortage of skilled carpenters. Prefabrication has the potential solution to satisfy this demand for well-crafted buildings; however, prefabricated buildings do not have the best reputation. Contemporary fabricators are addressing this issue by attempting to overcome this misperception by using other names such as offsite, preconfigured or pre-planned. Prefabrication creates an opportunity to assist in the DIY culture New Zealand has, producing kitset joinery for owners to set up at their property. Prefabrication is important to this thesis as it is a method of construction that has the potential to be cheaper, faster and more sustainable, therefore more accessible.

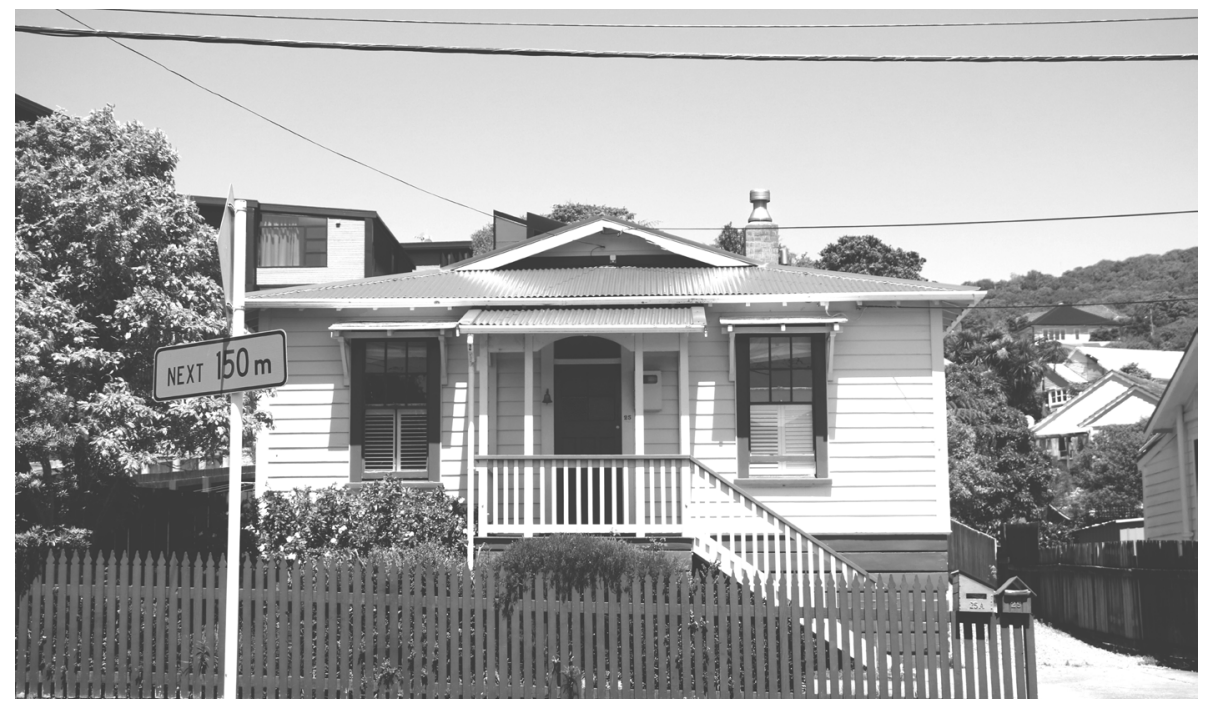

Fig. 19 Railway Cottage on Tarikaka Street, Ngaio. 


\section{CNC ROUTER}

CNC is an abbreviation for computer-numerically controlled. CNC machines are a system that moves a mechanical tool based on digital logarithms. The 2D and 3D movement of the mechanical tool can be controlled using logarithms

Traditional craftsmanship was only achievable by patience, diligence and skill. Using computer-aided design (CAD) software, designers have the ability to create the products of a skilled craftsman. The CAD model would be then exported to a computer-aided manufacturing (CAM) software. This converts the geometries of the design into toolpaths which are used as coordinates for a machine such as a CNC router. The router allows for the re-establishment of "quality and integrity that has gone missing in mass manufactured goods" (Filson et al., 2017).

Using a parametric software to communicate to the CNC machines allows for the capability to rapidly produce prototypes. This creates an opportunity for analyse, evaluation, and improvement to the digital model for fabrication, allowing for the process to repeat until the design has become conclusive. The rapid succession of modelling simulations and iterations naturally makes prototyping easier for designers, enticing them to use a parametric tools over traditional methods. This is important for this thesis, as it would allow for a higher level of craft in modern construction projects.

CNC routers use a tool on the end which is called an end mill, also known as a cutter, or router bit. End mills come in a "variety of geometries, each engineered to create different cut types and finishes in specific material types" (Filson et al., 2017). End mills follow toolpaths, which are a series of coordinates and codes, also known as G-codes. There are three methods a toolpath can be set to take: 


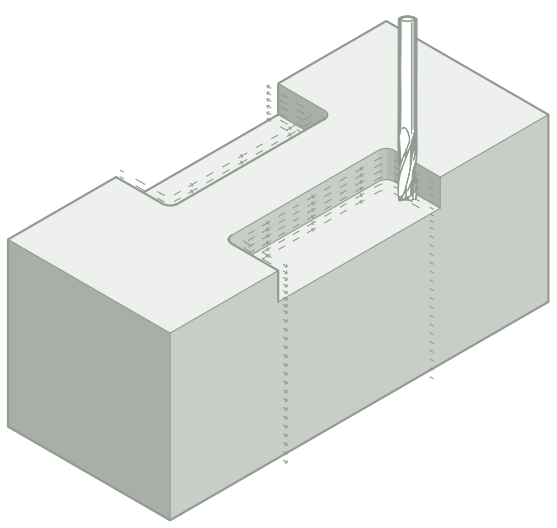

Profile toolpath - follows a line and cuts to a specified depth. There are three ways to for the tool to follow the profile, on the line, inside the line, or outside the line.

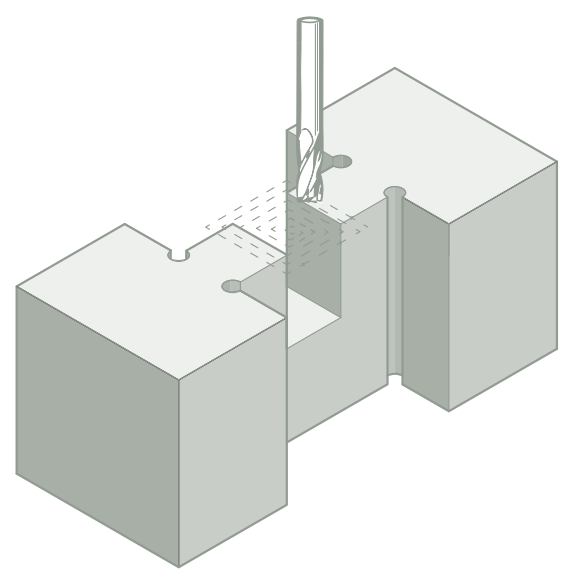

Pocket toolpath - cuts with a closed line or shape, removing the material within the area to a specified depth. Often referred to as 'clearing a pocket' or 'pocketing'.

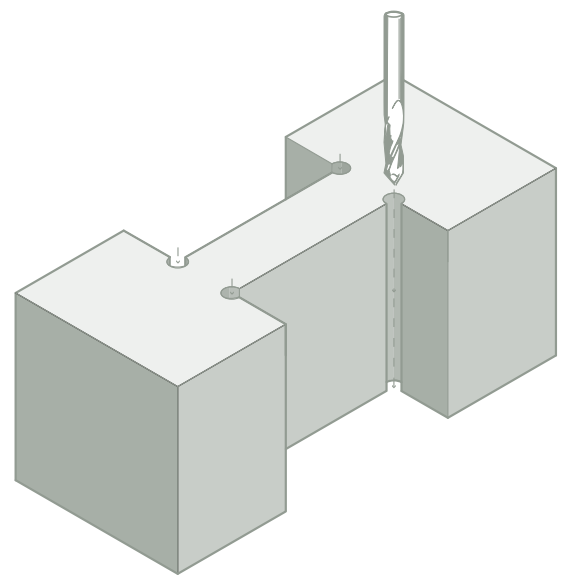

Drill toolpaths - operates like a drill press, where the end mill is plunged through the material vertically or used for peck drilling, where the tool is drilled to a specified depth and raised to clear the chip. This process repeats until the desired depth is achieved. 


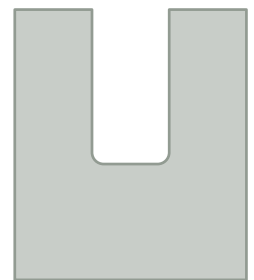

PLAIN CORNER

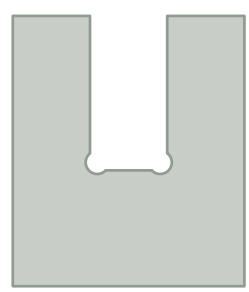

DOGBONE

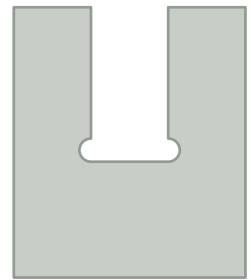

TBONE

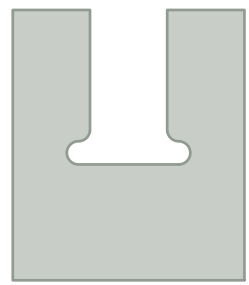

SINGLET

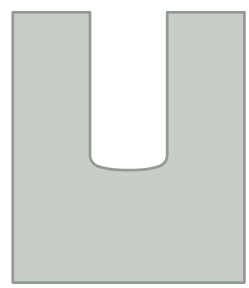

RUN PAST

CNC routers have a limitation when it comes to $90^{\circ}$ internal corners. The plain corner leave excess material is left behind due to the diameter of the end mill, which increases with the size of the end mill (Filson et al., 2017). There are ways to mitigate this, which is through the use of fillets, the dogbone fillet, $t$-bone fillet, singlet fillet and run past.

The most standard CNC router moves in 3 axes: $x, y$, and $z$. There are others that move in 4 and 5 less commonly found in workshops due to their high costs. The $\mathrm{CNC}$ robotic arm has the capability to execute intricate and complex data due to its ability to utilise 6-axis movement. The CNC robotic arm is the most efficient when it comes to prefabricating elaborate joinery; however, the robot arm is not within the scope of this thesis as it is not as readily accessible as a CNC router, as it is predominantly used by high-profile companies, or on-site machinery (Lansdown, 2019). 


\section{MACHINE JIGS}

Jigs are devices that assist woodworkers and carpenters in workshops with cuts, shaping, drilling and sanding elements quickly and accurately. While woodworkers and carpenters tend to own a few commercially made jigs such as mitre gauges, most create their unique jigs, especially for one-off and specific jobs. Jigs have an ability to expand a tools "basic repertoire and cut a variety of joinery, shape mouldings and panels" (Nagyszalanczy, 2006, p. 8). Jigs are an important tool that makes crafting timber faster, easier, and great for repetitive processes, where consistency, precision and safety are essential. There are endless variations of jigs that can be made and adapted for various tools and specific situations.

There are primarily two types of jigs with many subcategories:

Dedicated jigs - Suited for only one system, simple to construct and require little to no setup before use.

Adjustable jigs - Suitable for multiple systems; however, it uses more material, time and effort to construct, and must be adjusted before use, which can accidentally slip out of adjustment.

Subcategories:

Marking jigs - a fixed jig, helps layout precise dimensions and consistency. Set up jigs - setting consistent adjustments on machinery for the same result.

Sliding jigs - add consistency and safety to machine operation by aligning and guiding workpieces.

Tabletop jigs - an extension in function to machines.

Portable power tool jigs - increasing control and accuracy of routers, circular saws, etc.

Templates - assists in the creation of shapely parts as well as precision for tight fitting joinery.

(Nagyszalanczy, 2006) 
Discussing with a 4th year apprentice carpenter Isaac Graham, jigs are rarely used onsite and are considered time consuming to create. Graham states "if the jig was easy enough to use it would take a lot of the struggle out of cutting certain joints... It would have to be specified in the plans for the builder to decide to use a woodworking joint over modern conventional methods during construction, unless they were specifically aiming to use less steel fixings or more historically traditional methods". A system for quickly and easily fabricating joints could assist in making beautifully crafted joinery more accessible to $\mathrm{New}$ Zealand's DIY culture.

[ Transcript summary located in appendix B ]

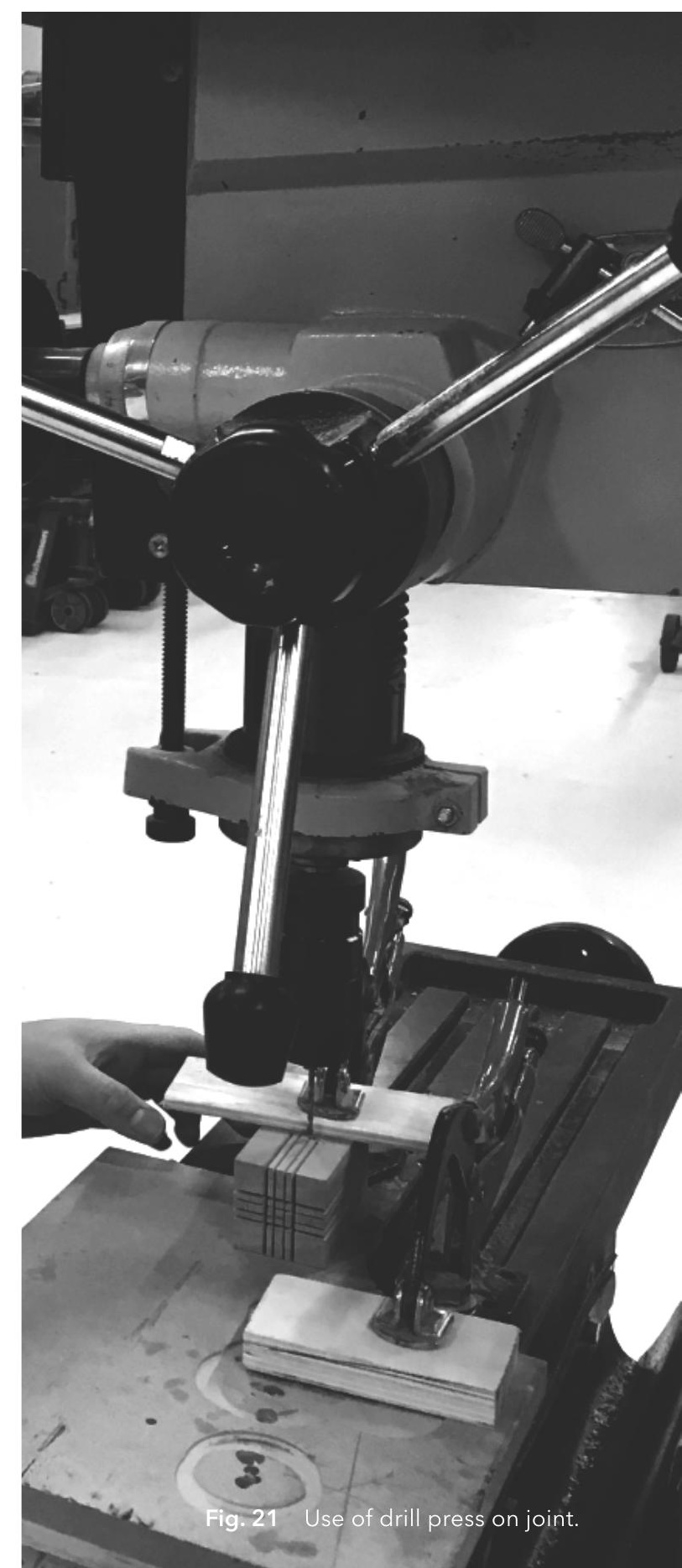




\section{PRECEDENT REVIEW}

\section{GC PROSTHO MUSEUM RESEARCH CENTER}

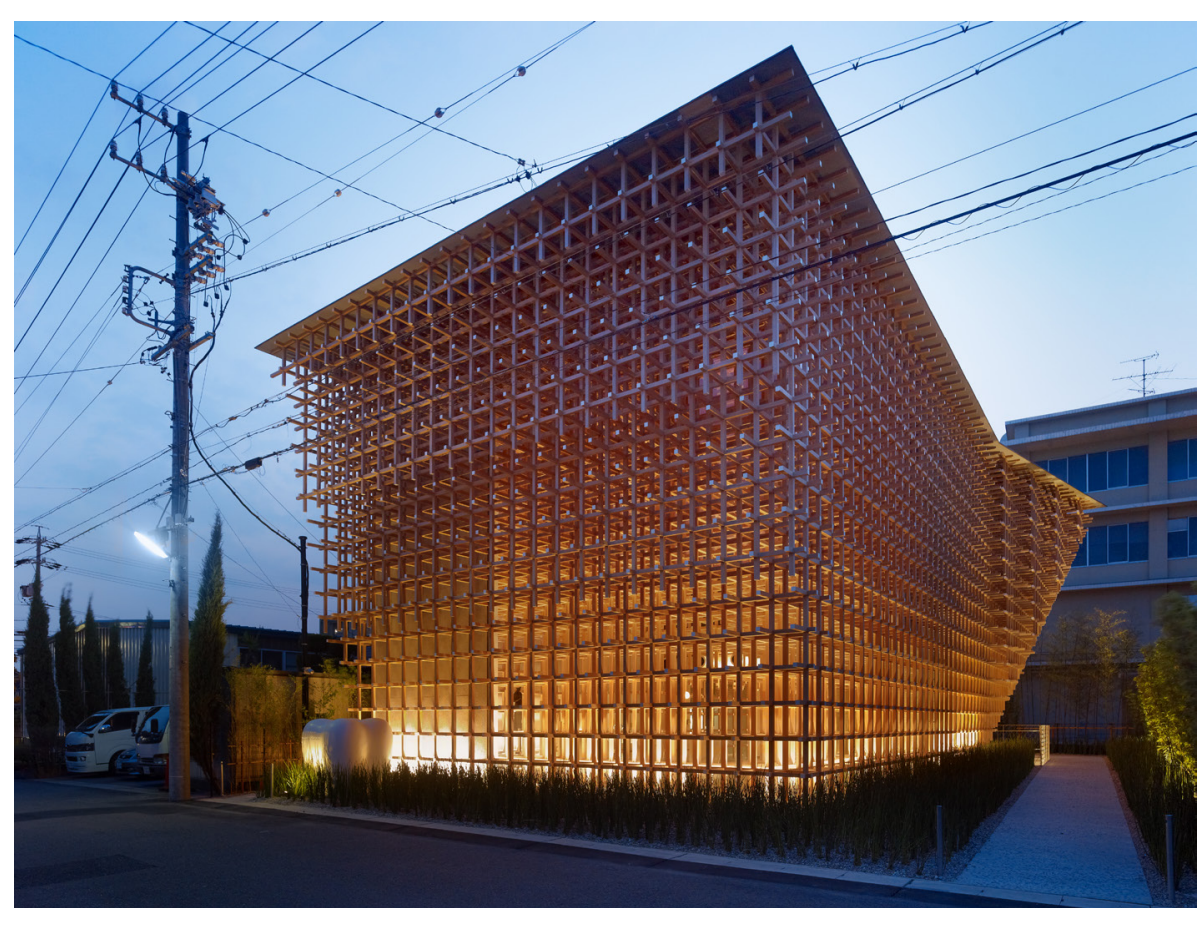

KENGO KUMA \& ASSOCIATES

2-294 TORII MATSU MACHI, KASUGAI-SHI, AICHI PREFECTURE, JAPAN 2010

The GC Prostho Museum Research Center is a fine example of traditional Japanese timber joinery used in contemporary architecture. Using the same joinery system as an old Japanese toy, cidori, the timber joinery was crafted by skilled carpenters with the help of engineers. Cidori originates from Hida Takayama, a small town in Gifu, which is known for its skilled and sophisticated carpentry. Cidori is an assembly of three wooden sticks that join together on the $x, y$, and $z$ axes without the requirements of adhesives or fixtures (fig. 23) (Kengo Kuma \& Associates, 2009; Khor Xin Suan, 2019). As the cidori joint is conventionally a toy, the structural engineer for this project conducted tests to check the

Fig. 22 GC Prostho Museum Research Center street view. 
strength of this system. Verification of the capabilities the cidori joint led to the adaption of a toy originally made for children to a structural art piece (Kengo Kuma \& Associates, 2009). This cubic grid system not only supports the structure but also serves as a platform for displaying items at exhibitions in the museum.

"We worked on the project in the hope that the era of machine-made architectures would be over, and human beings would build them again

by themselves"

(Kengo Kuma \& Associates, 2009).

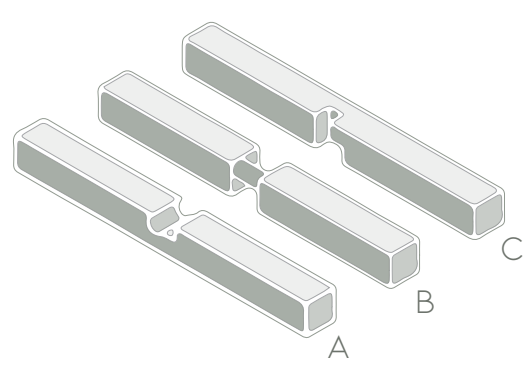

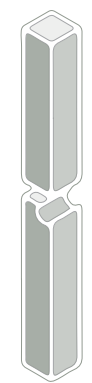

A
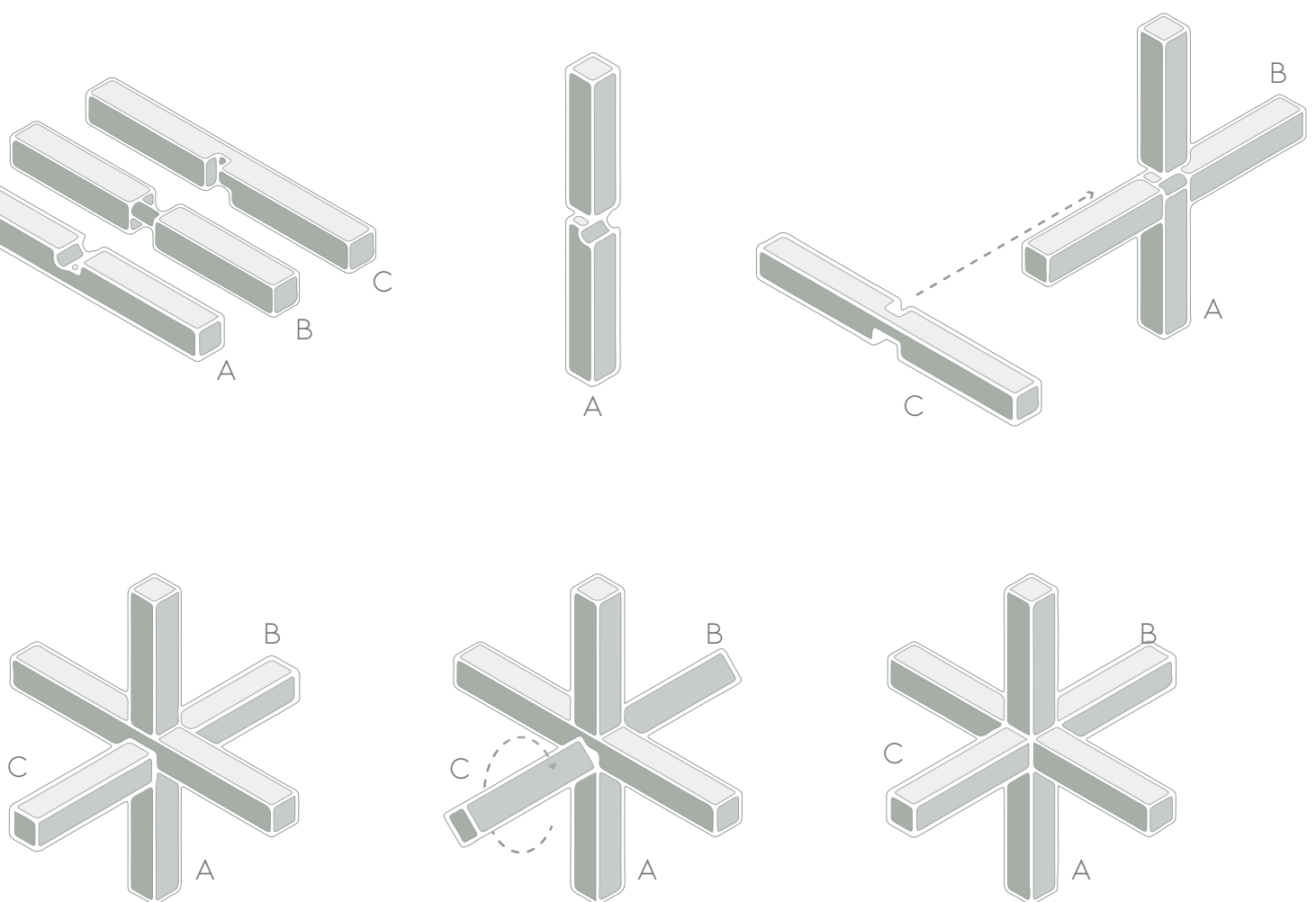

Fig. 23 Cidor joint system 


\section{SUNNYHILLS AT MINAMI-AOYAMA}

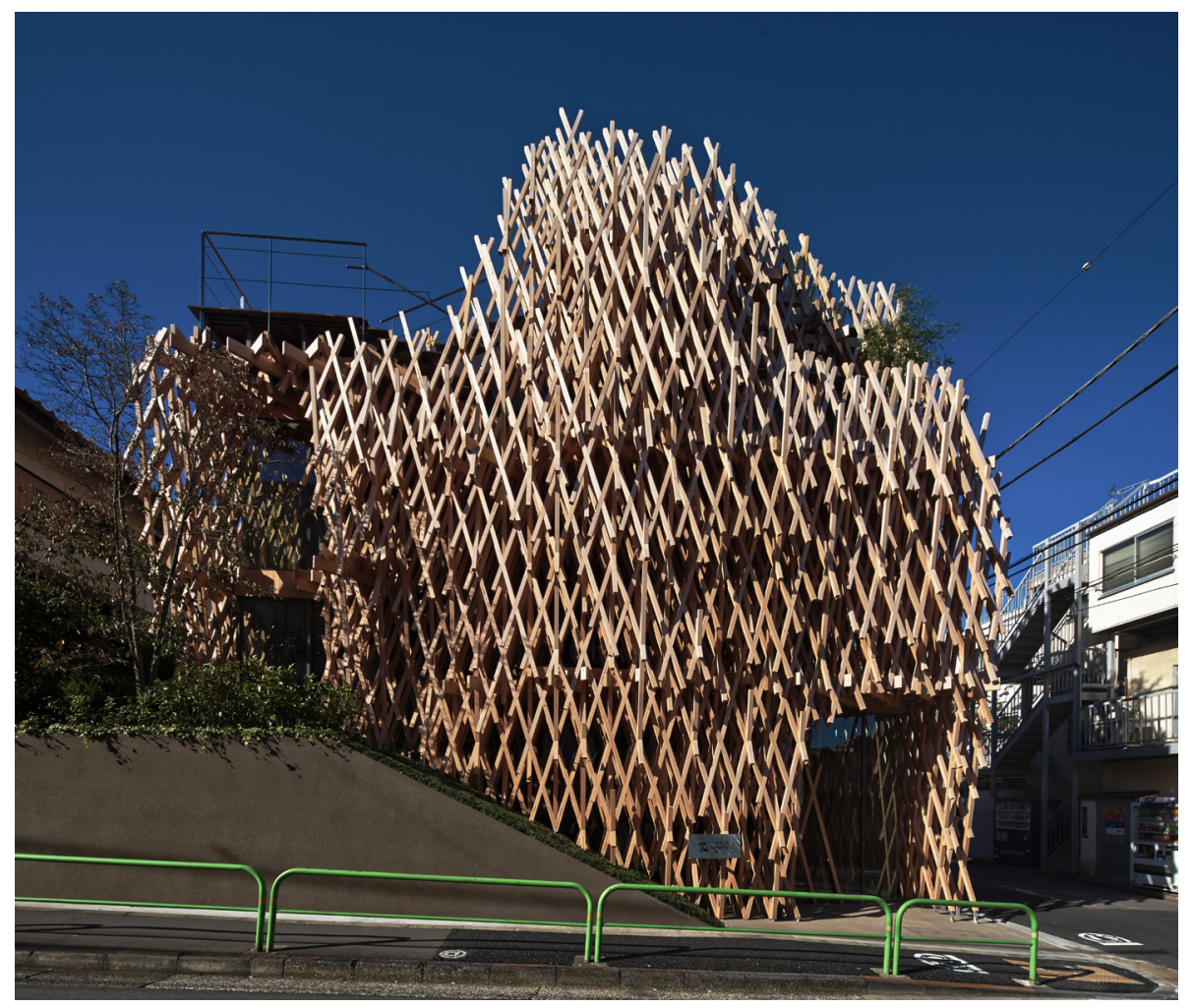

KENGO KUMA \& ASSOCIATES

3 CHOME-10-20 MINAMIAOYAMA, MINATO, TOKYO, JAPAN 2013

SunnyHills at Minami Aoyama is a shop that specialises in the popular Taiwanese sweet pineapple cake. Located in a residential area, Kuma hoped to design a building that emits a soft and subtle atmosphere to the suburb, something different from the standard concrete box (Kengo Kuma \& Associates, 2013). Stated by project architect Yuteki Dozono, the design of the building was not "necessarily about the structural integrity" but rather that intent to portray a "new aesthetic in the heart of Tokyo" (Khor Xin Suan, 2019, p. 38).

The building itself is in the shape of a bamboo basket, constructed with the traditional Japanese joint system 'Jigoku-Gumi' literally meaning

Fig. 24 Diagram adapted from Abodo Wood Ltd "What is Thermal Modification". 
'interlocking hell' "due to its resistance to dis-assembly" (Kengo Kuma \& Associates, 2013; Khor Xin Suan, 2019, p. 38). Jigoku-Gumi is not structural and "had not been used for constructing a building" (Balboa \& Paklone, 2014, p. 3). Shoji screen, often used as sliding door or room divider, are manufactured using the Jigoku-Gumi system, which requires no fixings or adhesives. The idea of using the Jigoku-Gumi system originally comes from the use of cidori, which can be seen on Kuma's earlier works. Kuma plays with the form of cidori in his Starbuck Coffee Shop in Dazaifu, Fukuoka, Japan, leading to "an oblique threedimensional lattice" (Khor Xin Suan, 2019, p. 32). By making the cidori grid oblique, it gave an illusion of depth in the space. This lead to the
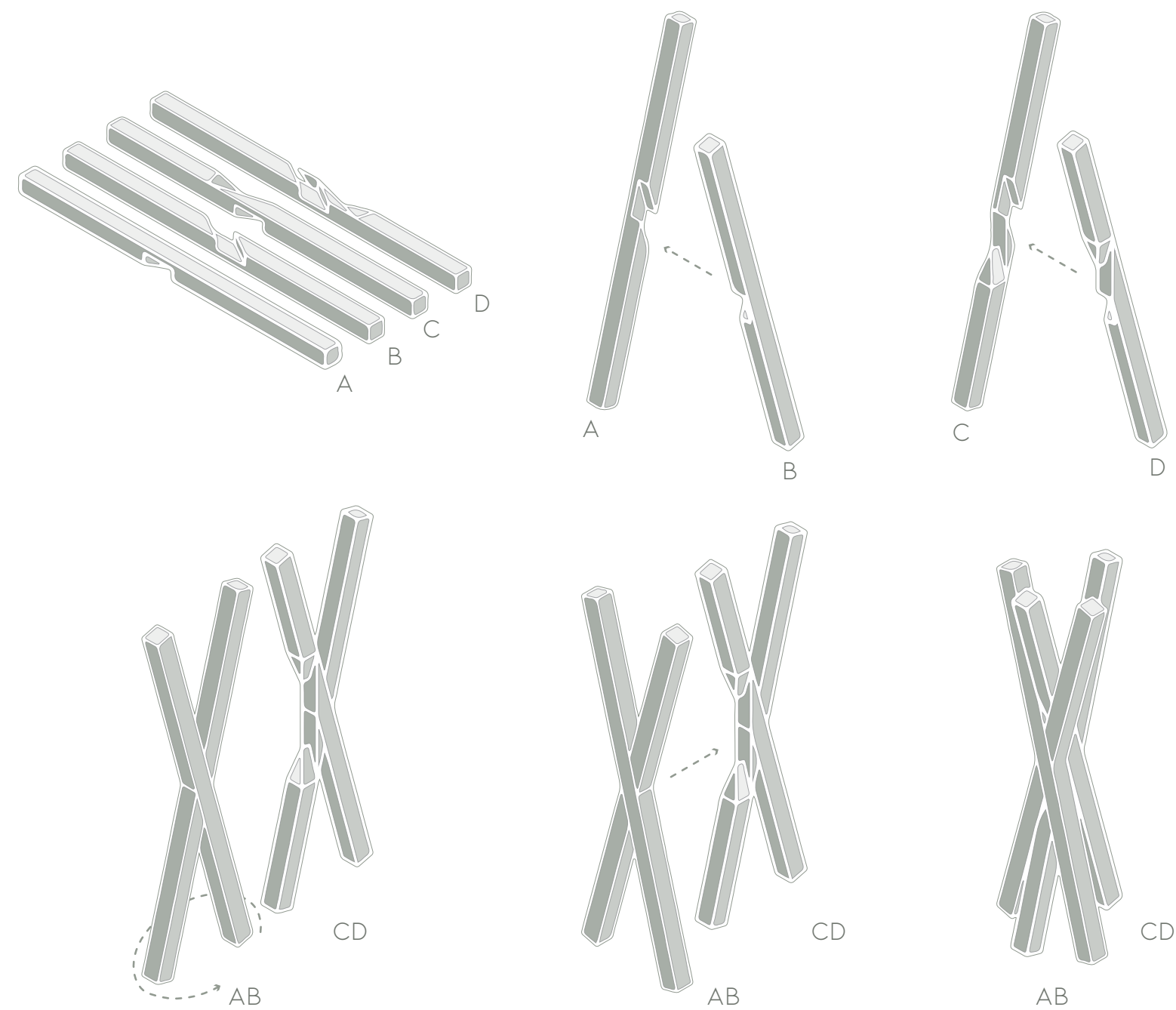

Fig. 25 Jigoku-Gumi joint system. 
adaption to the Jigoku-Gumi system for architecture. The Jigoku-Gumi system used in the SunnyHills at Minami Aoyama follows a traditional method that uses a contemporary structural system. Similar to knitting or weaving, the Jigoku-Gumi system is a "superposition of two layers [of slender wooden sticks], tightly fixed together with a third layer" (Balboa \& Paklone, 2014, p. 3). The standard practice of JiigokuGumi has two pieces intersect each other, forming a twodimensional arrangement, but

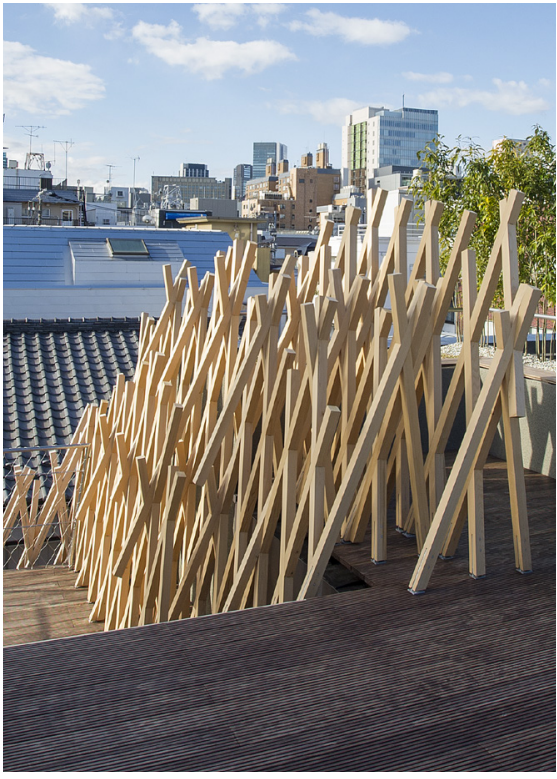

Fig. 26 Façade on roof top of SunnyHills at Minami Aoyama. here Kengo Kuma \& Associates combined a third piece. They played with $30^{\circ}$ and $60^{\circ}$ to create a threedimensional 'cloud' like structure, allowing the member sizes to the minimum size of $60 \mathrm{~mm} \times 60 \mathrm{~mm}$ (fig. 25).

This project is an excellent precedent to the limitations of timber, and how joinery can be incorporated into designs using digital information-

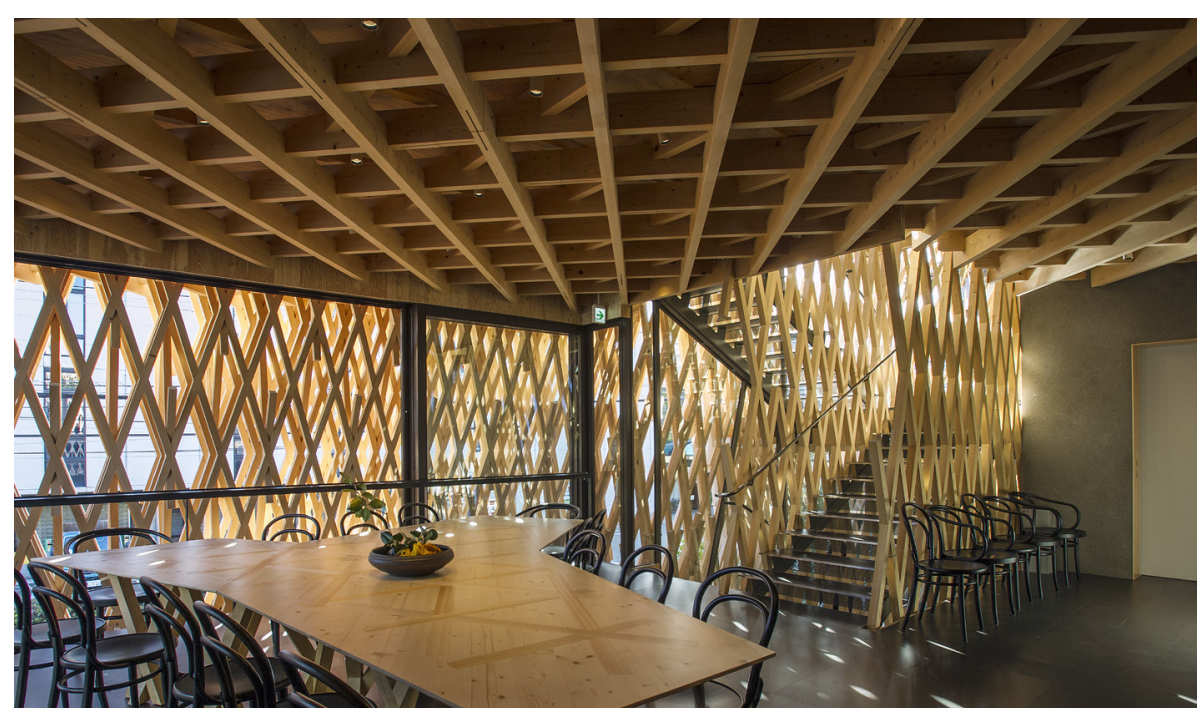

Fig. 27 Interior of SunnyHills at Minami Aoyama. 
tools and hand-tools. Initially, the joint system was proposed to follow traditional means of only using timber. However, due to site limitations, long timber members had to be cut shorter and made thicker. Thicker timber members was not desirable, as this changed the aesthetic of the design; therefore, metal connectors were employed and incorporated into the design (Khor Xin Suan, 2019, p. 38). Yuteki Dozono describes the workflow from digital design to traditional fabrication. First, the software Rhino was used to rough the design, which was then sent to engineers to calculate the forces. The consolidated design was then delivered to the craftsmen who would take drawings and printed them at 1:1 scale. Like boat builders, the craftsmen would lay the drawings onto the raw material to cut out using traditional means, as the joints are too challenging to prefabricate with machines (Man, 2017).

Fig. 28 Section of SunnyHills at Minami Aoyama.

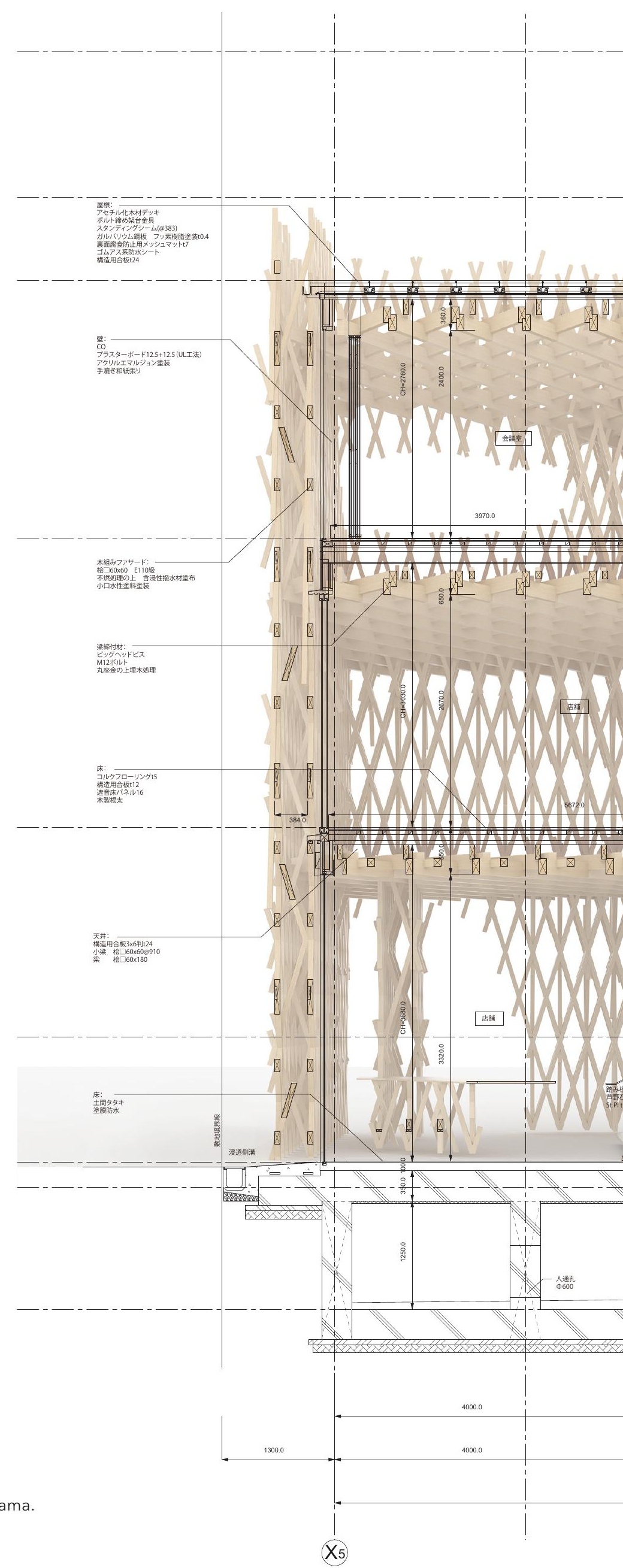




\section{FINANSPARKEN BJERGSTED}

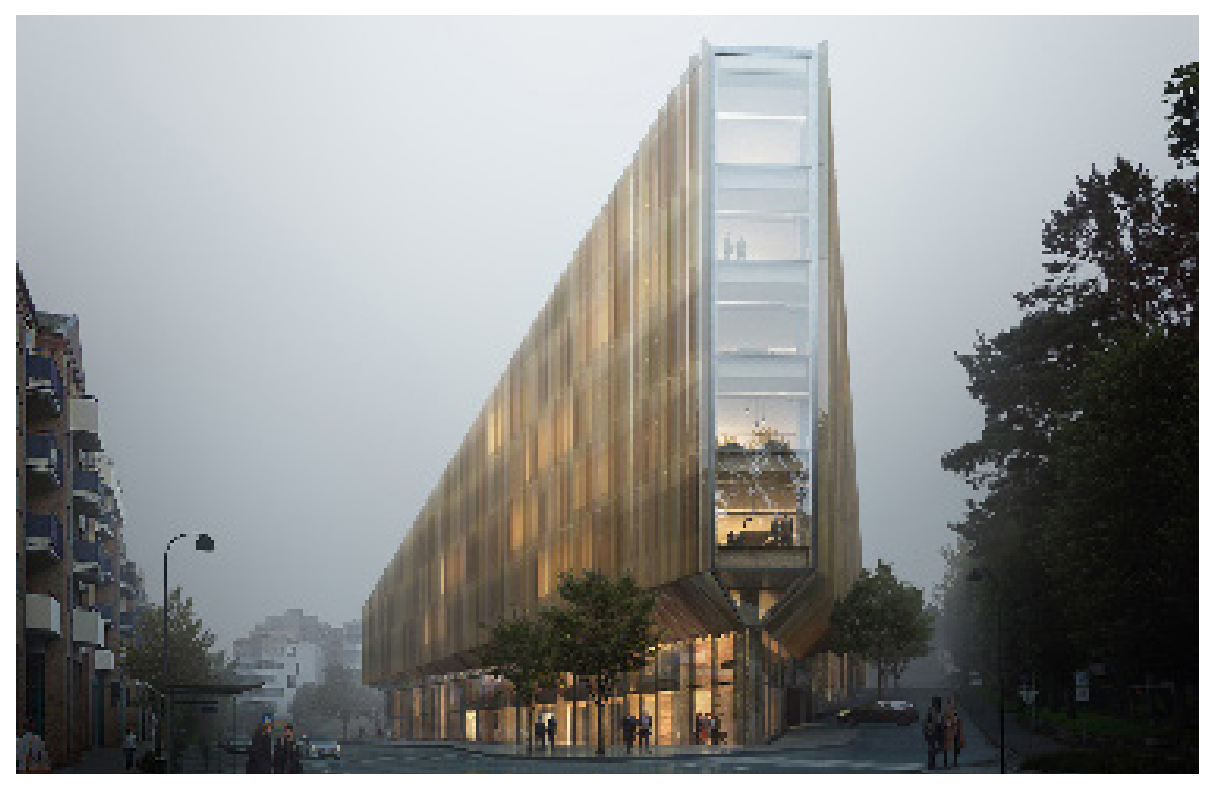

SAAHA, IARK AND LANDSKAPSFABRIKKEN

CHRISTEN TRANES GATE 35, 4007 STAVANGER, NORWAY

2019

Using information-tools, the design takes influences from timber joints found in traditional Norwegian houses. The Finansparken Bjergsted is one of Europe's largest timber office buildings and aims to set an example for the future workplace. The design uses minimum steel connections between junctions and relies heavily on the notches and beech dowels, pinning the joints together (Rando, 2019). Dowels used in this project have "high stability and can take the axial loads, shear loads and moments in the joints" (Helen \& Hard, 2019). The structure has been $\mathrm{CNC}$ routed from beech

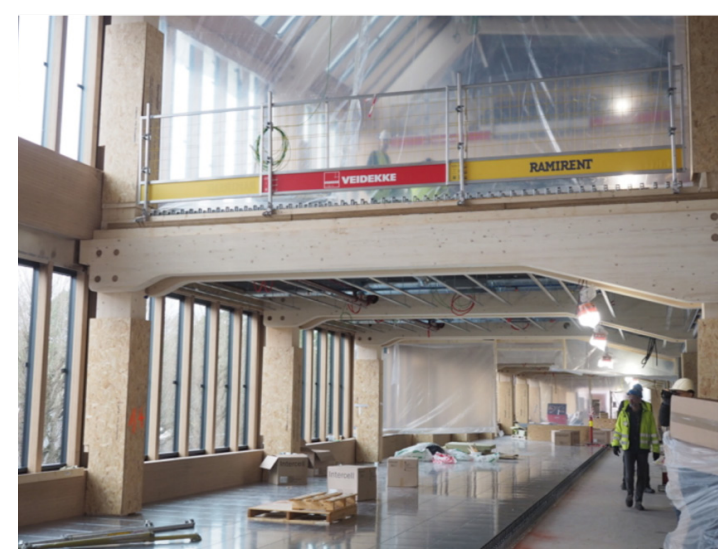

Fig. 29 Top image, render of Finansparken Bjergsted.

Fig. 30 Bottom right image, assembly of structure. 


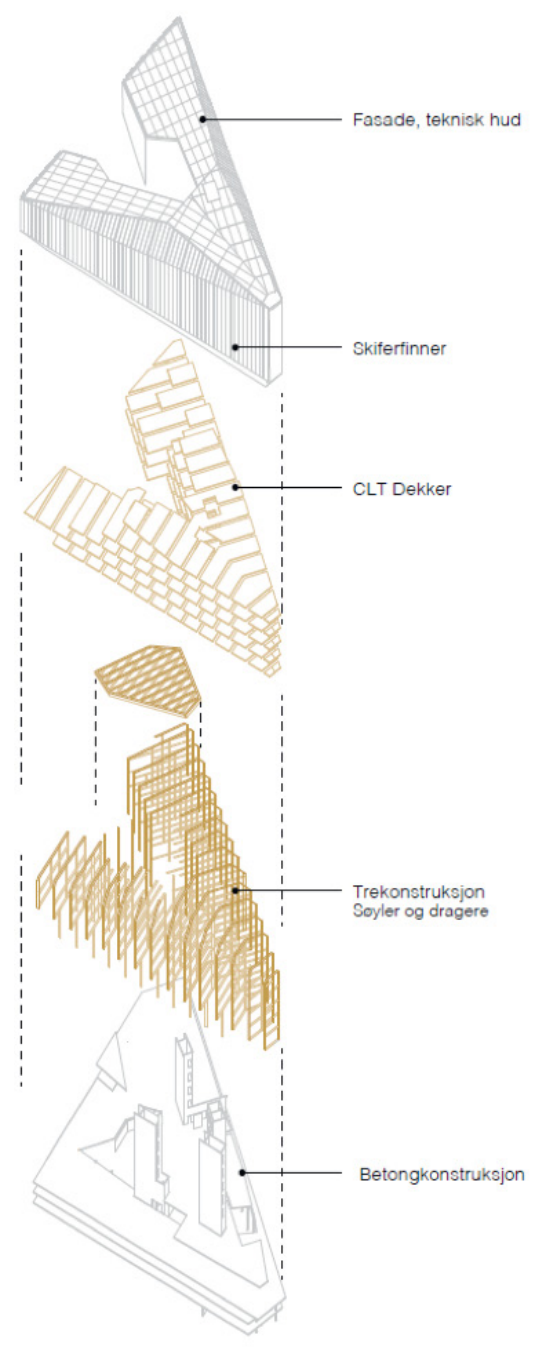

LVL beams and posts, spruce glulam joists, and spruce CLT diaphragms. Organised around the atrium, the layout allows the building to draw in "light, air and green qualities", creating a warm spatial atmosphere (SAAHA, 2019). Informal meeting spaces are located around the atrium to allow for quieter workspaces that are situated around the perimeter of the building.

The Finansparken Bjergsted is an excellent example of translating traditional joinery to prefabricated joints using information-tools. However, there are "few or none problems related to horizontal wind forces" (Ramstad \& Hallquist, 1980, p. 411). Scandinavian carpentry cannot be closely examined as a structural precedent as there is no great consideration for lateral forces.

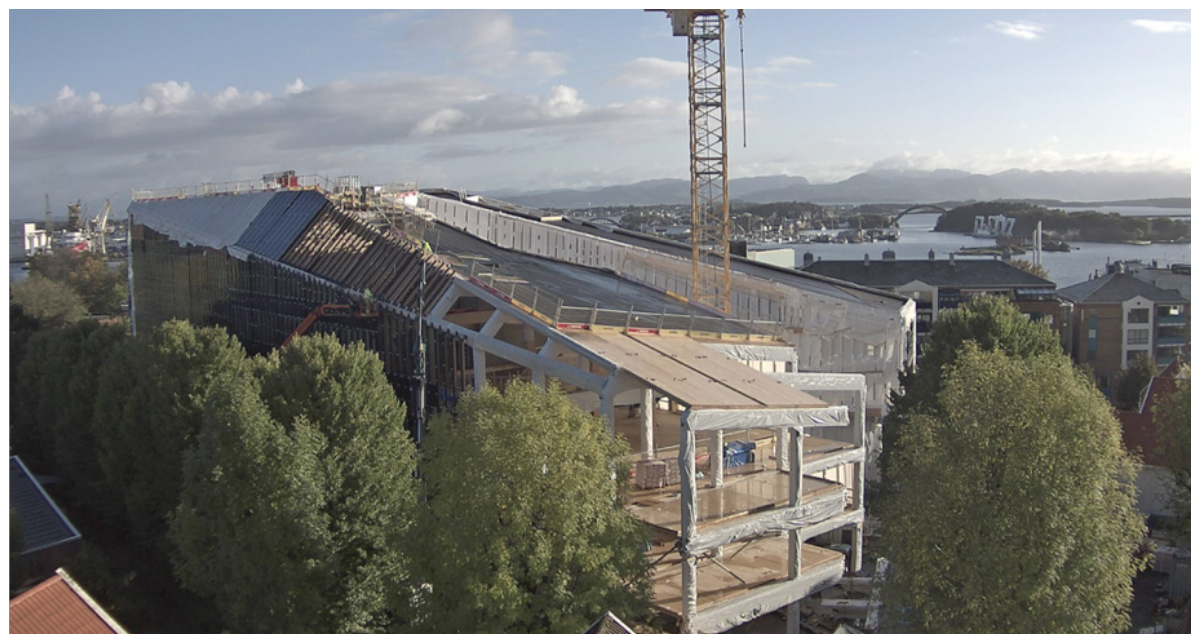

Fig. 31 Top left image, exploded isometric drawing of structure.

Fig. 32 Bottom image, mid-construction of the Finansparken Bjergsted. 


\section{RAILWAY COTTAGES}
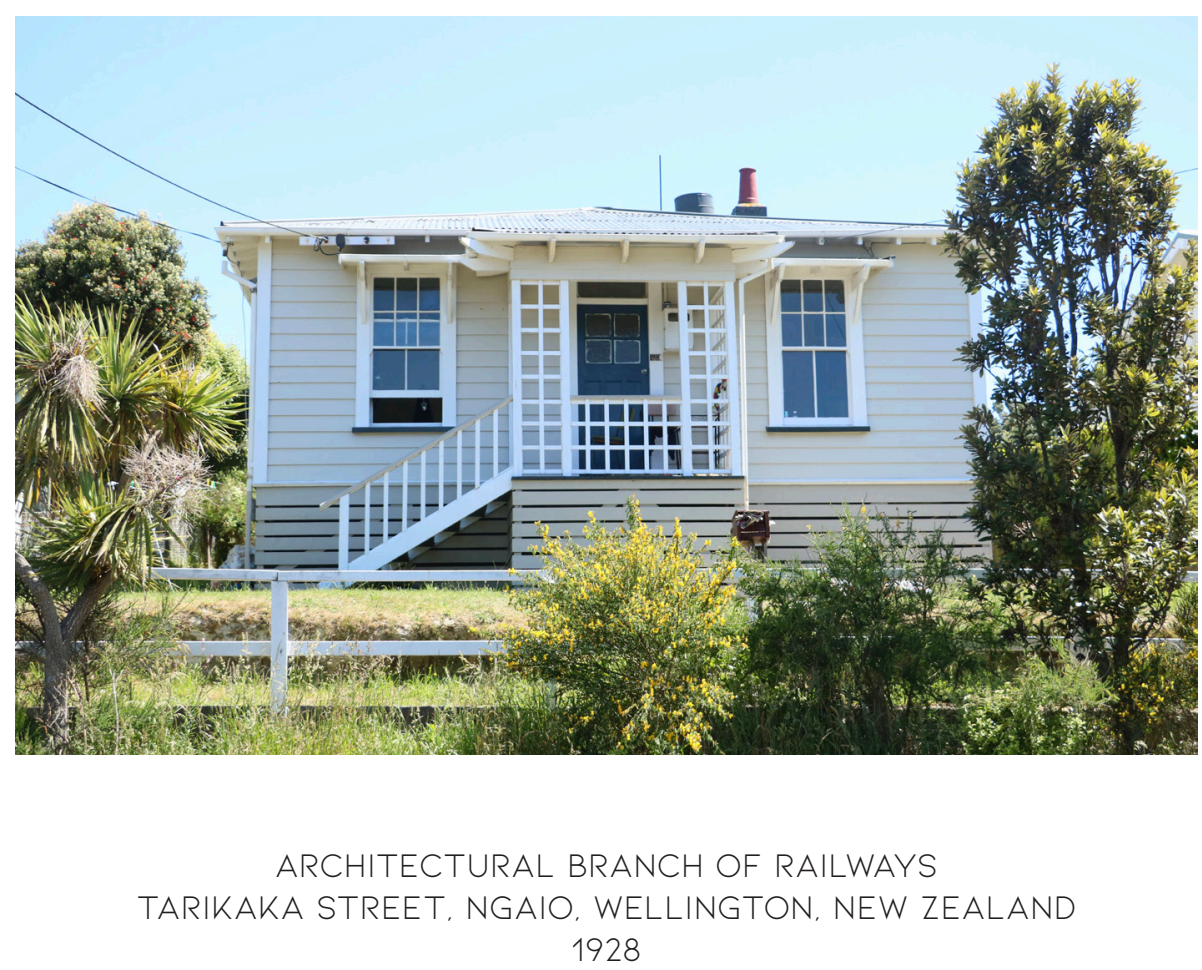

The New Zealand Railways Department was one of the country's largest landlords and fabricators of homes in the early 20th century. Since the late 1870s, the department purchased and built houses for their staff (Atkinson, 2016). Hit by a massive shortage of accommodation in the 1900s, the Architectural Branch of Railways, led by George Troup, developed the scheme to "mass produce architecturally designed houses, pre-cut in a factory at Frankton Junction" (Rail Heritage Trust of New Zealand, 2012). New Zealand Railways began production in 1923 of standardised prefabricated cottages for their workers, mainly using timber from railway-owned forests. These cottages are some of the first kitset housing systems produced in New Zealand (Branz, 2011). Parts were cut, marked and numbered for specific housing types, and complete kitsets were railed to the sites, with assembly usually taking two to three weeks. (Rail Heritage Trust of New Zealand, 2012; Schrader, 2012). The factory at Frankton Junction closed in 1929 with over 1590 cottages being fabricated over the time it was operating; no further

Fig. 33 Railway Cottage with a lattice style porch on Tarikaka Street, Ngaio. 
cottages of this distinctive style were manufactured at such volume since.

Railways cottage were very similar to Californian bungalows, the interior, roof and windows clearly derive from the bungalow designs. The cottages essentially have the design of a Georgian façade, but with the lower-pitched roof and exposed rafters of the Californian bungalow. Though these cottages appeared different from bungalows, the method of construction was very similar. The front façade was the most distinguishing characteristic of the Railways cottage, with doublehanging windows with small overhanging on either side of the central porch and front door. The central porch primarily had four designs:

a gothic style with curved brackets.

a Japanese style with a very shallow hipped roof.

a lattice style with a trellis filling the spaces between the posts.

a larger porch with a combination of solid panels and square trellis between the posts.

There were more variations of these basic designs, with the construction being the same for each (Branz, 2011). 


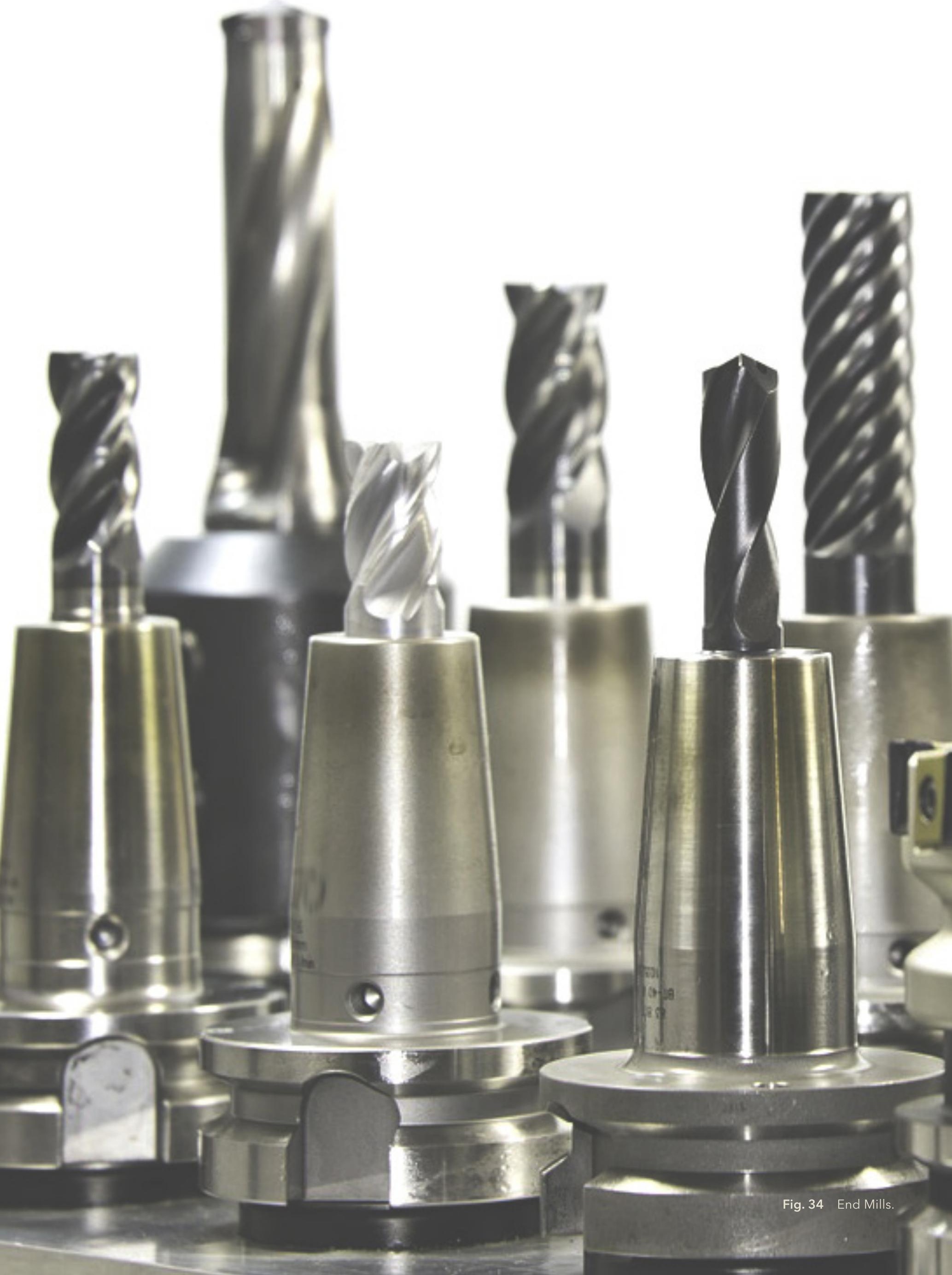


Joints should be reinforced with pins, dowels, metal straps, or an adhesive agent; however, not only the structural strength but the appearance of the finished joint should be taken into consideration"

(Seike, 1977, p. 93)

Beginning with hand-tools, chapter 3.1 focuses on the architectural tectonics. This method was tested to gain the understanding of producing joints. An abstraction was taken from the selected traditional ionts. leading to the idea of formulating joints at angles and intersections Moving towards madnine-tools and information-tools tests on standard joints were fabricated to iterate. and refine the method. Ins links to chapter 4.1. where the abstractions and test of tectomias converge together formulating a method of design.
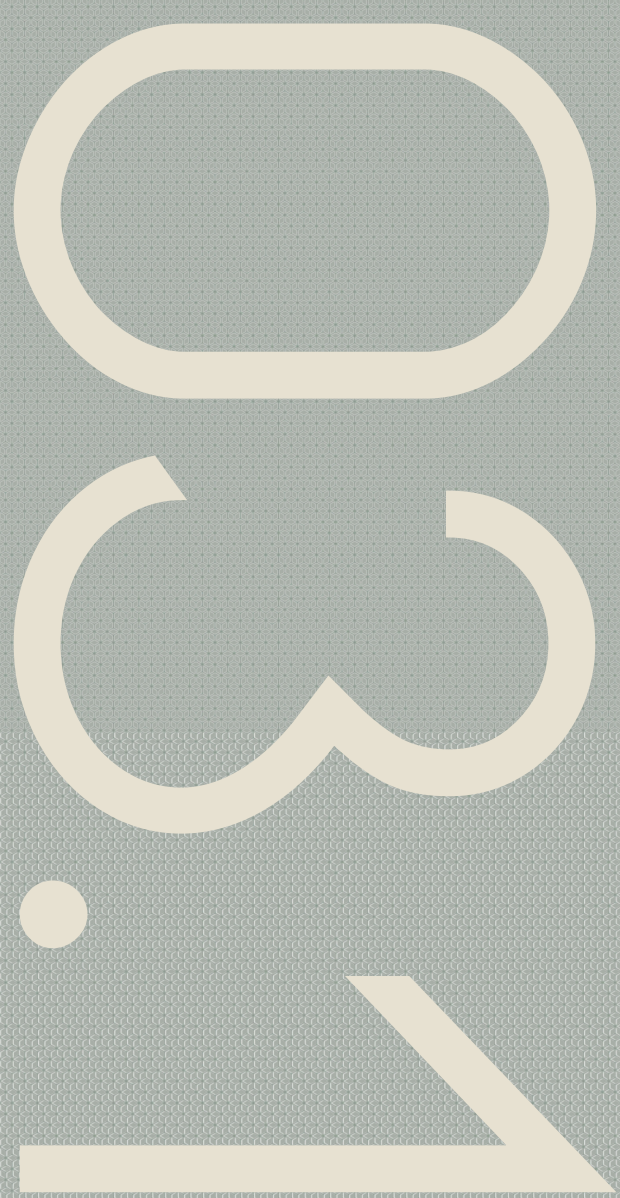

\section{DISCOVER}

DESIGN TERATION TRADITONAL JAPANESE DONTS

STRWIG NODE

ACR N L C MODEL

GRASSHOPPER + CNCROUTER

POWER TOOLS A UIGS 


\title{
DESIGN ITERATION
}

\section{TRADITIONAL JAPANESE JOINTS}

\begin{abstract}
MATERIALS The replication of traditional Japanese joints using
Fijian Kauri woodworking tools provided insight into the level of craftsmanship and time needed to produce the joints.

TOOLS

Pencil

Craft knife

Engineers Square

Band Saw

Metal File

$6 \mathrm{~mm}$ Chisel
\end{abstract}

$6 \mathrm{~mm}$ Drill Press

The first design iteration replicated Japanese joints using the chisel with assistance from powered machine-tools, as the level of skill required to handcraft the joints fully requires years of practice. The selected joints are all shiguchi (connecting joint) (fig. 36), which are all relatively simple to craft. The initial idea for selecting these joints was that they could potentially act as a structure that can be prefabricated.
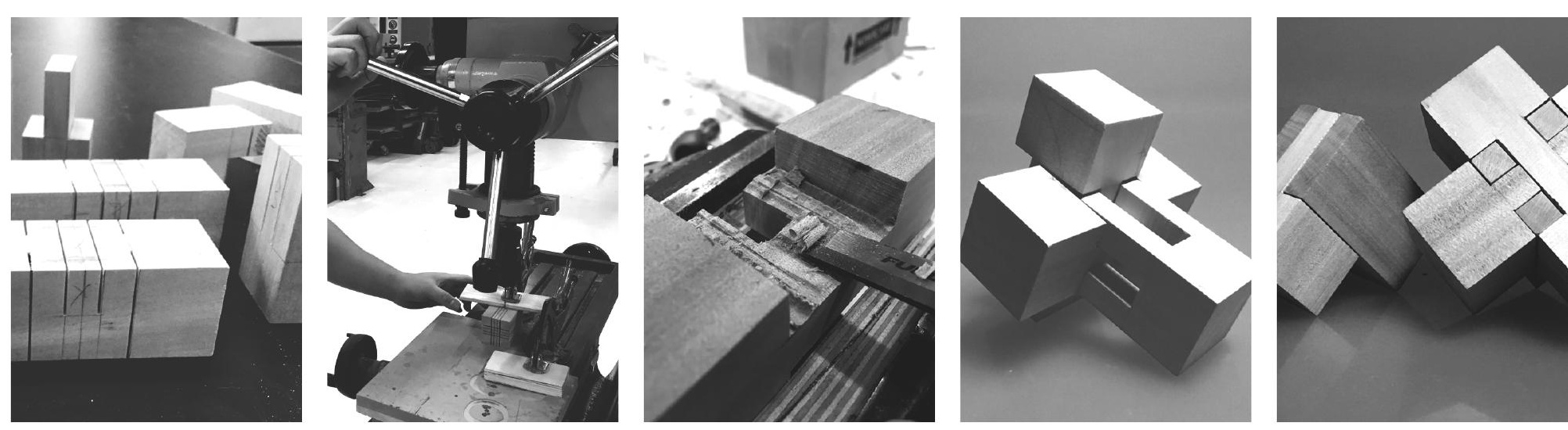

Fig. 35 Process of cutting traditional joints. 


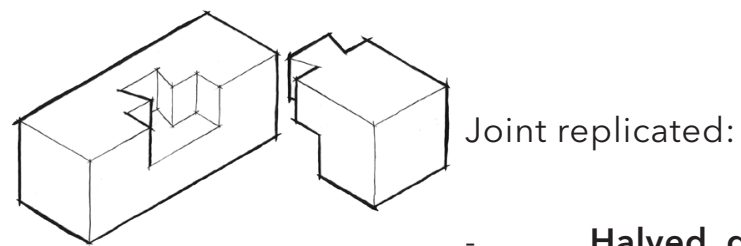

Halved dovetail, commonly used in furniture and as deck beams on traditional boats. The dovetail are often<smiles>C1CC2CC1CC2C1CCC2CC3CCC2CCC31</smiles>
seen on the corners of log cabins. Interlocking tenon joint (interlocking bridle joint), an interesting joint that can potentially act as a moment frame.

Mitred double bridle joint, often used<smiles></smiles><smiles>CCC1(C)C2CCC3CC(C2)CC1C3</smiles>
in furniture, this joint has the clean appearance of the mitred corner joint but has more strength due to the bridle.

Corner bridle joint (open mortise and tenon joint), a basic joint.

To begin this design iterations, technical drawings were produced, which then was translated onto the timber blocks. The cutting points on the $45 \times 45 \mathrm{~mm}$ timber blocks was

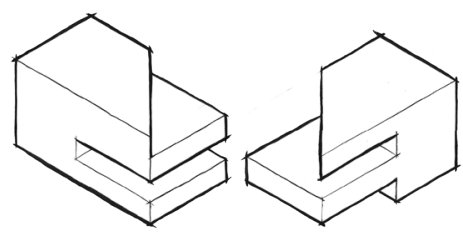
marked with a pencil and engineer square. Following the markings for the cuts, the fibre was scored with a craft knife, which acts as a marking knife, which is traditionally used in Japan. By cutting the fibres with

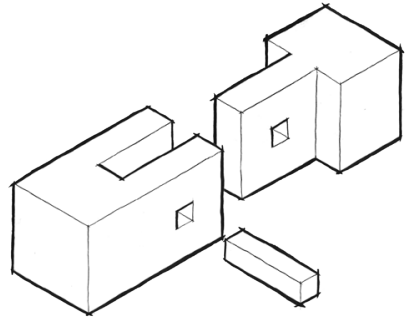
the craft knife, it prevented tearing and chipping when the joints were cut. This produced a cleaner finish with less tearing in the cross grain. Using the band saw, the notches in the joint were roughed out. Without

Fig. 36 Isometric drawings of selected test joints. From top to bottom, halved dovetail, interlocking tenon joint, mitred double bridle joint, and corner bridle joint. 
fully understanding kiwari, there was a lot of inaccuracy in initial cut on the band saw, as it was not made based on the centre line. Learning from this error, the use of a centre line and dividing sections became apparent. It is important to note the speed the timber is processed through using machine-tools; the faster the material was fed through the band saw, the more likely the notch was wobbly (fig. 37). Passing the joint through the band saw slowly led to better quality cuts. After the use of the band saw, the chisel was used to attempt to cut out the remaining pieces still in the join; however, this required a lot of skill and strength which only skilled carpenters have. To overcome this, a drill press with a $6 \mathrm{~mm}$ drill bit was initially used to clear the segments left in the join (fig. 35). This was followed by the use of a $6 \mathrm{~mm}$ chisel to clean up the remaining segments. The use of a sharp chisel is essential to crafting joints, as a dull chisel will rip the fibres of the timber, causing the final product to be chipped and unclean. Without the years of experience and skill of a master carpenter, power-tools have made fabricating joints a lot more accessible.

Some of the difficulties faced when crafting these joints was the translation of the drawings to the timber and figuring out where to cut. There must be a consideration for the thickness of the band saw when cutting joints, recognising where the blade should sit concerning the line engraved on the timber. The issues that emerged while handcrafting the joint were taken into consideration for how this information could be applied to the CNC router, and jigs for prefabrication and builders.
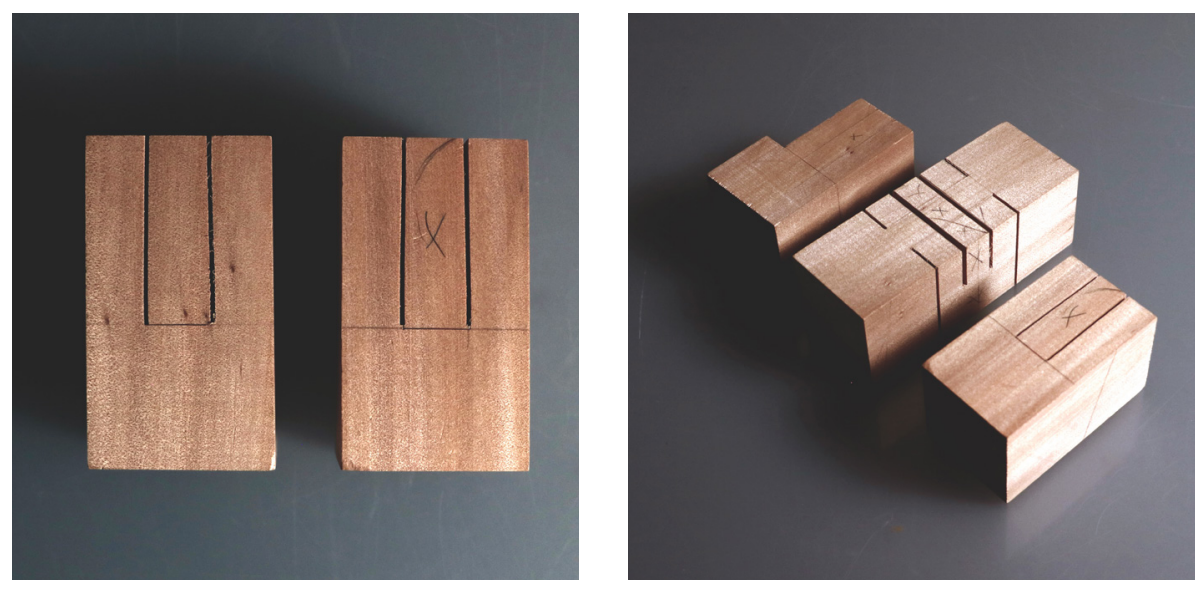

Fig. 37 Roughing of joints - pushing joint through band saw fast, leading to wobbly cuts. 


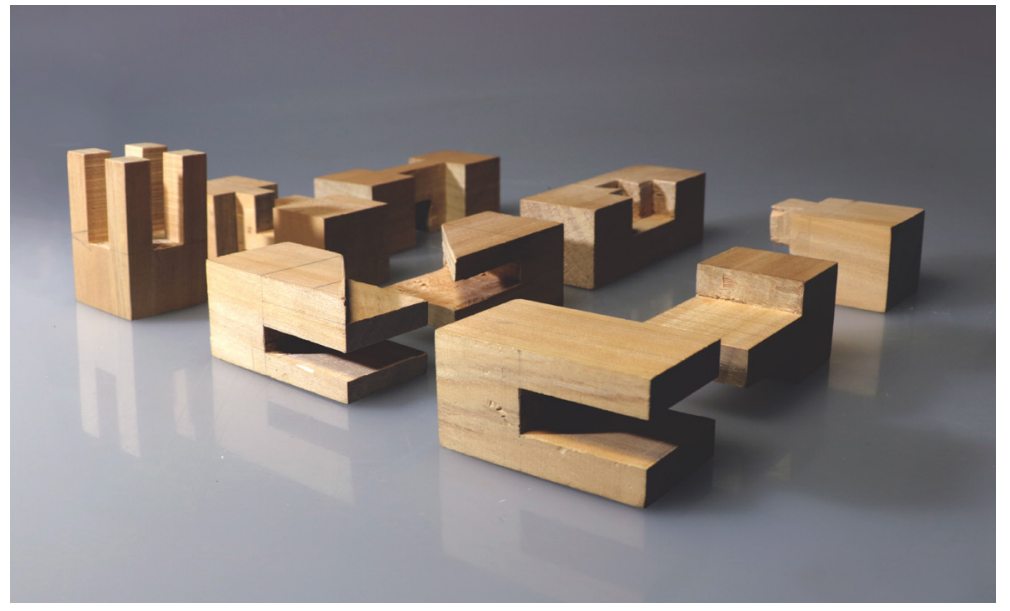

Fig. 38

Hand-tool tectonic test jointsmade of Fijian kauri, disassembled.

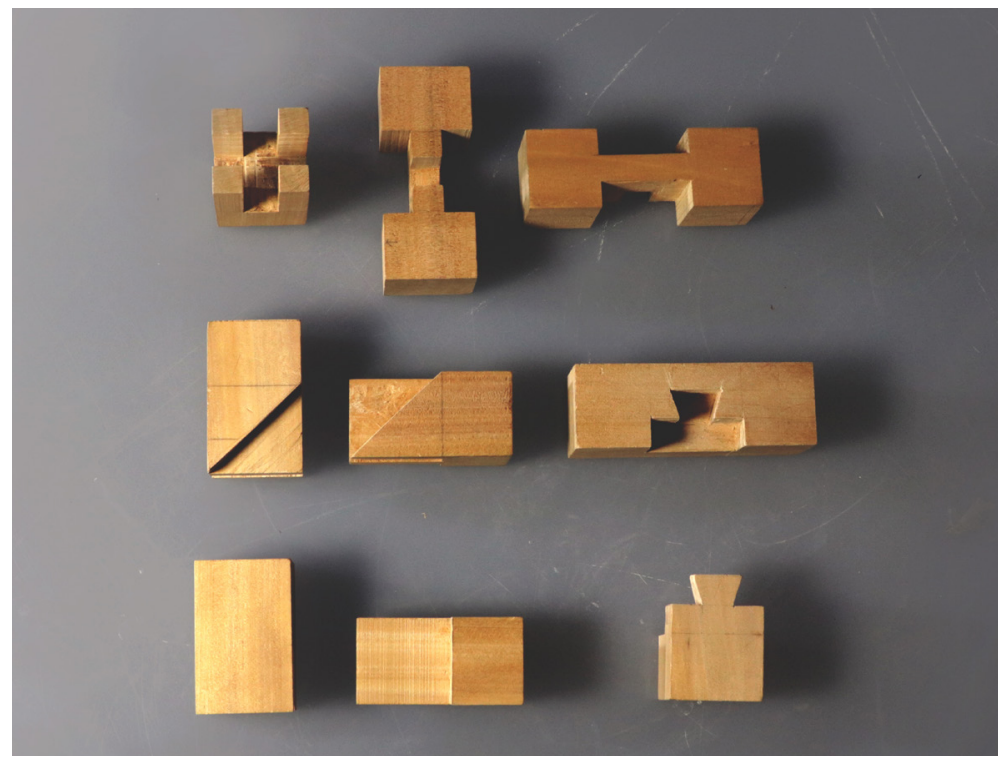

\section{Fig. 39}

Hand-tool tectonic test joints made of Fijian kauri, plan view and disassembled.

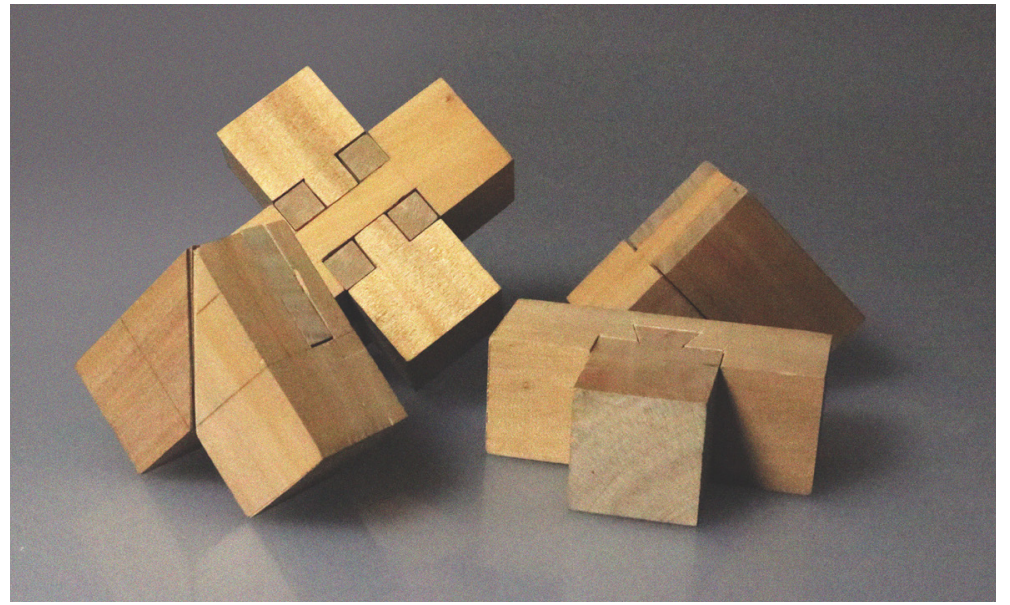

Fig. 40

Hand-tool tectonic test joints made of Fijian kauri, assembled. 


\section{STRING MODELS}

ITERATION ONE
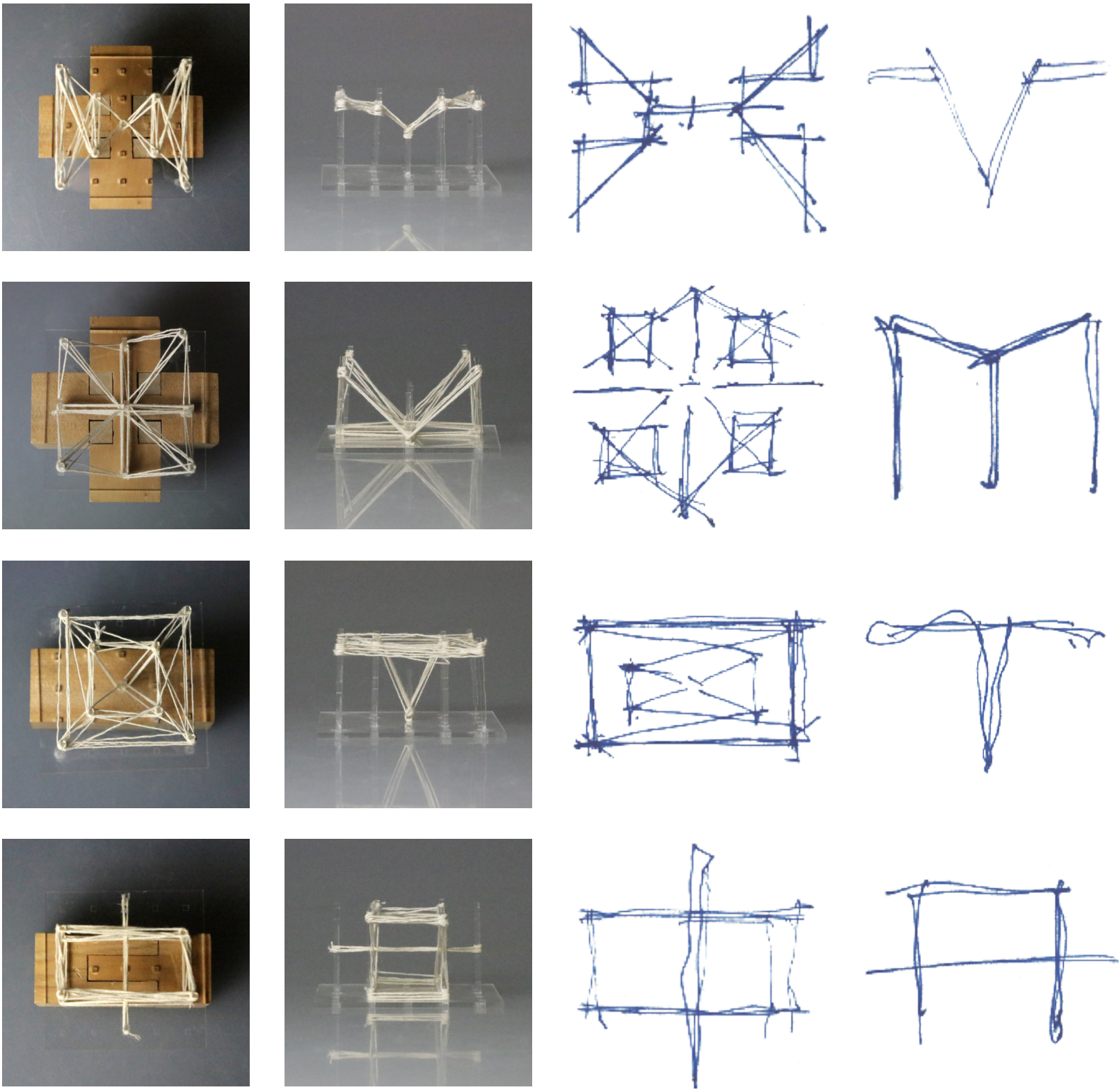

Fig. 41 Series of string models iteration one. 
MATERIALS

$3 \mathrm{~mm}$ Clear Acrylic $6 \mathrm{~mm}$ Clear Acrylic

Acrylic Glue

Cotton String

\section{TOOLS}

Computer (Illustrator) Laser Cutter
Selecting the key points on the joints cut, this led to the exploration of form and connections. Investigation of the nodes was achieved through the use of clear acrylic and string. Laser cutting the base and pegs with three notches on the clear acrylic acted as a foundation for the form, created with the string which represents the height of the nodes (fig. 41). The string was the link between each node and shows the relationship between the positive and negative nodes, creating an opportunity for examining connection joints.

\section{ITERATION TWO}

Iterating from the first series of string models, this looked closely at the differences in the space, and points where the elements meet (fig. 42). Visually representing the differences between the nodes, this information has the potential to act as forms for pergolas and pavilions, in particular looking at points of interest and where joints could potentially meet. There is a potential for spatial qualities and looking at how the structure can control how people move through space and what they feel.
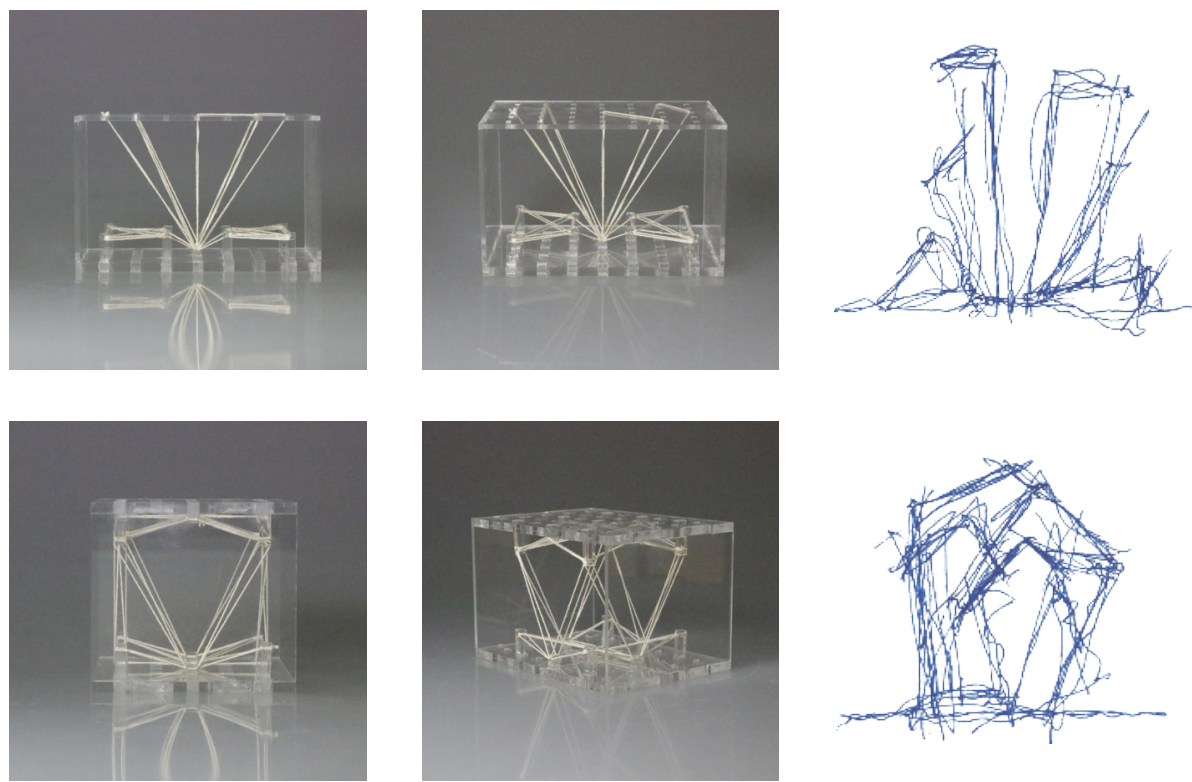

Fig. 42 Series of string models iteration two. 


\title{
ACRYLIC MODELS
}

$\begin{array}{ll}\text { MATERIALS } & \text { TOOLS } \\ \text { 3mm Acrylic } & \text { Computer (Illustrator) } \\ \text { Tape } & \text { Laser Cutter } \\ \text { Tracing Paper } & \text { Scissors } \\ & \text { Paint brush } \\ & \text { Water Colour Paint }\end{array}$

\begin{abstract}
Looking at the interlocking tenon joint, mitred double bridle joint, and corner bridle joint, the acrylic model plays with the negative spaces and layers within the joint (fig. 43). The painted areas are the
\end{abstract} voids, while the lightly washed portions are where the points were cut out. The overlaying of key sections acts as a visual representation of how the joints work. This model can be useful information on how to create a layout for environments and how it can be layered in an area.
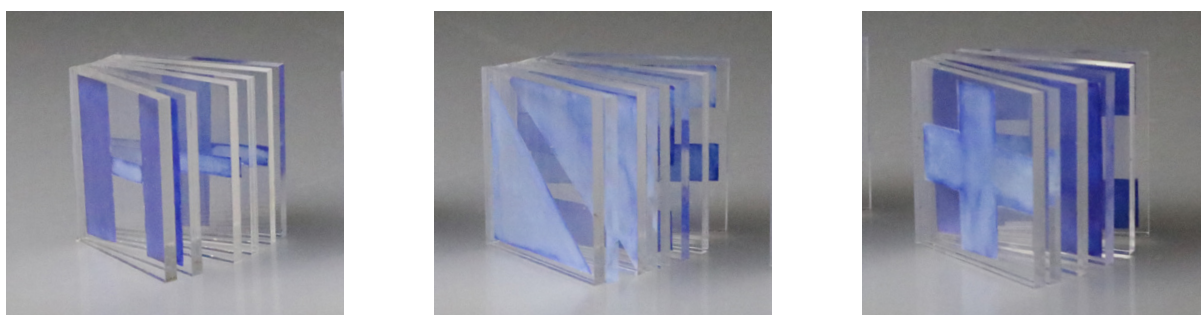

Fig. 43 Abstract acrylic models.

\section{GRASSHOPPER + CNC ROUTER}

\section{MATERIALS}

Fijian Kauri

\section{TOOLS}

Computer (Rhino 6,

Grasshopper, and Rhino

CAM)

CNC Router (6mm Head)

Plywood (sacrifice board)

Hot Glue Gun

Metal Scraper
Based on the centre points and kiwari, the interlocking tenon joint, corner bridle joint and halved corner dovetail joint was modelled parametrically. The plug-in software Grasshopper was used to model the joints, this allowed for the ability to change dimensions with just a change in numeric value.

With the consideration of the CNC router limitations around the internal corners, the 


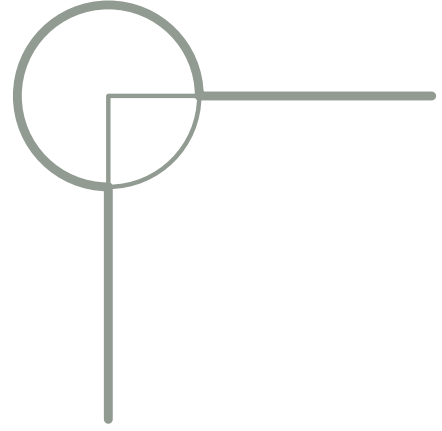

Fig. 44 Dogbone fillet internal centred on the corner.

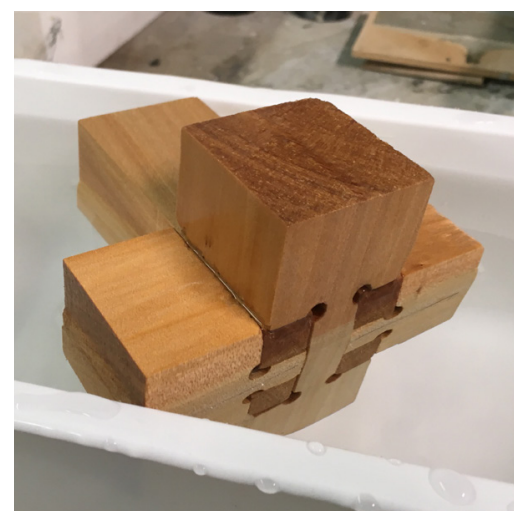

Fig. 45 Interlocking tenon joint soaking in water.

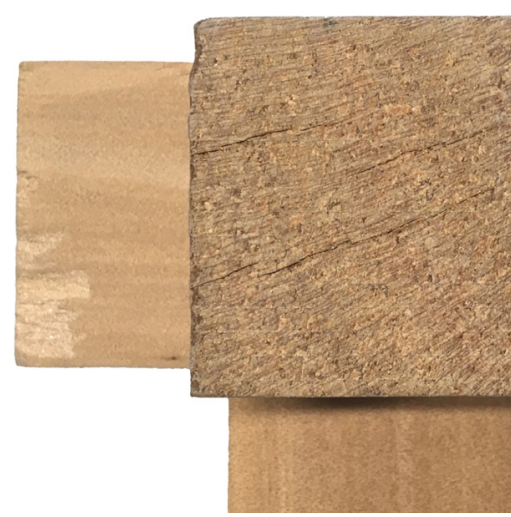

Fig. 46 Cracking on the end grain of the interlocking tenon joint. parametric models have the dogbone fillet incorporated. These fillets are centred directly on the internal corner points (fig. 44) and are the same diameter as the end mill, which is plunged into the material rather than cut. Creating the family for the corner bridle joint and interlocking tenon joint was simple; however the dovetail was a lot more complicated. There was an issue around the corners that are not $90^{\circ}$. This led to a problem in regards to the tolerance with the end mill size. The iteration of the halved dovetail corner using the traditional method is based on thirds; however, this proportion no longer worked as a parametric model. A new system was used, where the dovetail joint now scaled with the diameter of the router end mill. Using Rhino 6, the plug-in Rhino CAM converted the information into G-codes for the $\mathrm{CNC}$ router to translate and move accordingly. To reduce waste with the material, the Fijian Kauri had been cut into $46 \times 46 \mathrm{~mm}$ square profiles, where there was no need for the router to trim the edges.

The 3-axis CNC router was used to prototype the joints. The first set of prototypes revealed the importance of cutting order on the square profiled timber. Multiple joints were set into one timber piece where the profile of the joinery was cut out (fig. 
50); however, this caused issues for flipping the timber for the second cut as everything became unaligned. Due to this, joint profiles needed to be cut last in order to reduce error on the flip. This is when the robot arm would be more efficient; however, the robot arm was not a part of the scope and therefore not tested.

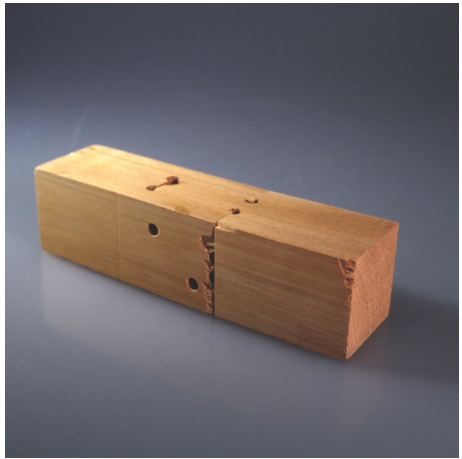
the dogbone fillets and swell shut. However, when removed and dried in an interior condition, the timber only showed minimal cracking at the end grain and became very tight (fig. 46). At a prototype scale, the joint was still able to disassemble with great force; however, at an architectural scale, this may not be applicable.

The first output of prototypes had flaws to be improve on. The dogbone fillet on the first iteration of joints was too large. This was due to the positioning of the centre of the 'circle', located at the point of the corner (fig. 44). This disturbed the structural integrity of the joints as the 'circle' cuts into the designated portions. There was also an issue of the $\mathrm{CNC}$ router tearing the fibres as the end mill leaves the timber (fig. 47). To mitigate these issues, there was an adjustment to the toolpath taken.

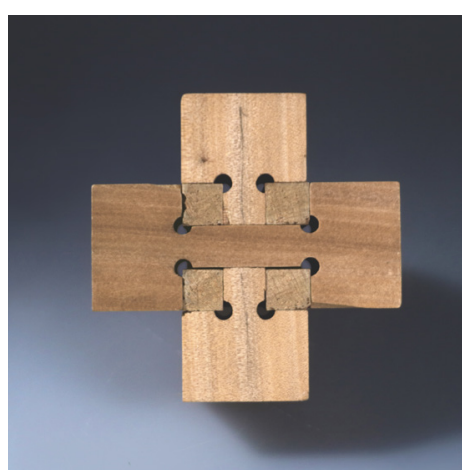

Fig. 47

First iteration, bridle joint - major tearing of fibres from the $\mathrm{CNC}$ router.

\section{Fig. 48}

First iteration, interlocking tenon joint.

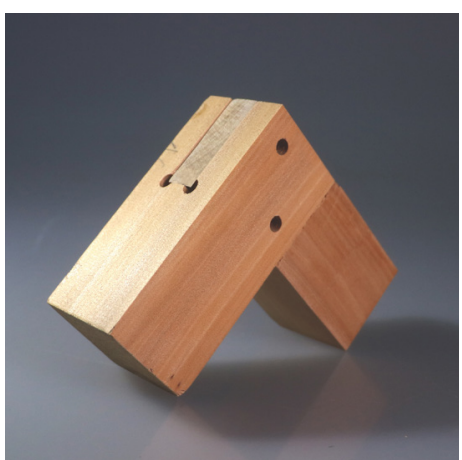

\section{Fig. 49}

First iteration, corner bridle joint. 


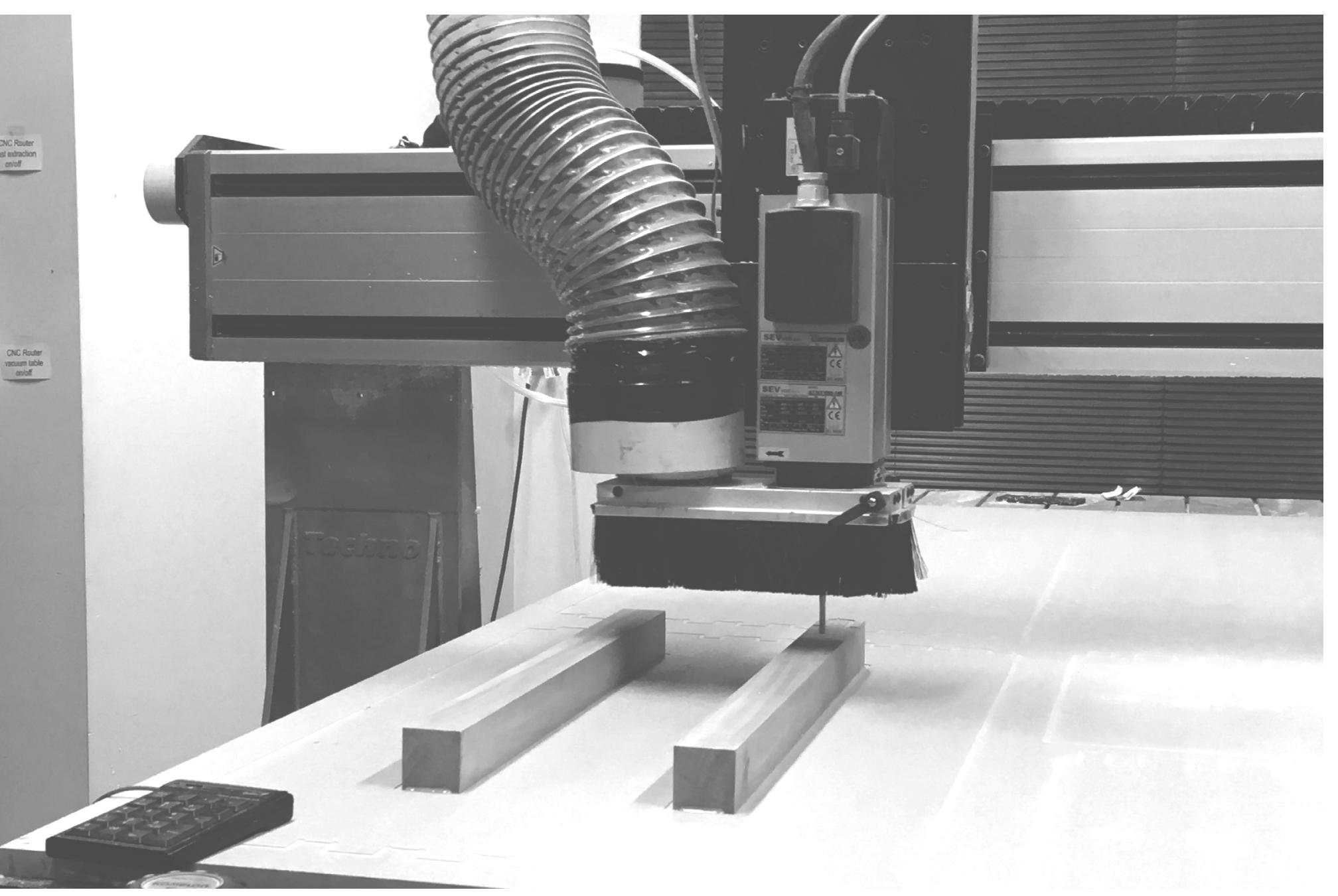

Fig. 50 CNC Router profiling joints, iteration one. 


\section{POWER TOOLS + JIGS}

MATERIALS There are many types of tools used on the construction

Foam board site. For this research, the mitre saw was selected as the primary tool to fabricated timber joints. The handheld

TOOLS circular saw is more universally applicable than the

Mitre saw mitre saw, as it is portable and has the capability to Engineers Square cut curves. However, for the simplicity of this thesis Ruler the handheld circular saw was not as appropriate as

Pencil the mitre drop saw for joints as the handheld circular saw required guards and jigs to perform cuts. The oscillating tool and hand router are also portable and have the potential to cut tight details due to the smaller blade/end mill. As there was a limited length and width to the blade/end mill, usually $50 \mathrm{~mm}$ max, it was not selected for assisting this research.
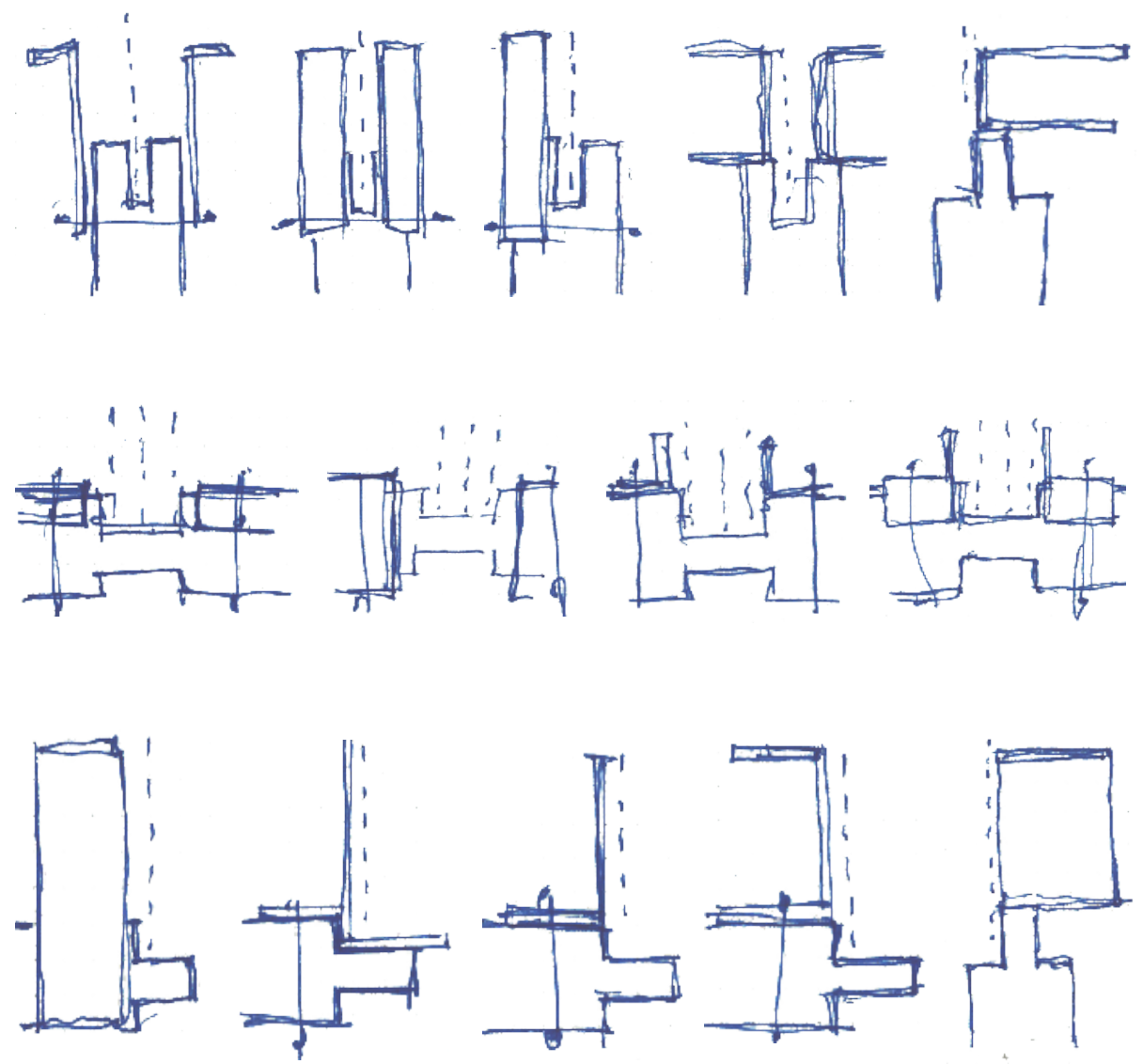

Fig. 51 Sketch series of jig configuration. 


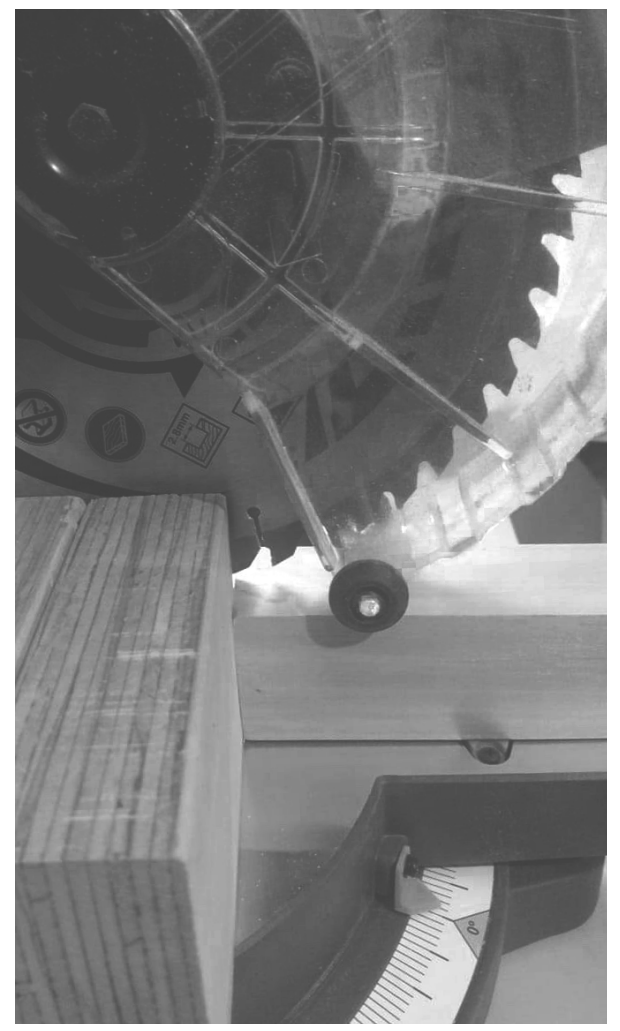

Fig. 52 Close up image of dual bevel sliding mitre saw blade.
The orientation and layout of potential jigs were sketched to find the most efficient technique to cut an open mortise and a tenon joint (fig. 51). These looked at a method of cutting the joints by using a jig. The iterations function by pushing the material towards the end of the blade, allowing for the blade tip to cut the joint. Here came the realisation of the fact the mitre drop saw cannot cut a mortise due to the curvature of the blade as it plunges into the material (fig. 52). Other techniques to cut joints and the material was to be reviewed and developed, which led to the testing of the basic tsugite.

The simple lap joint (koshikake tsugi) and scarf joint (sogi tsugi) were examined. The lap joint (fig. 53 ) is one of the most basic splicing joints - koshikake means 'seat' or 'chair', where the male joint overlaps the female joint. No simple scarf joint (fig. 54) or lap joint has adequate structural integrity; therefore, they require a form of fixing, such as dowels, bolts, straps or an adhesive. Investigating these joints on the mitre drop saw allowed for a greater understanding as to how this tool functioned. These experiments were conducted using $50 \times 50 \mathrm{~mm}$ foam boards for low-cost and quick prototypes. Cutting lap joint at the set depth into multiple segments allowed for easy removal that could be done by hand; however, a file was required to tidy these pieces (fig. 55). Observation of the tool and the outcome of the product provided a greater understanding of what type of jigs were applicable to this saw, which leads into chapter 4.1. 

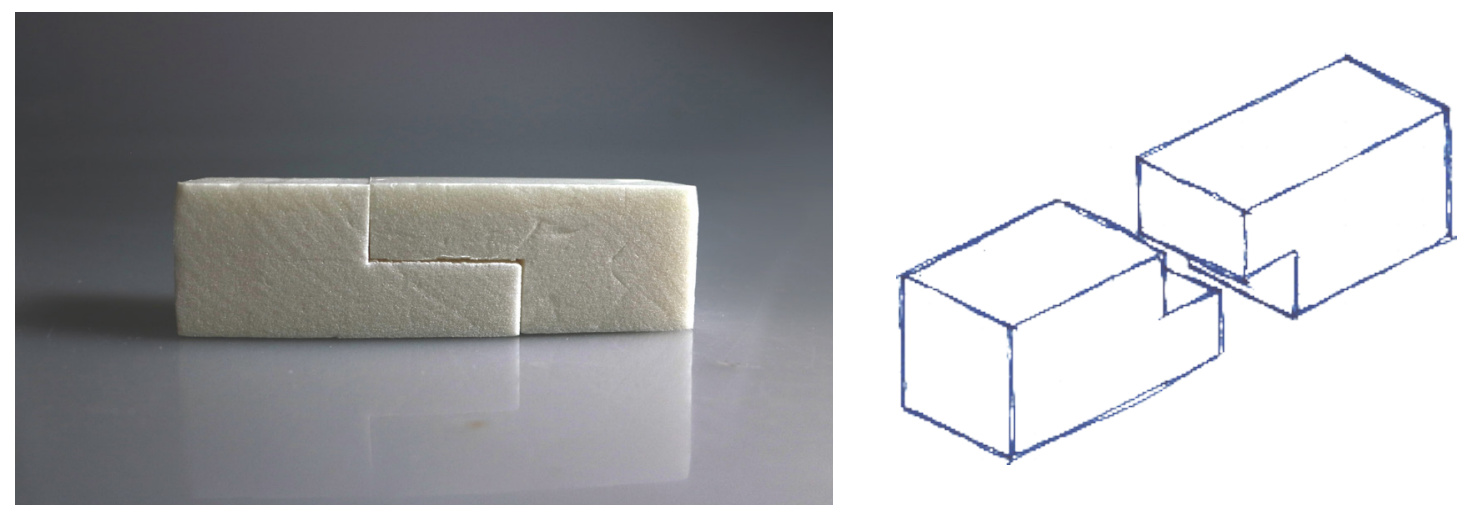

Fig. 53 Foam board lap joint.
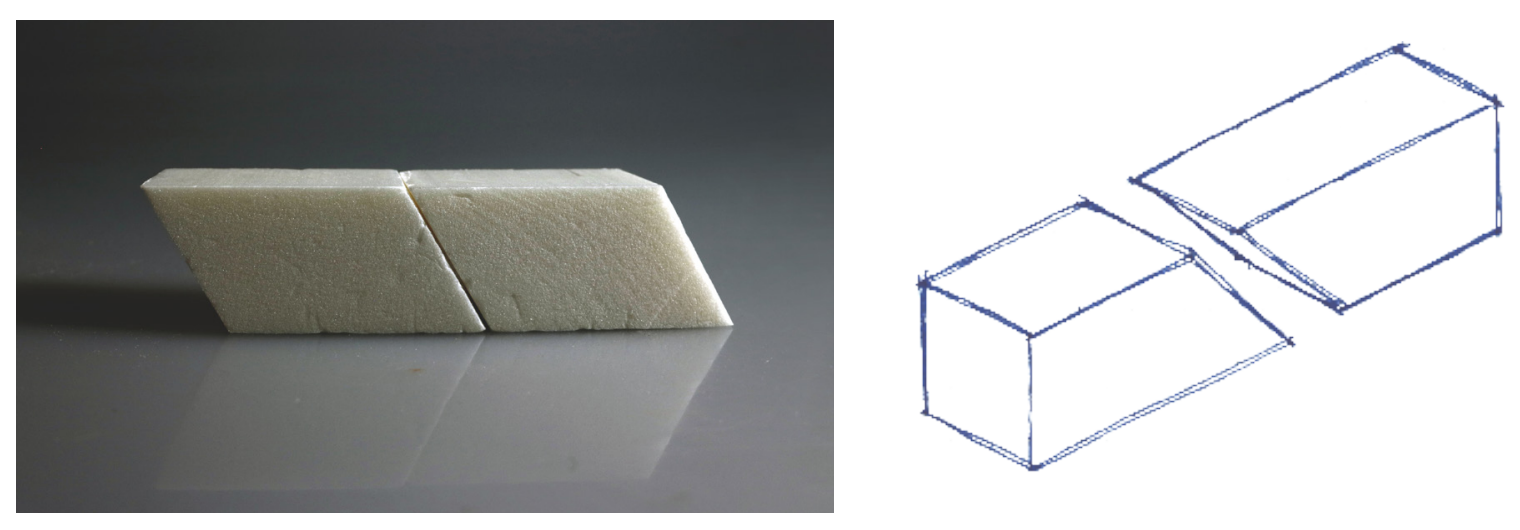

Fig. 54 Foam board scarf joint.

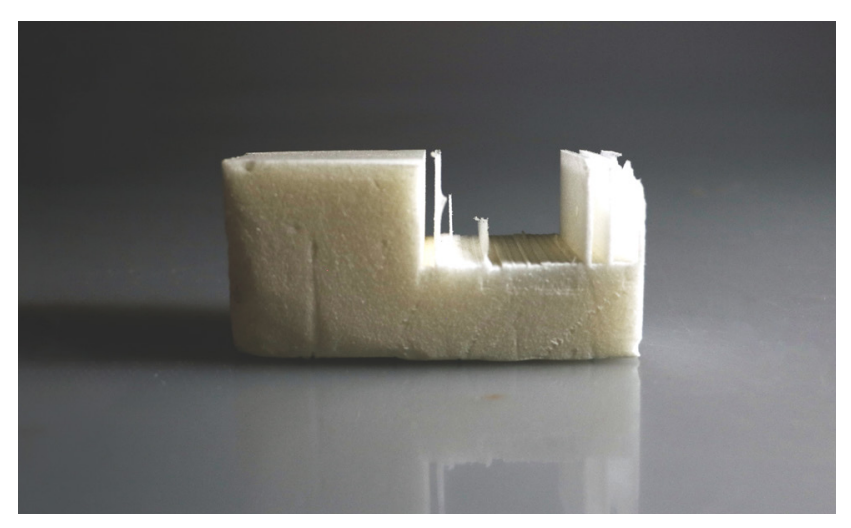

Fig. 55 Foam board roughing out of segments. 


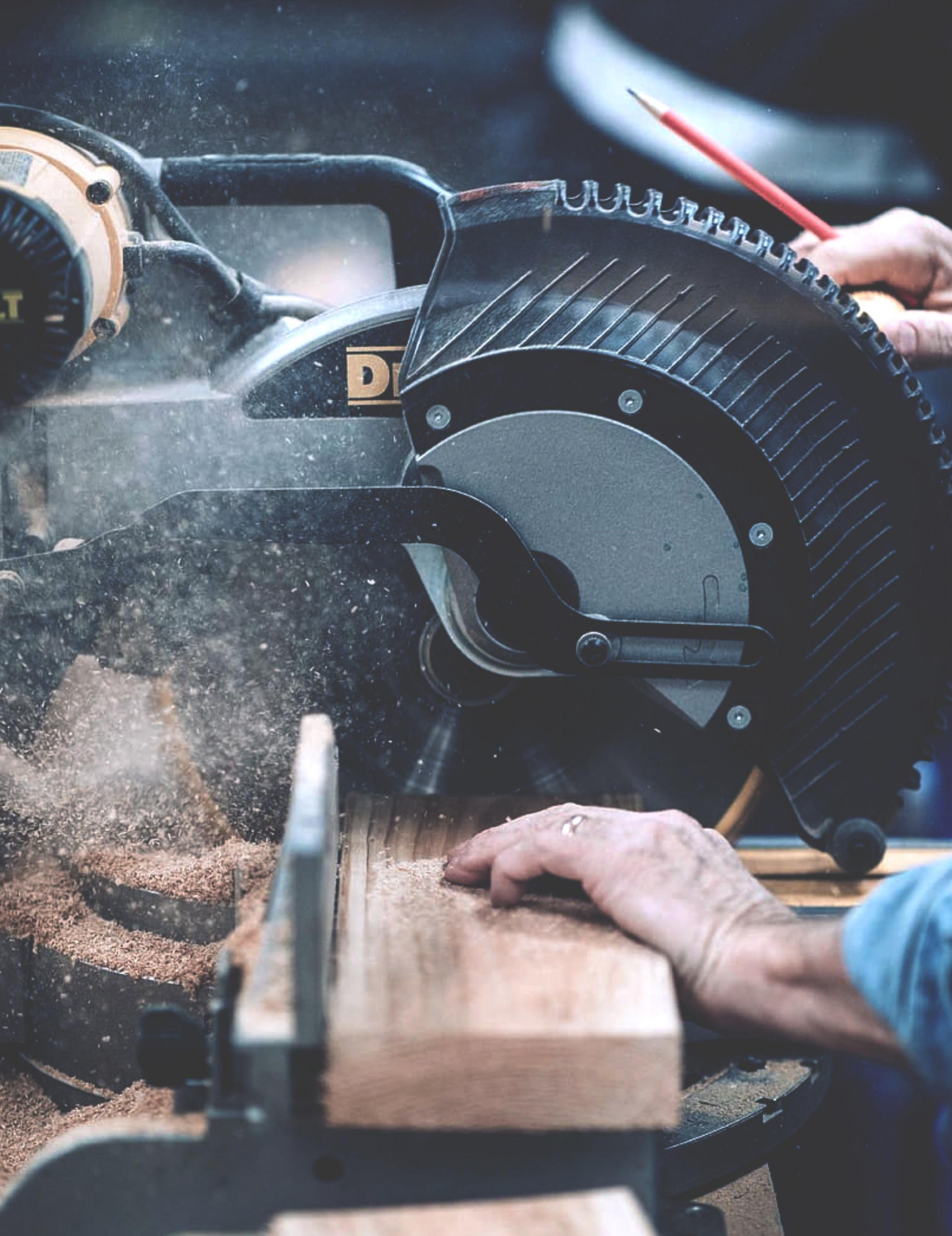

Fig. 56 Mitre saw. 
This chapter focuses on the development of the design iterations produced in chapter 3.1. After testing all three tectonics in the previous section, this has led to the development of the parametric models and methods to cut joints on a mitre saw for an easy production. Fabricating prototypes allowed for furtherer understanding as to what are the issues were and what solutions were available, which links to chapter 5.1, where the method for fabrication was reviewed, concluding the discovery, development and delivery.

\section{DISCOVER + DELIVER}

DESIGN DEVELOPMENT: GRASSHOPPER + CNC ROUTER

JOINT ANALYSIS

TECHNICAL REVIEW

DESIGN DEVELOPMENT:

POWER TOOLS + JIGS

LAP JOINT ITERATIONS

SCARF JOINT ITERATIONS

MARKING DIAGRAMS

DESIGN DELIVERY:

FABRICATION

ASSEMBLY

IMPLEMENTATIONS 


\section{DESIGN DEVELOPMENT: GRASSHOPPER + CNC ROUTER}

The aim was to find a system that allowed for efficient fabrication of joinery using information-tools. Using this method allowed for an opportunity to prefabricate joints, which can then become kitsets, feeding the DIY culture New Zealand has.

\section{JOINT ANALYSIS}

The corner bridle joint was tested with the variables taken into consideration (fig. 57). The same methods used in the technical review are used to test how angles can be parametrically controlled and fabricated. Due to the angle of the corner bridle joint, there was a need for pocketing the tenon rather than profiling (fig. 58). This use of pocketing was to accommodate the angle at which the two joints meet. Profiling was used to cut the mortise, leading to the big slit on the underside of the joint (fig. 59). This joint has been limited due to the use of a 3-axis CNC router.

The butterfly joint, also known as the Nakashima joint, has been briefly reviewed. The butterfly joint is a form of splicing two members together (fig. 60). It is more of an aesthetical joint rather than structural and is often used to reinforce cracks in timber panels. Here this research briefly attempted to look at the butterfly joint with timber profiles rather than sheets. The cutting of the key for the joint was a finicky process where it would often fly away due to its size. Once fabricated, the joint became a very strong splicing joint, with very little slack. There is a potential for another form of keys, such as the ' $X$ ' or reflected diagonal slits (fig. 61). 
Fig. 57

Corner bridle joint.
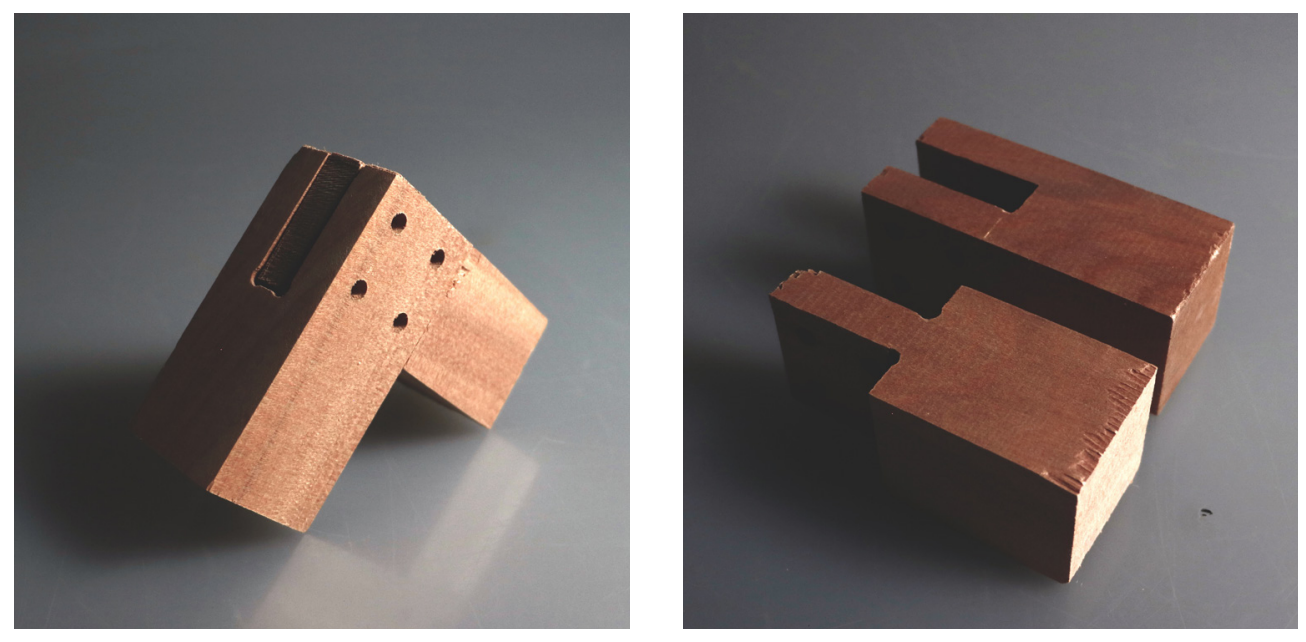

Fig. 58

Angled corner bridle joint.
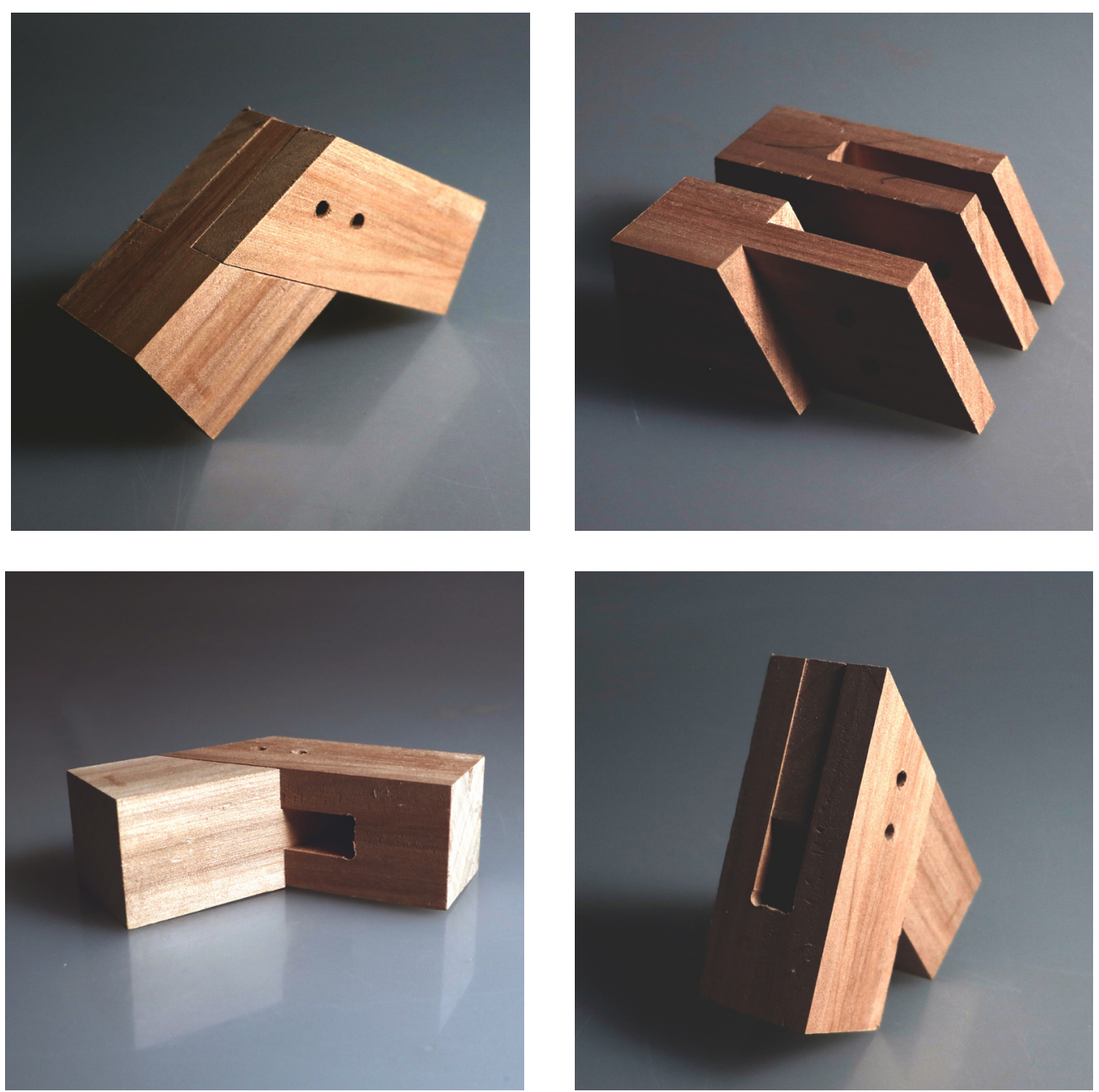

Fig. 59

Underside of angled corner bridle joint. 
Fig. 60

Butterfly Joint.

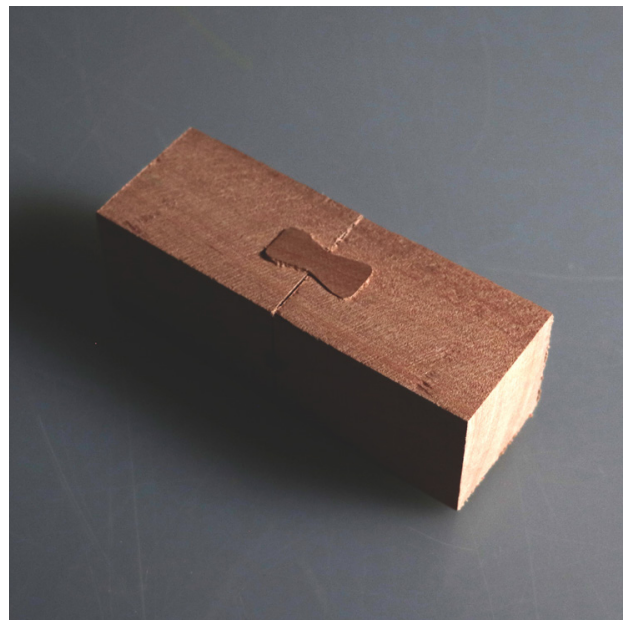

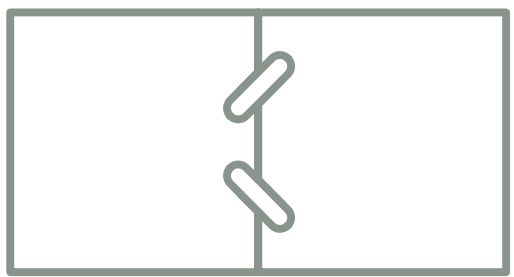

Fig. 61

Keys for the

butterfly Joint. 


\section{TECHNICAL REVIEW}

The method of parametric modelling and use CNC router for prototyping timber joints needed development, in particular, the fillets, and toolpath. This primarily looked at the method of producing a clean product efficiently.

Filleting the corners with large dogbones was unnecessary and therefore needed to be reconsidered. Continuing with the same tools, the toolpath on the parametric models were adjusted. A few iterations were made to the corner fillets, where curvature was tested on the splicing of mortise and tenon. The other iteration focused on the centre of the 'circle' which was readjusted to align at the radius of the circle (fig. 62), reducing the prominence of the dogbone fillet. This reduction increased the structural integrity and decreased visual offset.

Flipping the timber for this research was crucial, with majority of the issues occurred during this stage in the first prototype. Discovering that the profiling should have been the final cut, a rectangular profile was used. This meant the shorter depth on the timber was to be cut first and cleared of the excess material before the flip. On that flip, the profiling of the joint was done. However, that was when the majority of the tearing

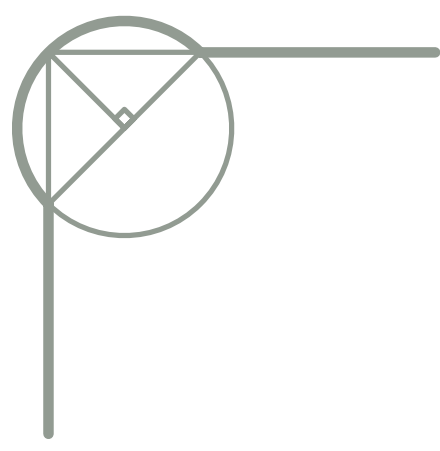

Fig.62 Dogbone fillet internal, radius perpendicular to edges. occurred. This issue was next mitigated through testing of toolpaths; however, this may not necessarily be an issue a manufacturer would face. Depending on the member sizes, there may not be a need to emphasise the cutting order for the flipping as there may only be one joint per timber element.

A significant defect from the $\mathrm{CNC}$ router was the ripping of fibres on the material (fig. 63). A method to prevent the departure of the end mill from further pulling out the material must 


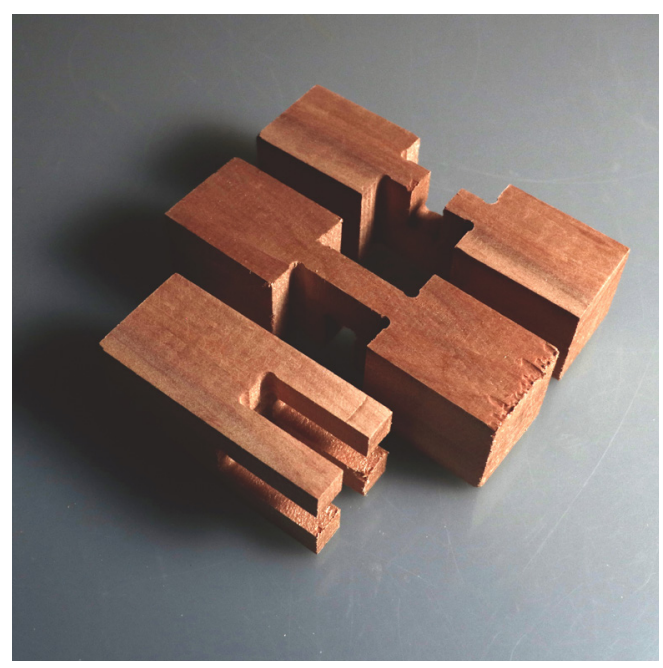

Fig. 63 Interlocking tenon joint, ripping of fibres.

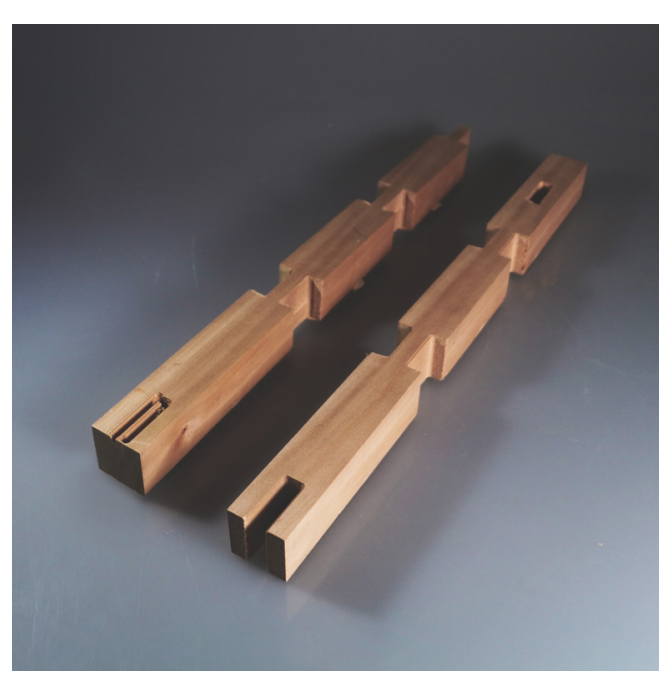

Fig. 64 Test error, CNC profile cut in Fijian Kauri.

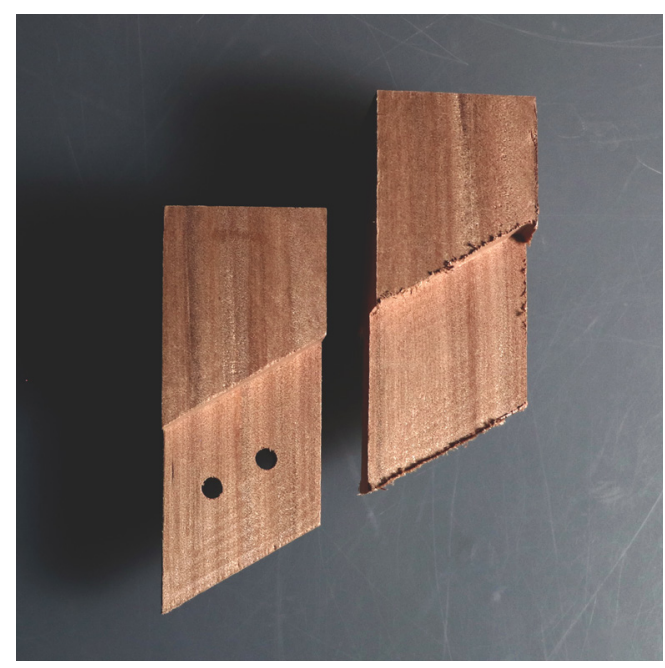

Fig. 65 Angle bridle, comparison of edges. be reviewed. Firstly, the spindle speed was reduced when it exited the material, which did relatively reduce the tearing of fibres, but was still present (fig. 64). The next iteration looked at the size of the material. As the tearing occurred on the sides, the profile would no longer be square, but rectangular to allowing for an overall trim at the end. This was only applicable in one axis as there was still a flip required. The last consideration was the testing of toolpaths, where the end mill retracts through the same way it approached to reduce tearing (fig. 65). This method minimises the tearing at the cost of the time taken to cut the joint.

Cutting internal sections on the first cut led to the spindle becoming tangled in sawdust. This was due to the longer strands being contained in a pocket. The pressure from the end mill causes the strands to 'fly away'; however, the only option available was to flying upwards, twisting 


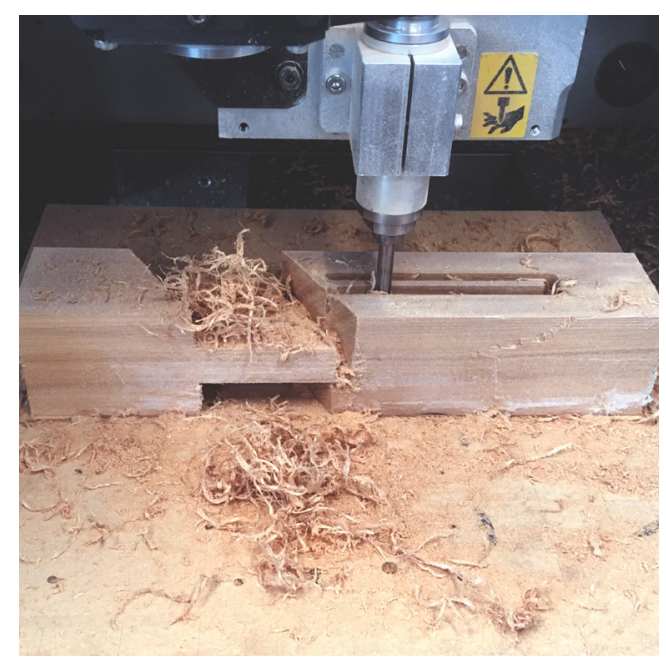

around the end mill (fig. 66). To combat this issue, the toolpath was revaluated, producing a path that always had an exit point to prevent the end mill from becoming ensnared by the strands of offcut.

Reviewing the joints selected, the variables regarding the fillet and toolpath have been mitigated with tests through prototyping the joints. By readjusting the 'centre' of the dogbone fillet on the parametric model, this allowed for a stronger product with a less prominent 'hole'. Through experimenting with the toolpaths, it produced an outcome that reduced the ripping of the material as the end mill retracts at the cost of time.

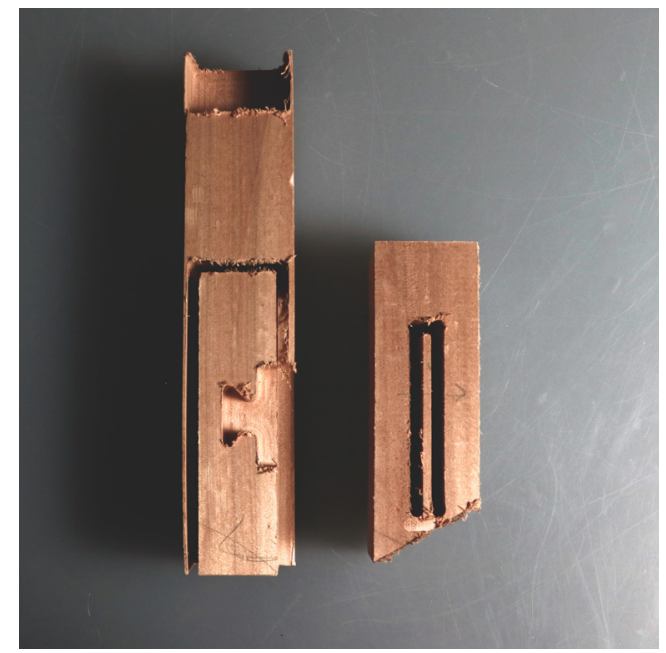

Fig. 66 Twisting of end mill. 


\section{DESIGN DEVELOPMENT: POWER TOOLS + JIGS}

This thesis intended to efficiently fabricate joints, by furthering the research of machine-tools and jigs to produce a system; there is an opportunity to make crafted joinery more accessible to New Zealand's DIY culture. The mitre saw used for this research was the dual bevel sliding mitre saw. The sliding blade and the base can rotate up to $45^{\circ}$, allowing for the capability to cut various angles. The mitre saw is able to fabricate lap joints, and mitre joints easily (fig. 68); however, the mitre saw does not necessarily require jigs for assisting in cutting joints. Using marking jigs and set up jigs can make arranging the heights and depths more efficient.

Continuing the experiment from the previous chapter, timber set up jigs were created based on the dimension of the foam board. To adjust the plunge height on the machine, set up jigs were used, positioned directly under the blade. Using kiwari, the jigs were cut at 1/4, 1/2,3/4, 1/3, and $2 / 3$ of the height of the material which was $50 \mathrm{~mm}$. These correlated to the proportions used in the fabricated prototype joints, following the same method of cutting multiple segments that can be easily snapped off (fig. 55, refer to page 85). After the initial testing of the lap joint and scarf joint, iterations of these were formed. Initially testing the splicing joints, inspiration was taken from the watari-ago (cross lap joint).

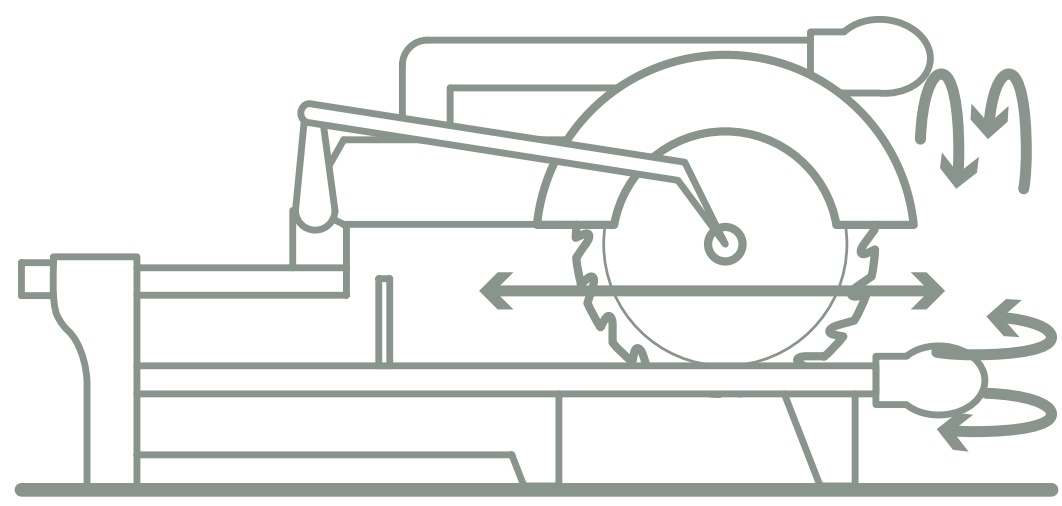

Fig. 68 Mitre saw diagram. 


\section{LAP JOINT ITERATIONS}

Perfecting the use of the mitre saw required practice on how to cut and slide consistently (fig. 69). The conduction of a few tests had the help of set up jigs. The jig made setting the cutting depth a lot faster, as different heights were needed for the various proportions the joint had.

Iteration one was divided into quarters (fig. 69). Aesthetically this was very interesting; however, as it has been divided four times in both $X$ and $Y$ axes, the structural integrity had been compromised.

Iteration two simplified iteration one, being divided in half and by thirds (fig. 70). As traditional lap joints required a form of a fixture, a dowel would be inserted in the centre. However, this may not be applicable for the architectural scale as a drill must pass through the whole member to align the hole.

Iteration three used the basis of iteration two and developed to a connection joint with an additional member inserted (fig. 71). Based on thirds, structural integrity is questioned, especially since the splice had been rotated $90^{\circ}$ from its standard position.

Iteration four took inspiration from the corner bridle joint and also the cross lap joint (fig. 72). By combining these two, the appearance is unique and was based on halves and thirds. 
Fig. 69

Lap joint -

Iteration one.
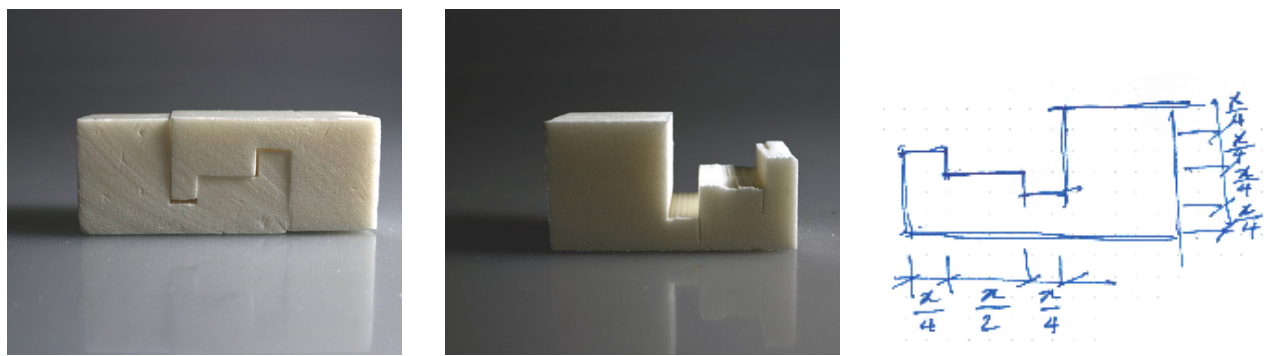

Fig. 70

Lap joint -

Iteration two.
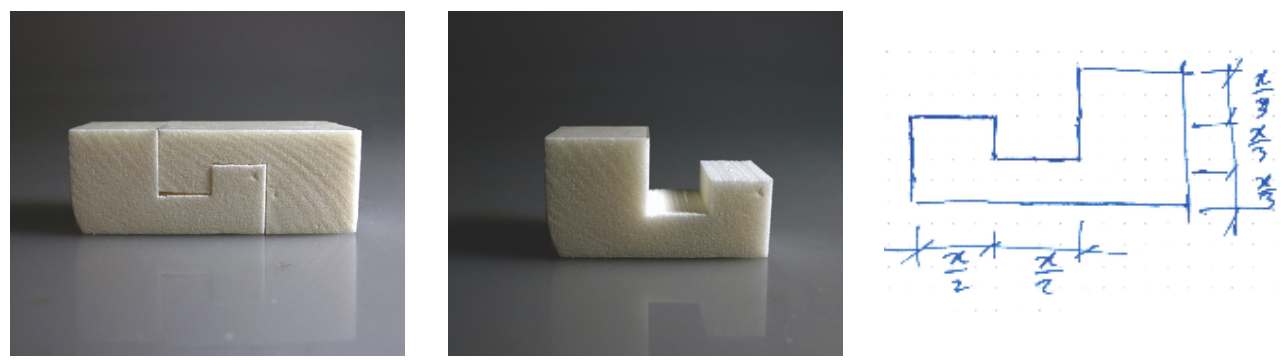

Fig. 71

Lap joint -

Iteration three.
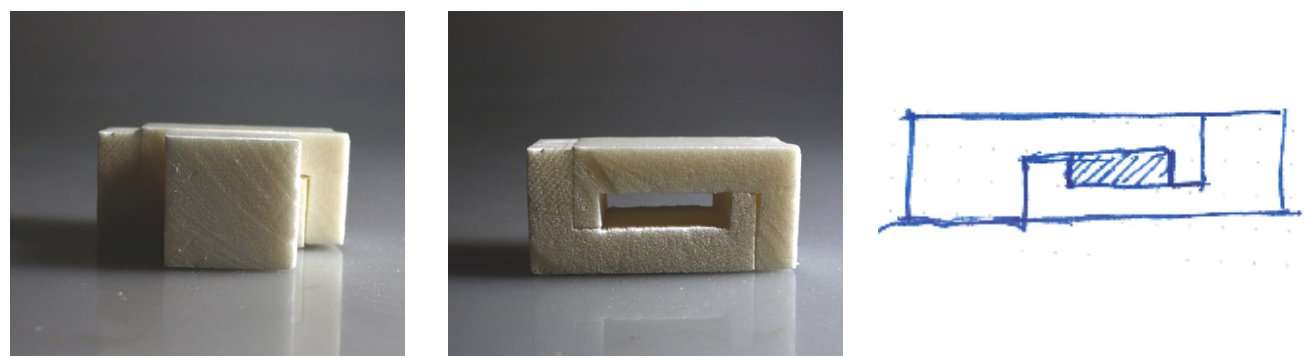

Fig. 72

Lap joint -

Iteration four.
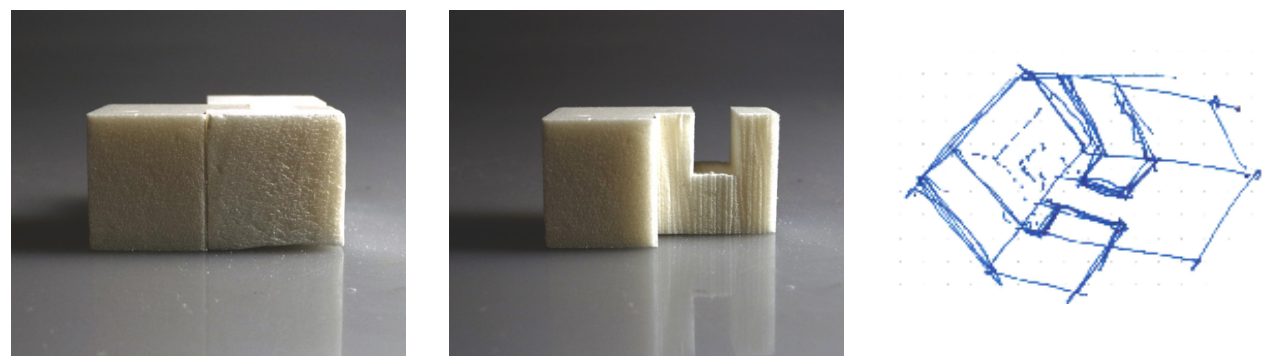


\section{SCARF JOINT ITERATIONS}

Combining scarf joints and lap joints, the scarf joints provided the opportunity to use fixing like dowels. The angle the scarf joint was cut on could turn it into an angled lap joint. This joint was further iterated through drawing (fig. 73).

These iteration of the lap joints
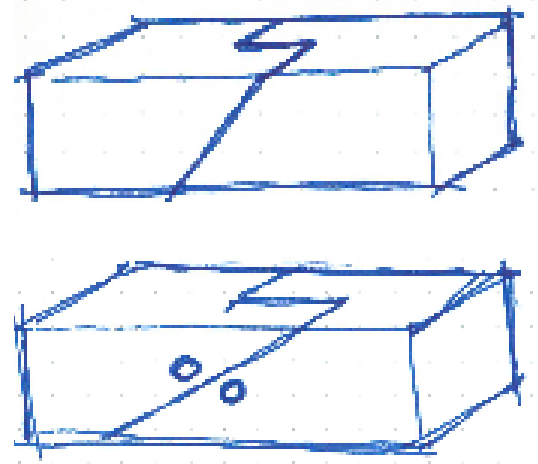
and the scarf joint were all viable as they were physically prototyped. However, the structural integrity of the joints is unknown and was not within the scope.
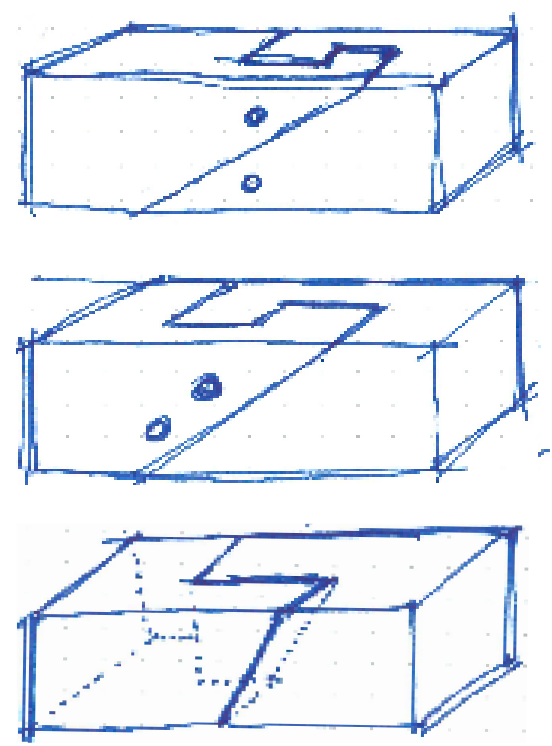

Fig. 73 Scarf joint - Iterations.

\section{MARKING DIAGRAMS}

A series on marking diagrams have been produced and tested on the mitre saw. These iterations are focusing on the form and aesthetic of the splicing connection. These have the ability to be flipped; therefore, only one set of markings are required for the joints (fig. 74 - 79). 


\section{SPLICING JOINTS}
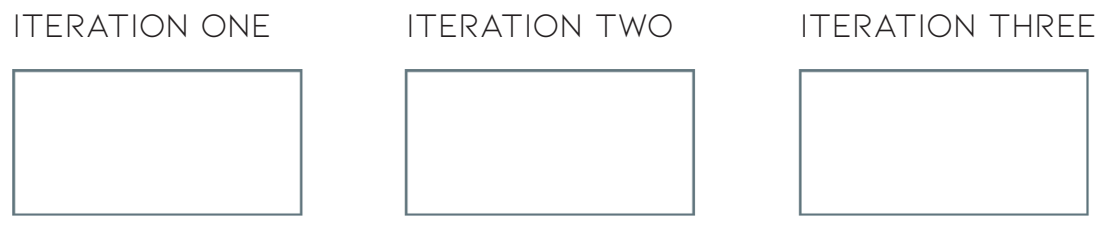

ITERATION FOUR
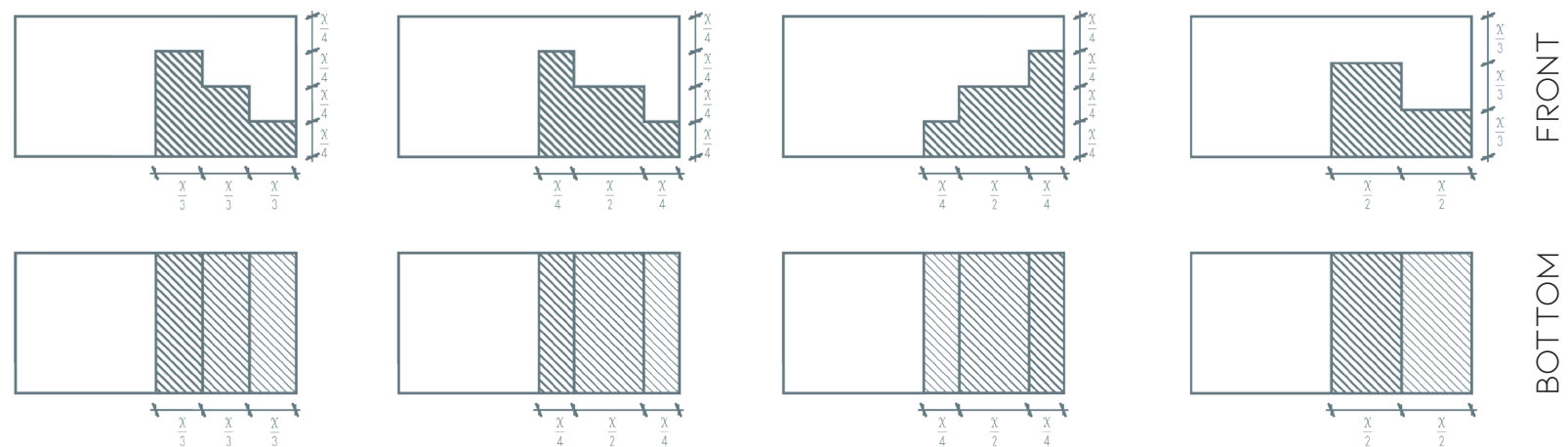

\begin{tabular}{l}
$\sum_{0}$ \\
$\vdash$ \\
$\vdash$ \\
\hdashline
\end{tabular}
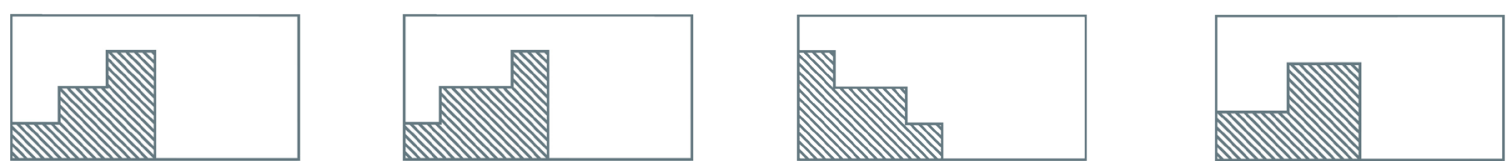

$\underset{\cup}{\cup}$

ITERATION FIVE

ITERATION SIX

ITERATION SEVEN

ITERATION EIGHT
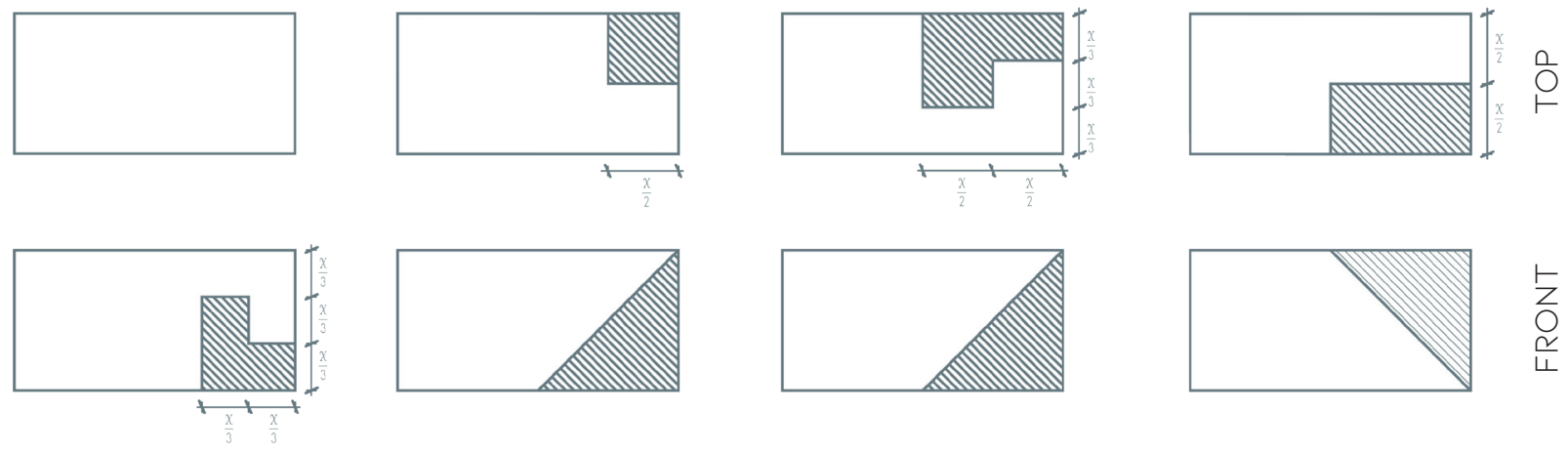

$\frac{\vdash}{Z}$
$\bigcirc$
$\frac{1}{u}$
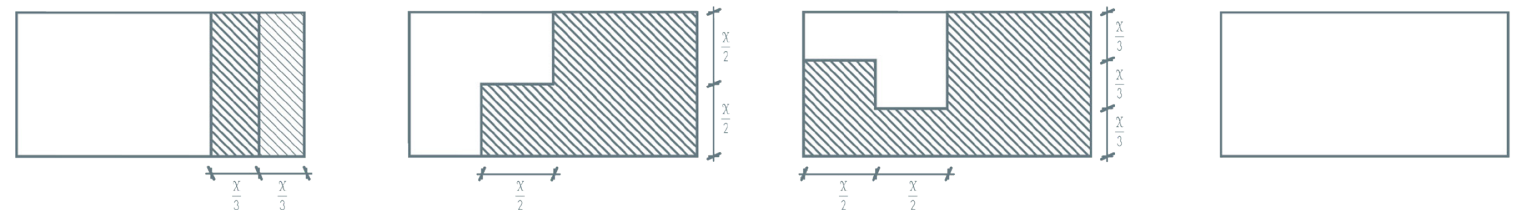

$\sum$
$\circ$
$\vdash$
$\circ$
0
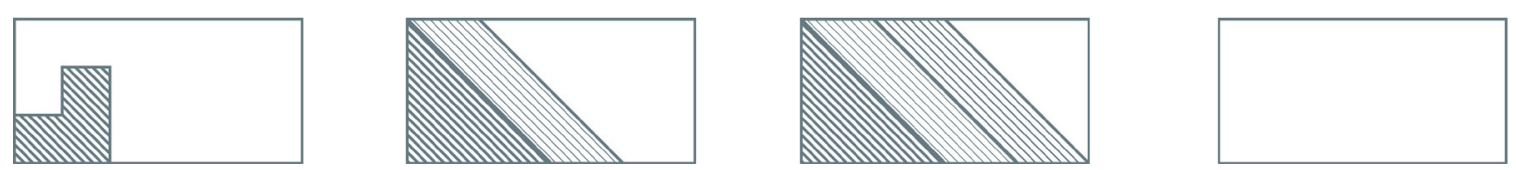

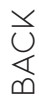

Fig. 74 Splicing joint marking diagrams. 


\section{CONNECTION JOINTS}

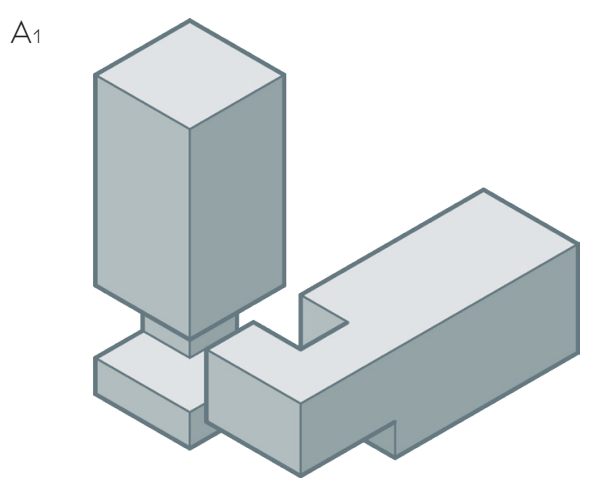

$\mathrm{B}_{1}$

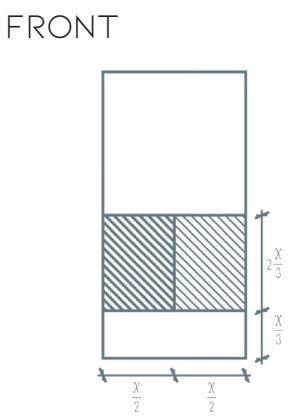

LEFT
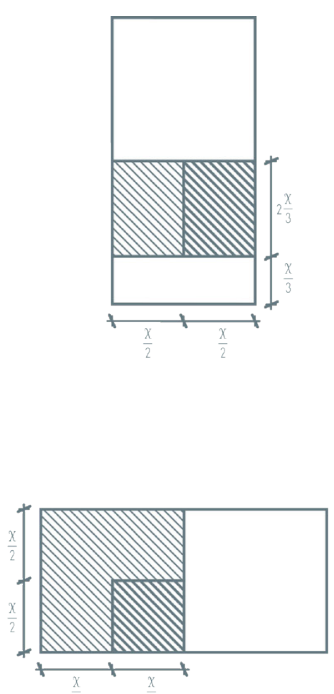

BACK
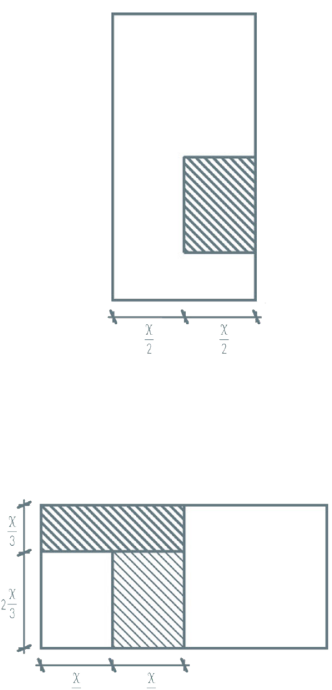

RIGHT

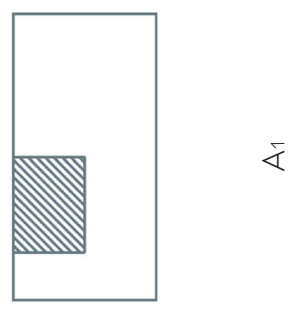

¿

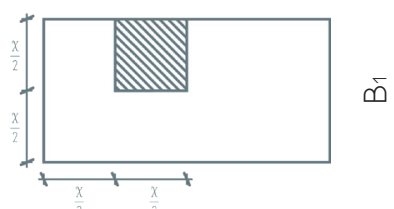

Fig. 75 Connection joint marking diagrams 1. 

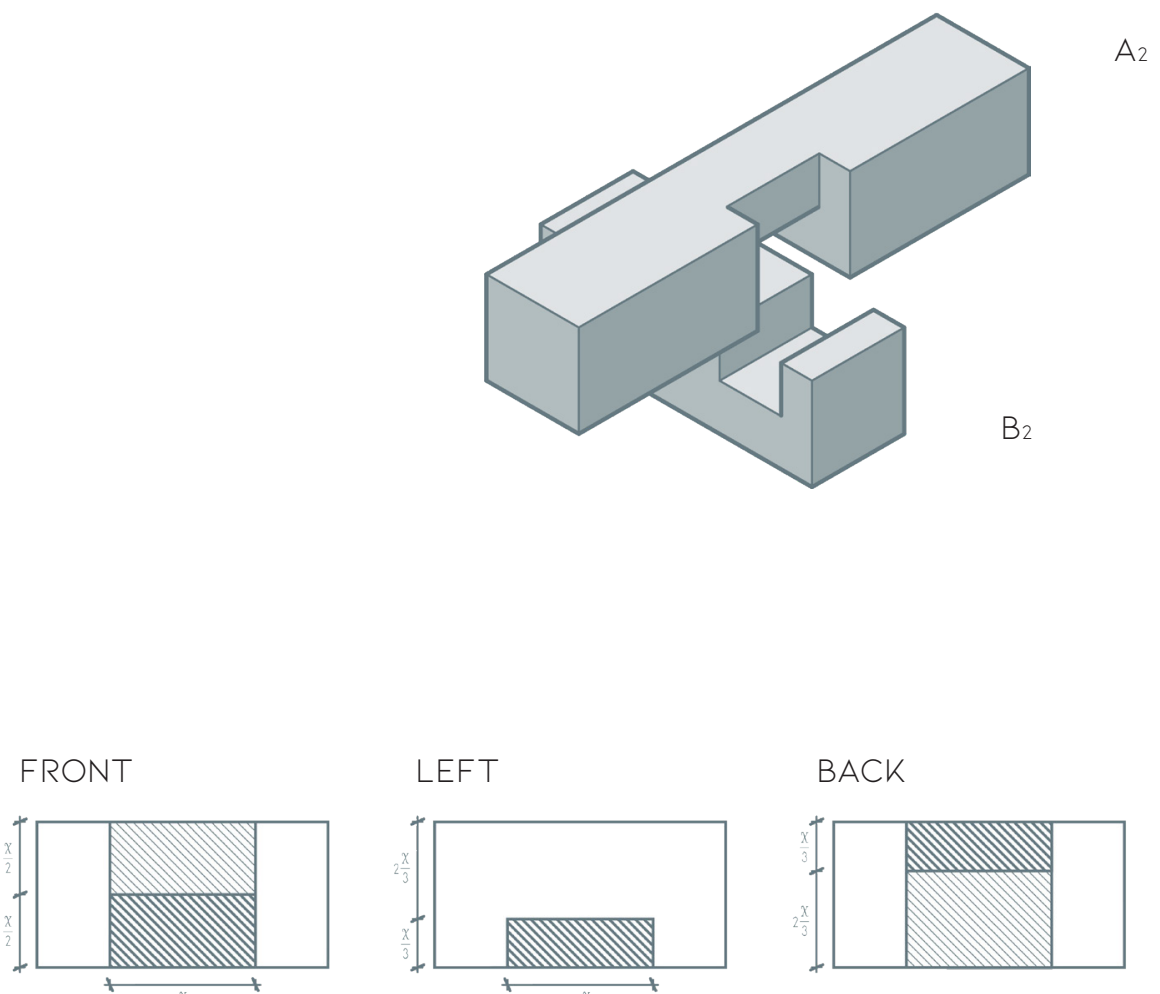

RIGHT
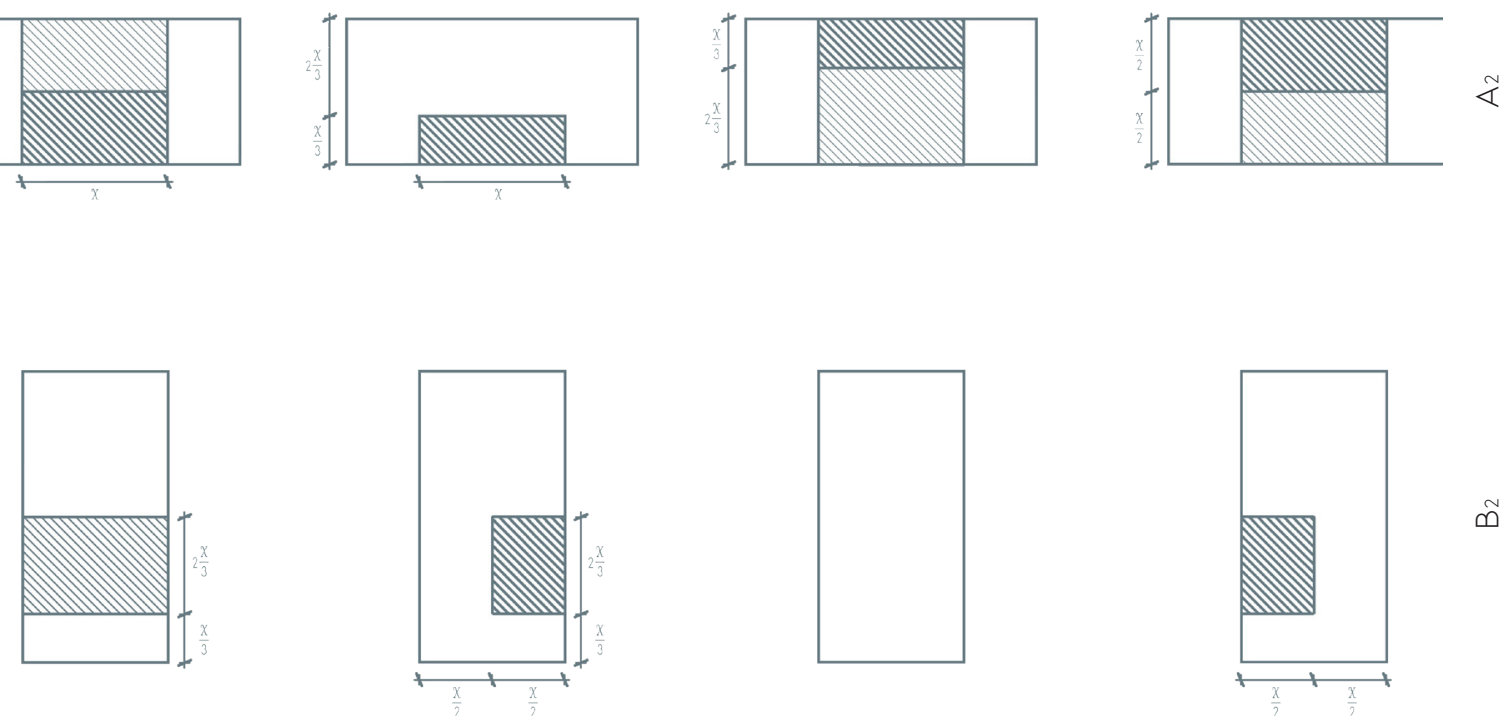

Fig. 76 Connection joint marking diagrams 2. 

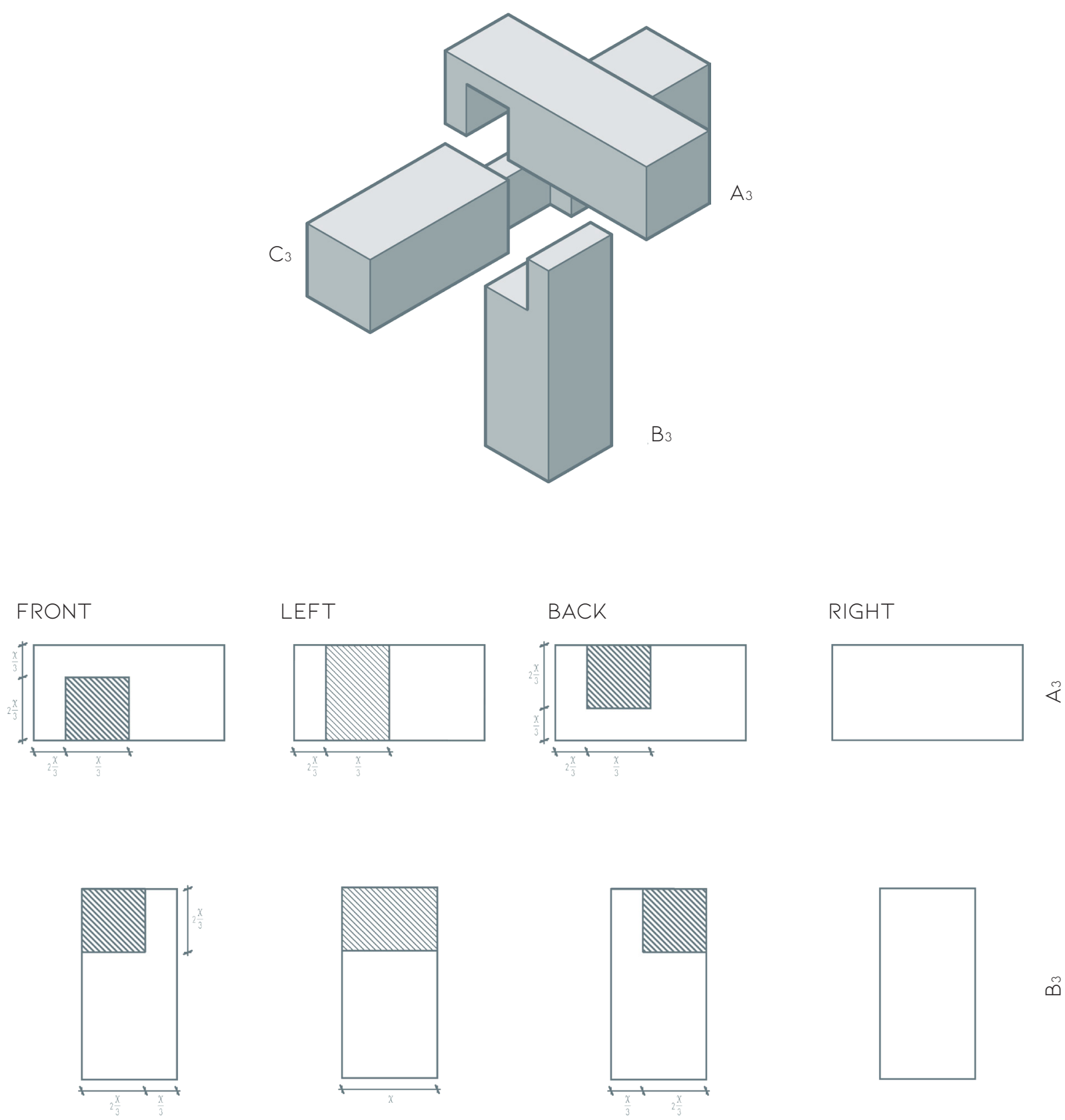

๓
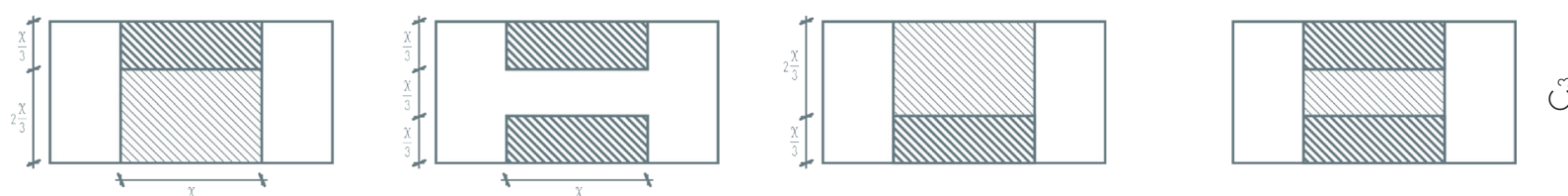

Fig. 77 Connection joint marking diagrams 3. 

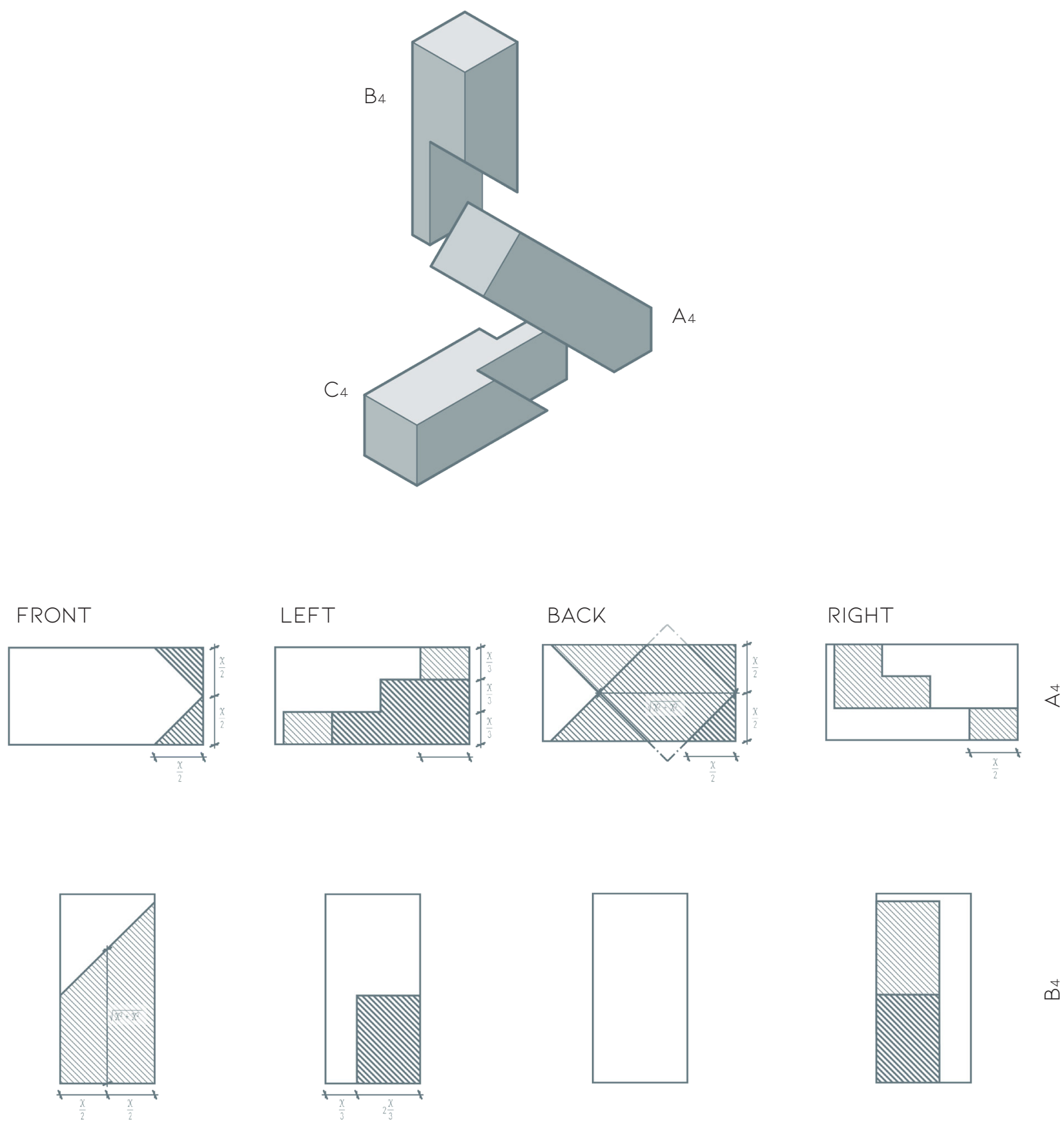

Ð
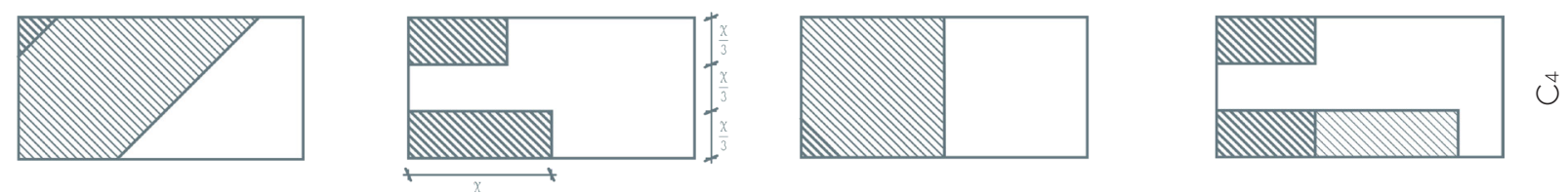

Fig. 78 Connection joint marking diagrams 4. 

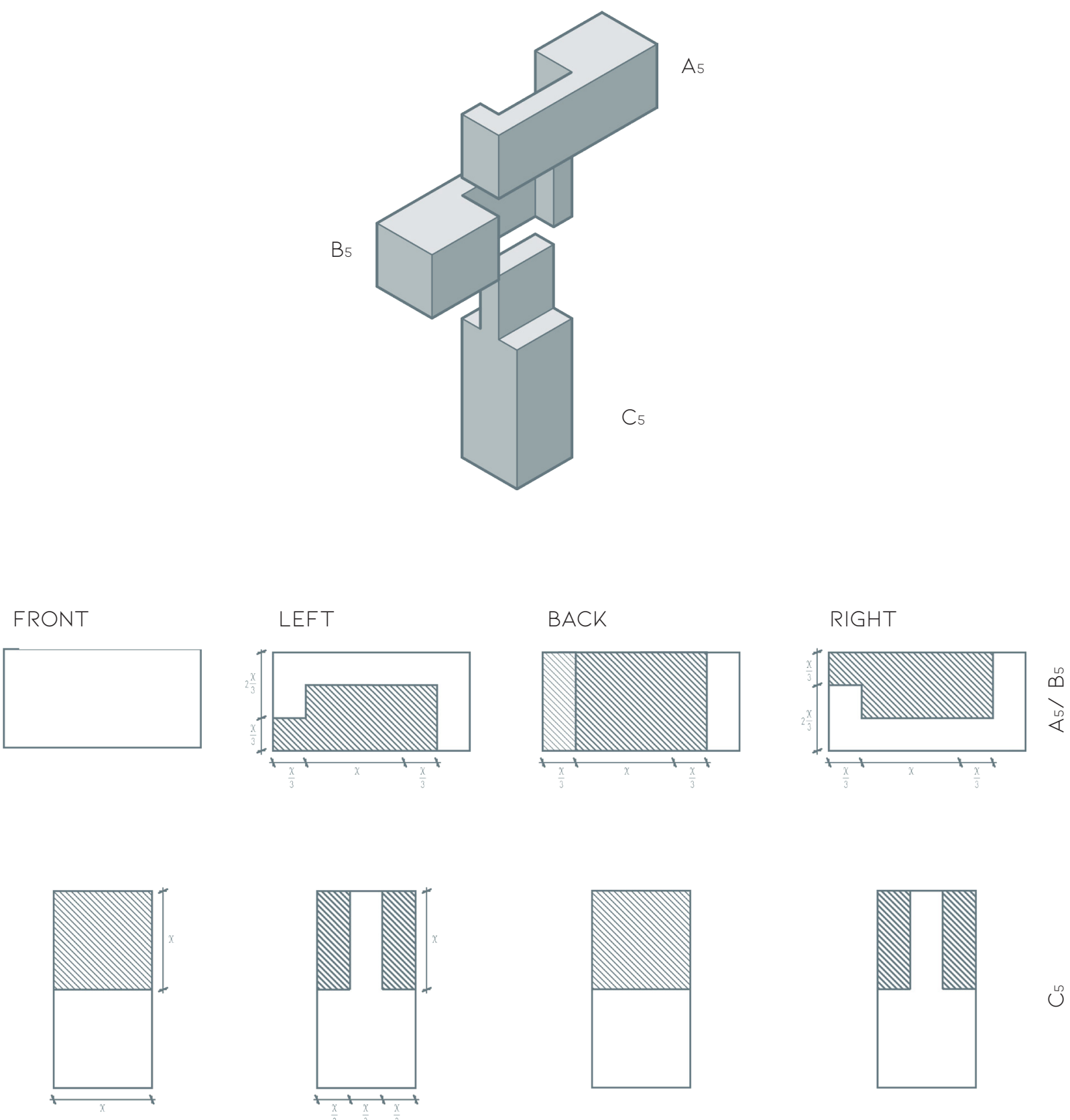

离

Fig. 79 Connection joint marking diagrams 5. 
This section tested the limits of machine-tool technology and how jigs can assist the production of joints. However, the mitre saw did not require the first proposed jigs that were to be clamped to the material. It instead needed marking jigs and set up jigs to assist in the adjustment of the plunge height and placement of the material under the saw. This presents an opportunity to encourage the New Zealand DIY culture as these jigs made setting up the tool more efficient. By using these jigs, it could assist in the creation of well-made joints that are accessible to the wider audience.

\section{DESIGN DELIVERY}

After perfecting the developed iterations of lap joints and scarf joints using, they were fabricated with the dual bevel sliding mitre saw. A lot of additions to homes are DIY projects. These add-ons are usually store bought from the hardware store, and are slapped together with a nail and hammer. Additions, such as pergolas, provide an opportunity for a system where timber joints can be beautifully crafted and disassembled. By providing a system or a guide that can be found at the local hardware store can assist home owners with DIY projects.

\section{FABRICATION}

To test the timber joints explored, a stand has been crafted using radiata pine. Orientation is essential when crafting joints. All sides on the timber were marked 'front', 'back', 'left', and 'right'. To begin, setting up the heights on the mitre saw is essential, here the use of a premeasured jig allowed for a faster set up. By placing the lowest tooth of the blade on the jig allowed for the set length to be locked in place. This is then tightened and tested. Adjustments are made to meet the required height (fig. 80). Basing the cuts on the centre point through the use of kiwari, a marking jig is used to set the length for multiple cuts. This can be for multiple members, or the same piece of material that is flipped (fig. 81). By sliding the blade back and forwards, the simple lap joint can be fabricated (fig. 82). 
Fig. 80 Set up of the height on the mitre saw.

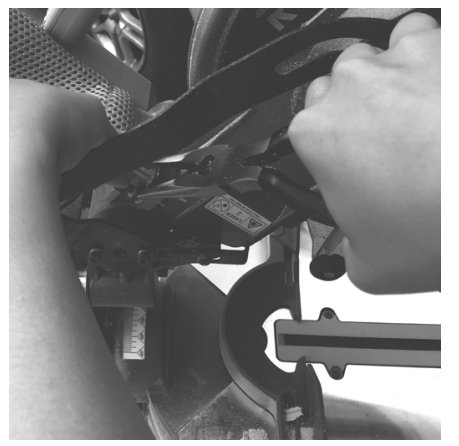

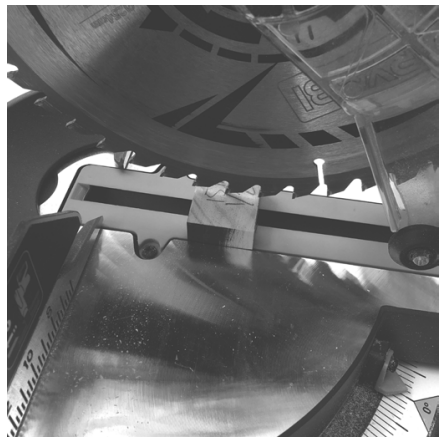
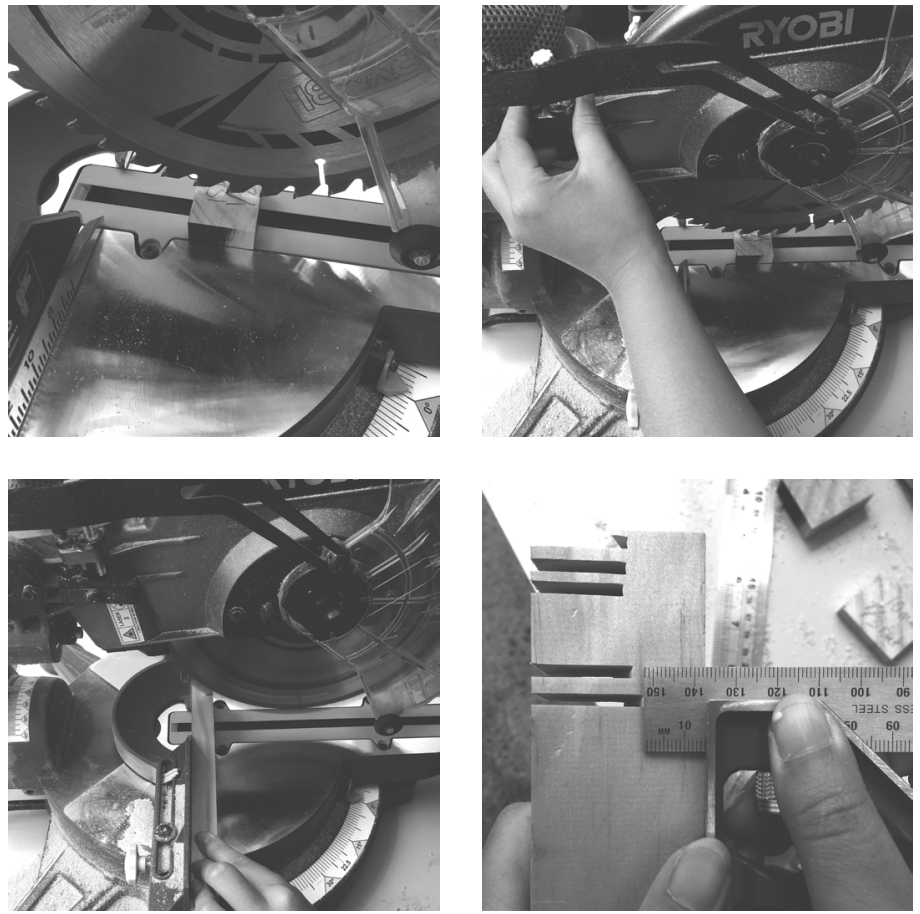
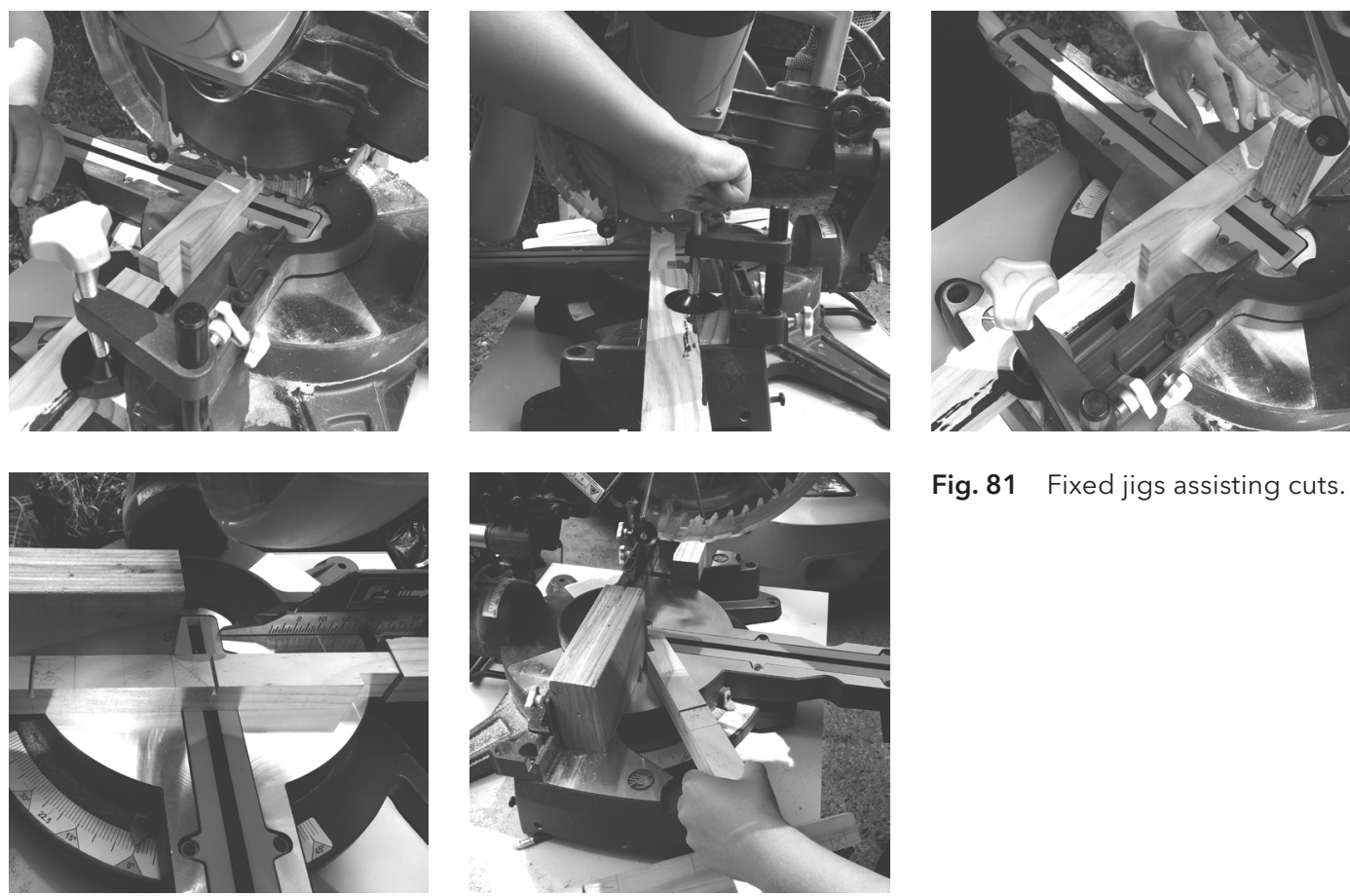

Fig. 81 Fixed jigs assisting cuts. 

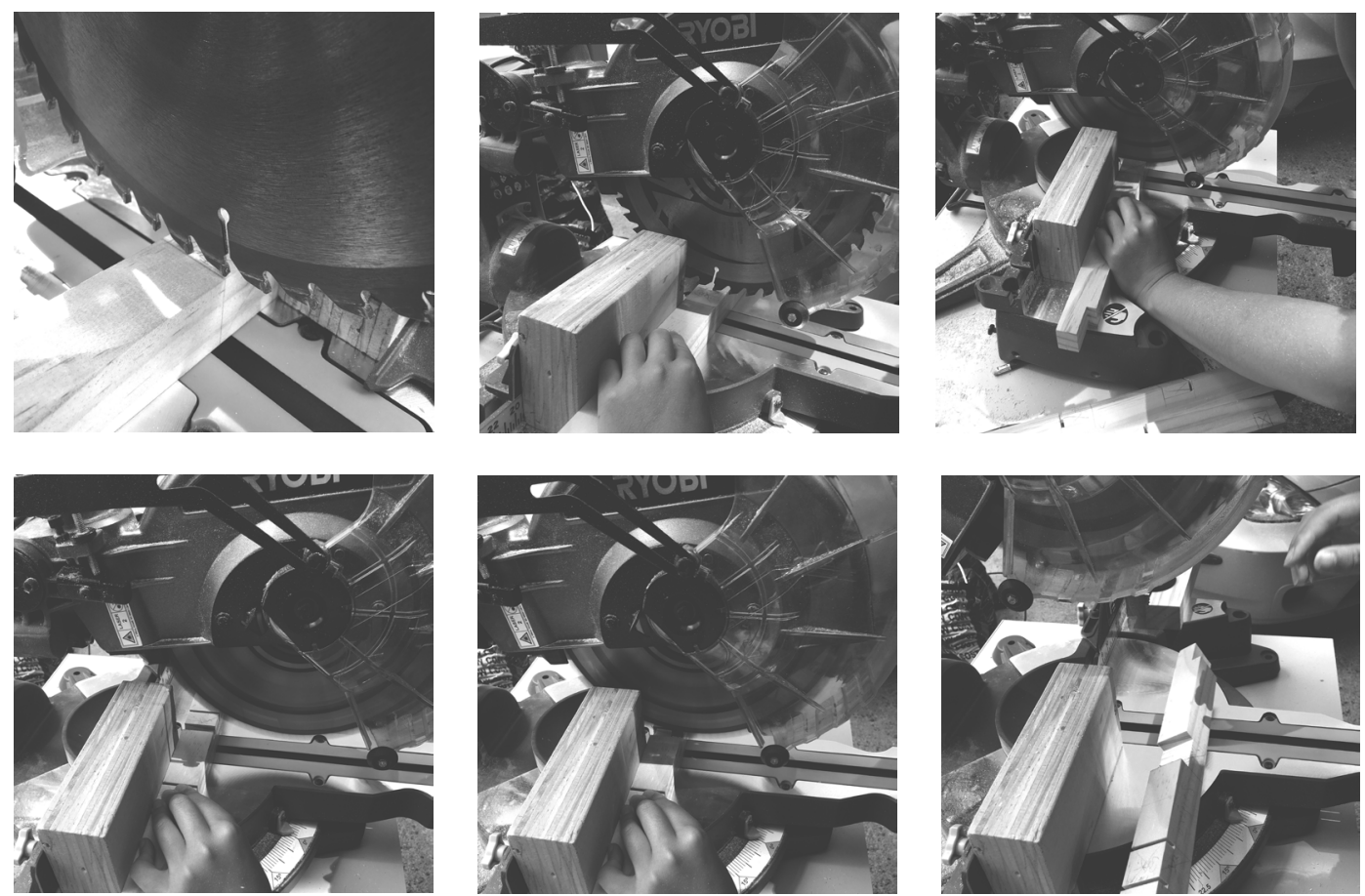

Fig. 82 Cutting joints with mitre saw.

\section{ASSEMBLY}

This system consists of three members that assemble into two different connection joints (fig. 83). These connection joints are notched out using halves and thirds (fig. 84). A series of images have been documented to

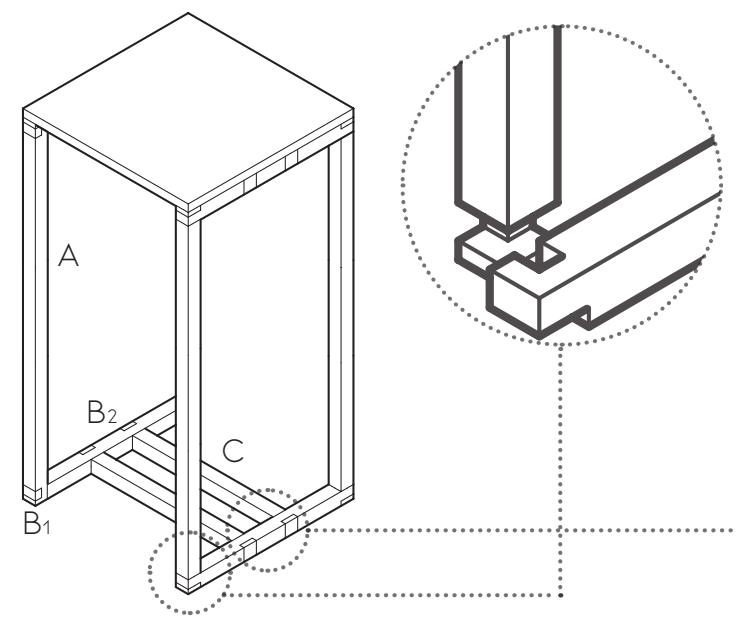
show the process of assembling the fabricated stand (fig. 85, fig. 86).

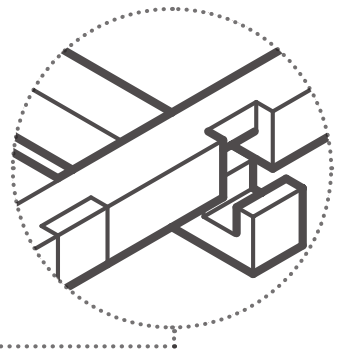

Fig. 83 Isometric call out of joints. 
A

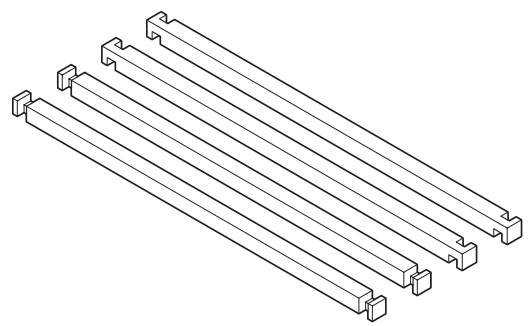

$\mathrm{B}_{1}$

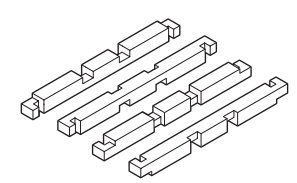

B2

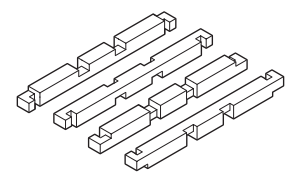

C

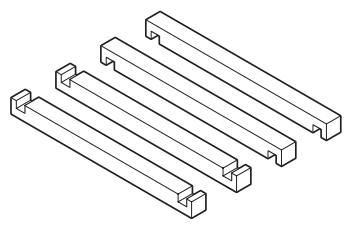

FRONT

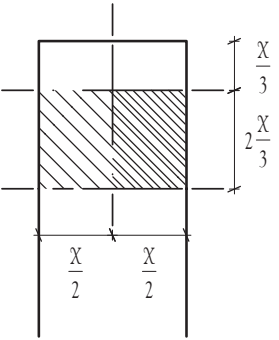

FRONT

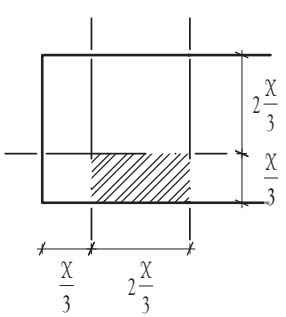

FRONT

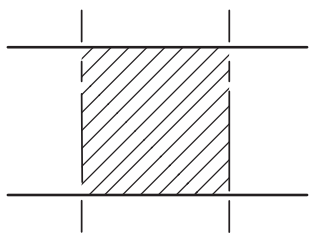

TOP

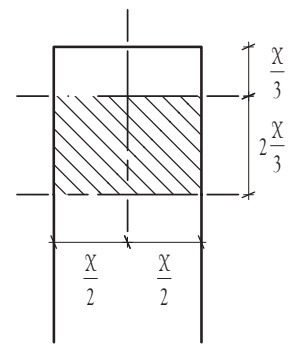

OUTER SIDE

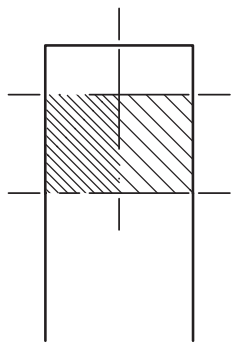

TOP
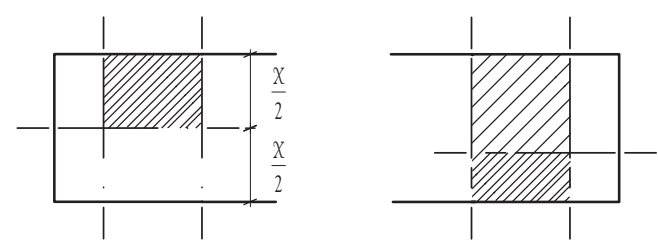

INNER SIDE

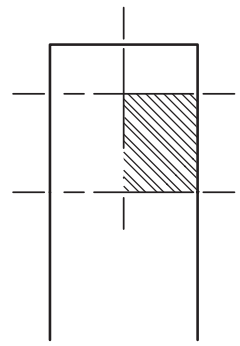

INNER SIDE
BACK
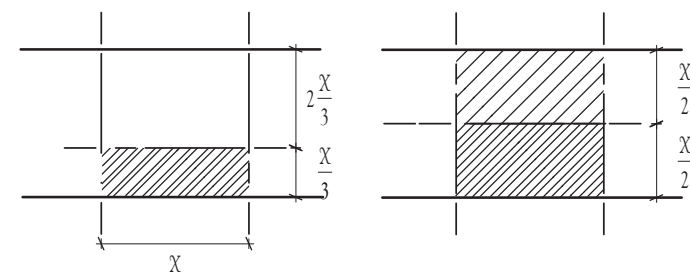

SIDE

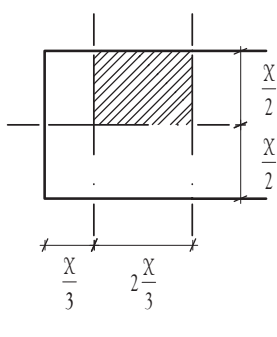

Fig. 84 Marking Diagram of joints. 


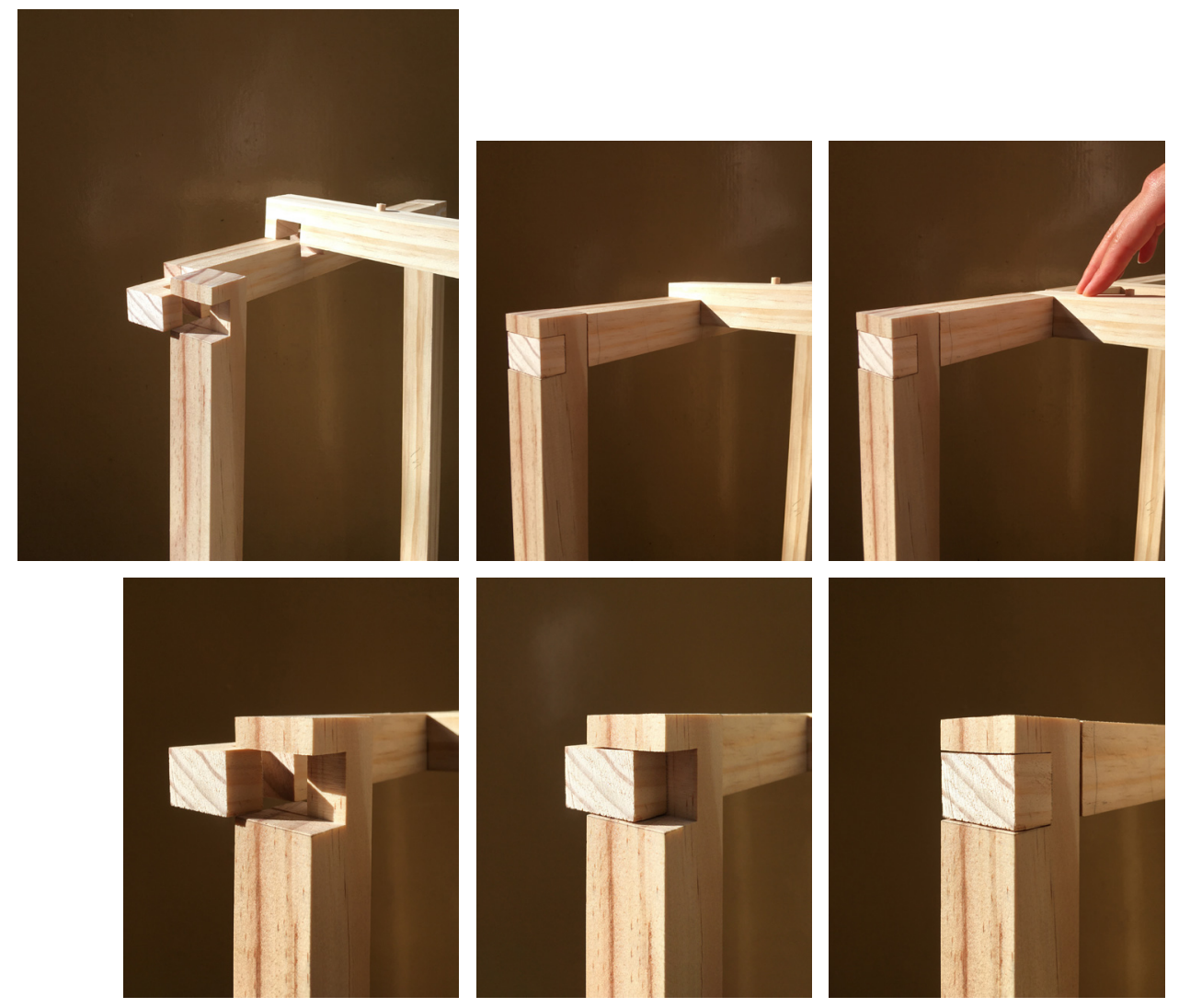

Fig. 85 Series showing the assembly of the joints. 

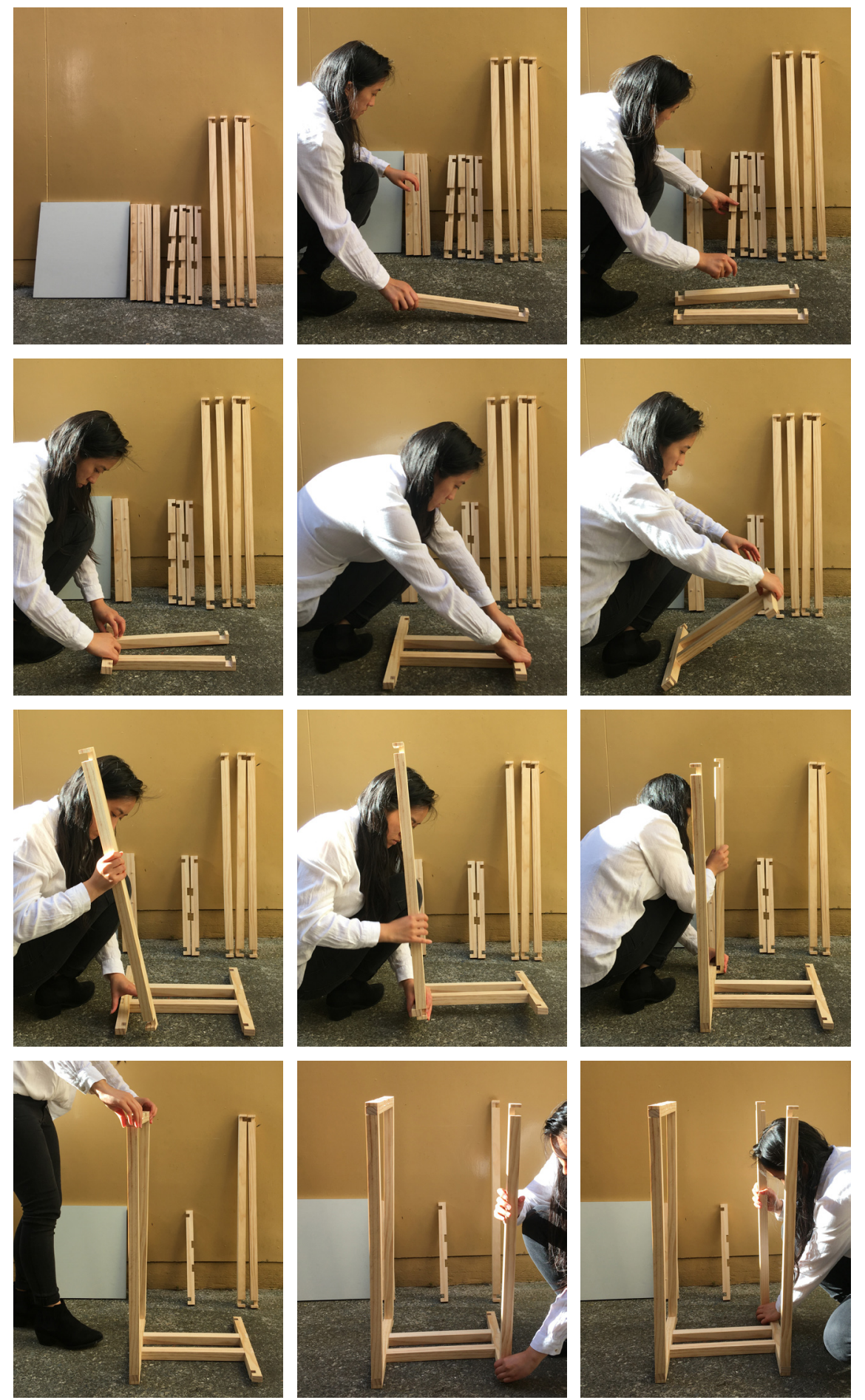

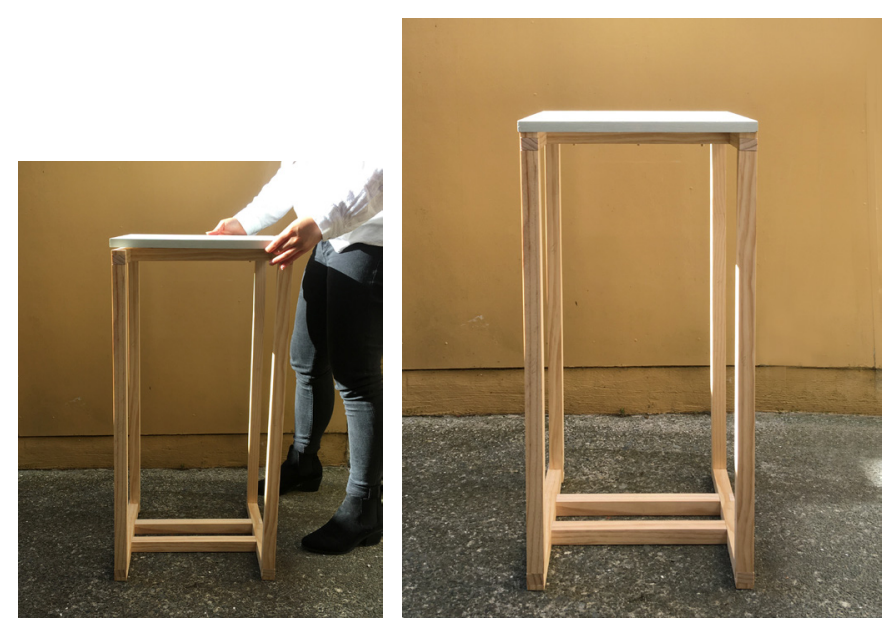

Fig. 86 Series showing the assembly of the stand.

\section{IMPLEMENTATIONS}

Reviewing existing products allowed for iteration of existing joints. This created an opportunity to design alternative joints for existing structures. Here an existing pergola has been patched together with a new pergola (fig. 87), which provides an opportunity to look at an alternative solution where joints can be added on when required (fig. 88). Some pavilion styles that appear to be popular around residential areas of Wellington have been reviewed as well (fig. 89, fig.91). Alternative sketch has been designed with the mitre saw in mind (fig. 90, fig.92). If another tool, such as the circular saw, oscillating tool, or hand router, was to be used for construction, the joinery has the potential to be more detailed and fluid.
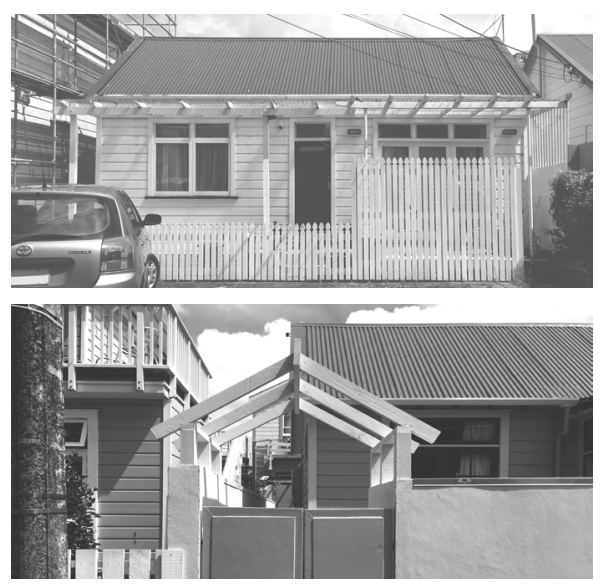

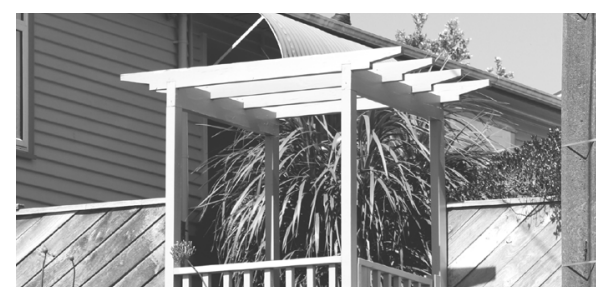

Fig. 87 Top left image - Existing pergola at Wellington Central home.

Fig. 87 Bottom left image - Existing pavilion at Wellington Central home.

Fig. 87 Top right image - Existing pavilion at Ngaio home. 

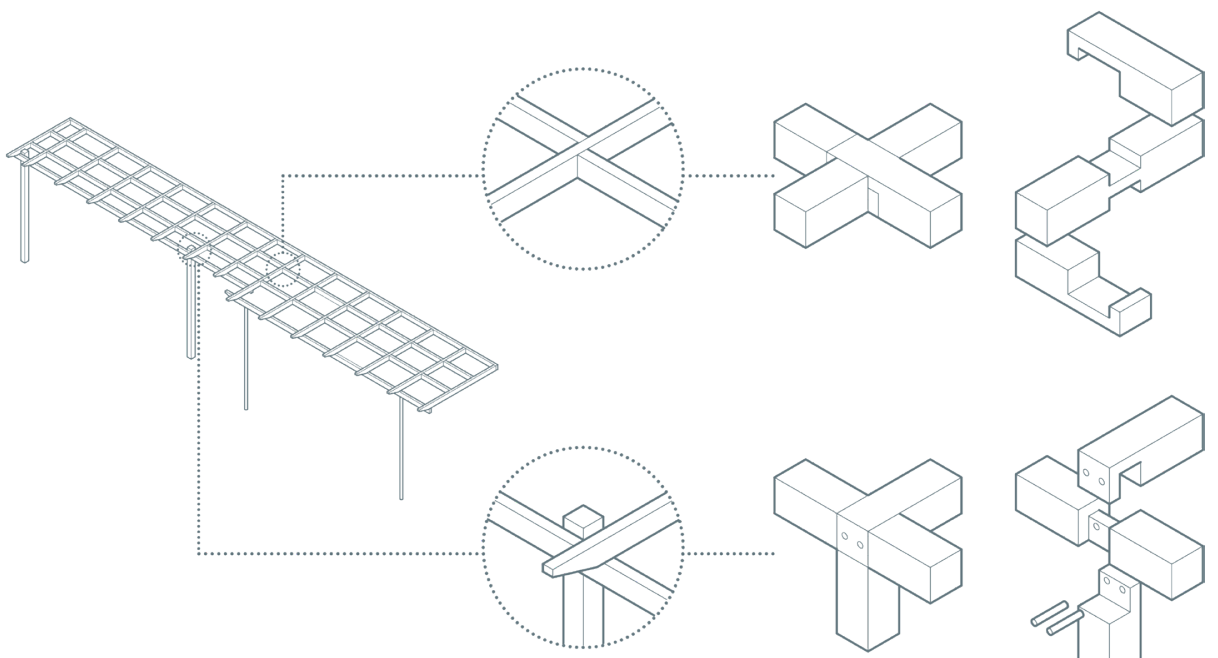

Fig. 90 Alternative joints for pergola.
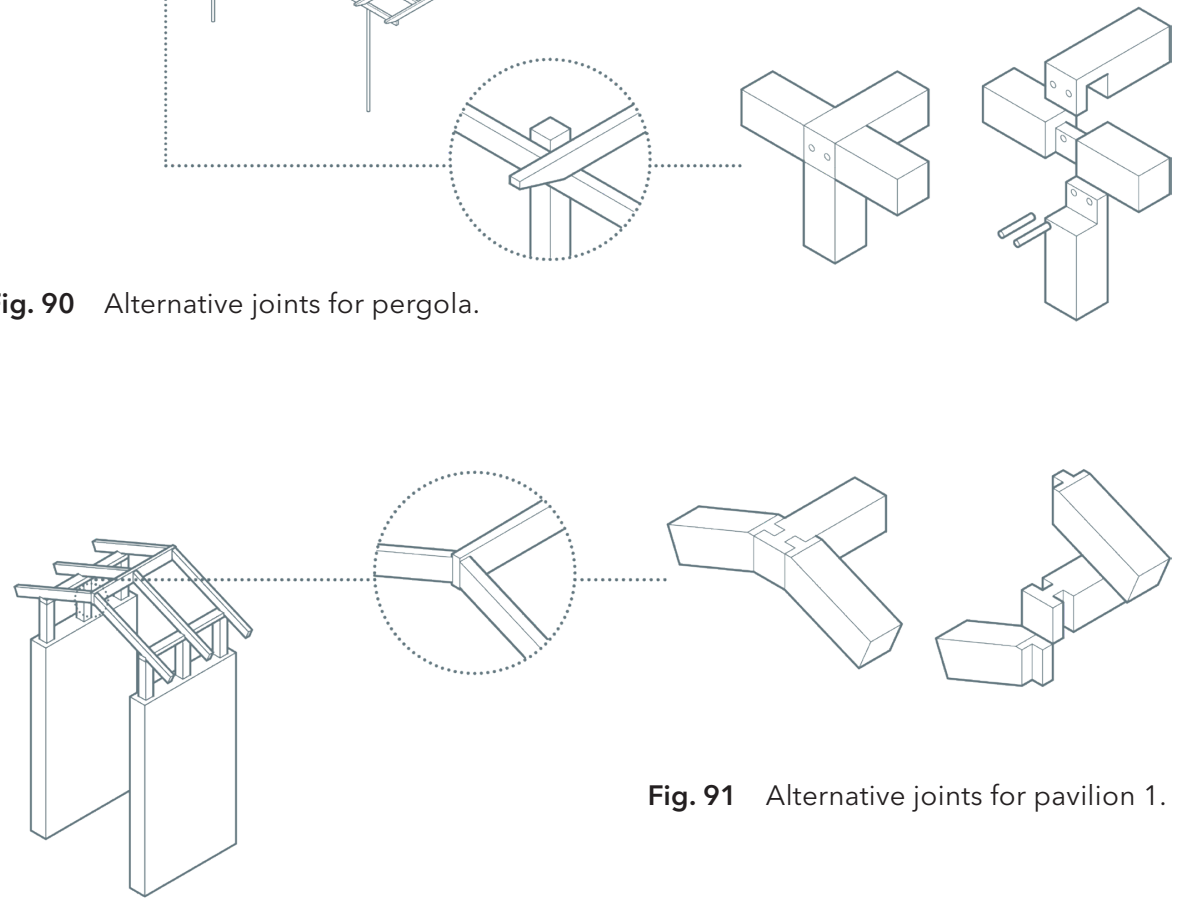

Fig. 91 Alternative joints for pavilion 1.
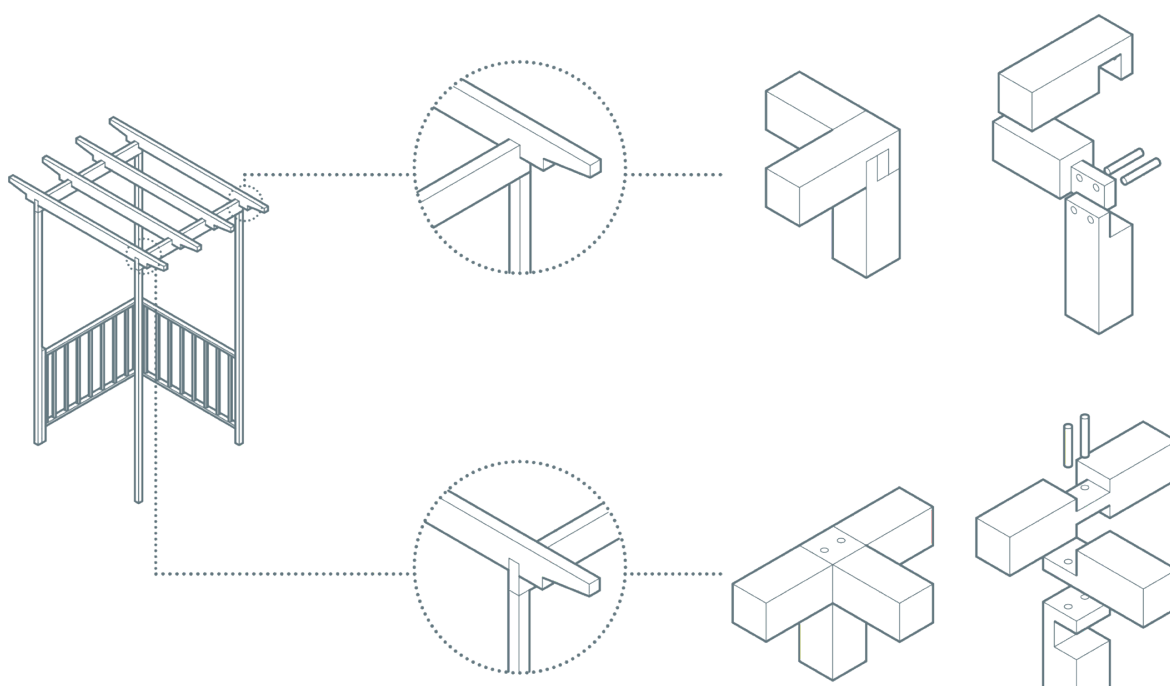

Fig. 92 Alternative joints for pavilion 2.

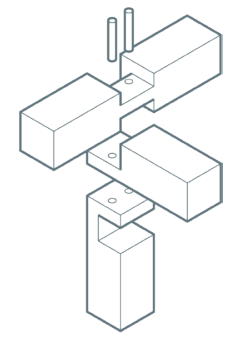




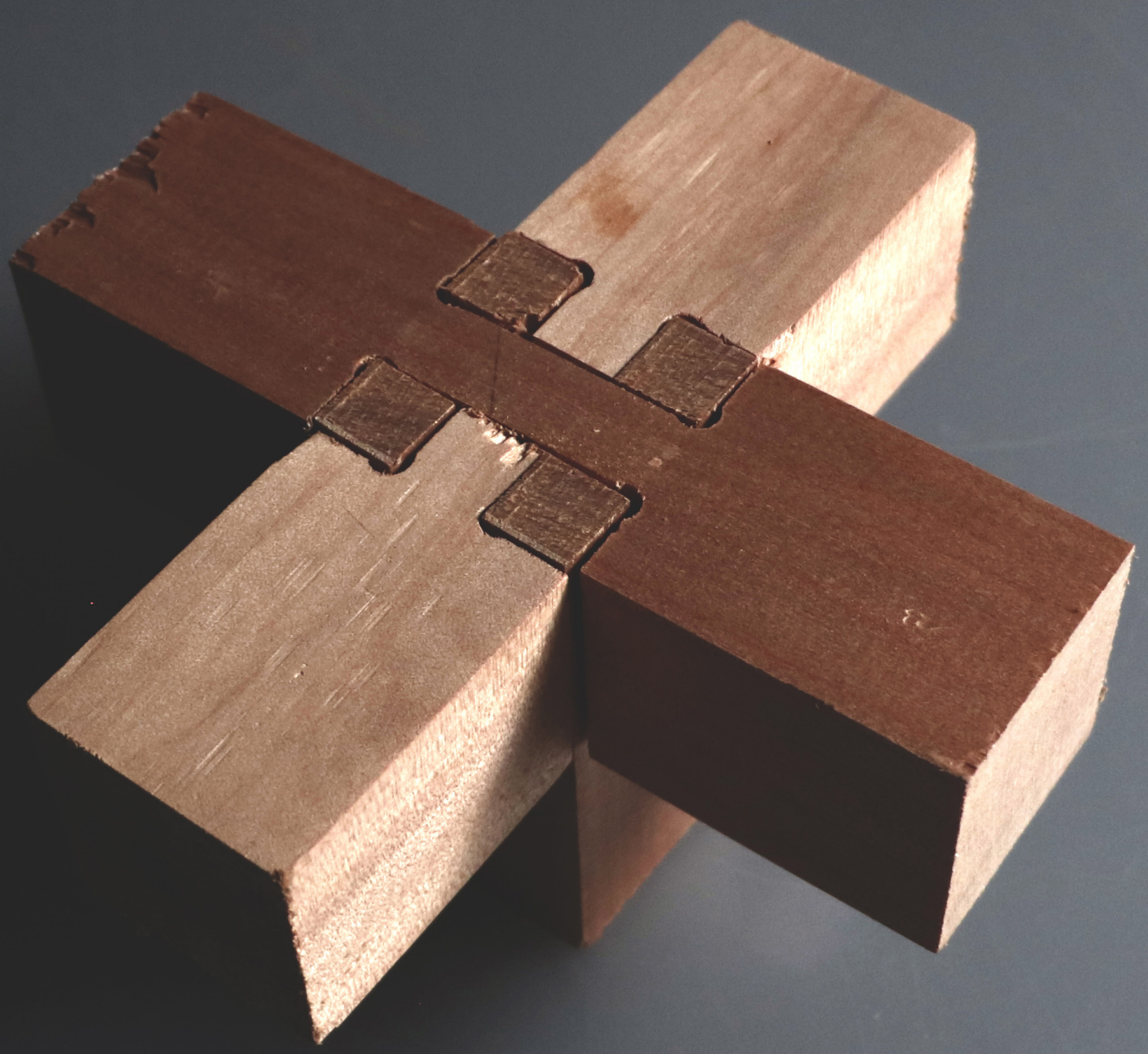

Fig. 74 Interlocking tenon joint. 
This section reviews the outcome of this research, reviewing the problem and how it can be addressed. Reflecting upon the investigation of fabricating timber joint, this section includes the discussion and outcome, summary of the research, limitations and the future work that could take place.

\section{DELIVER}

DISCUSSION + OUTCOME

LIMITATIONS

FUTURE WORK

CONCLUSION
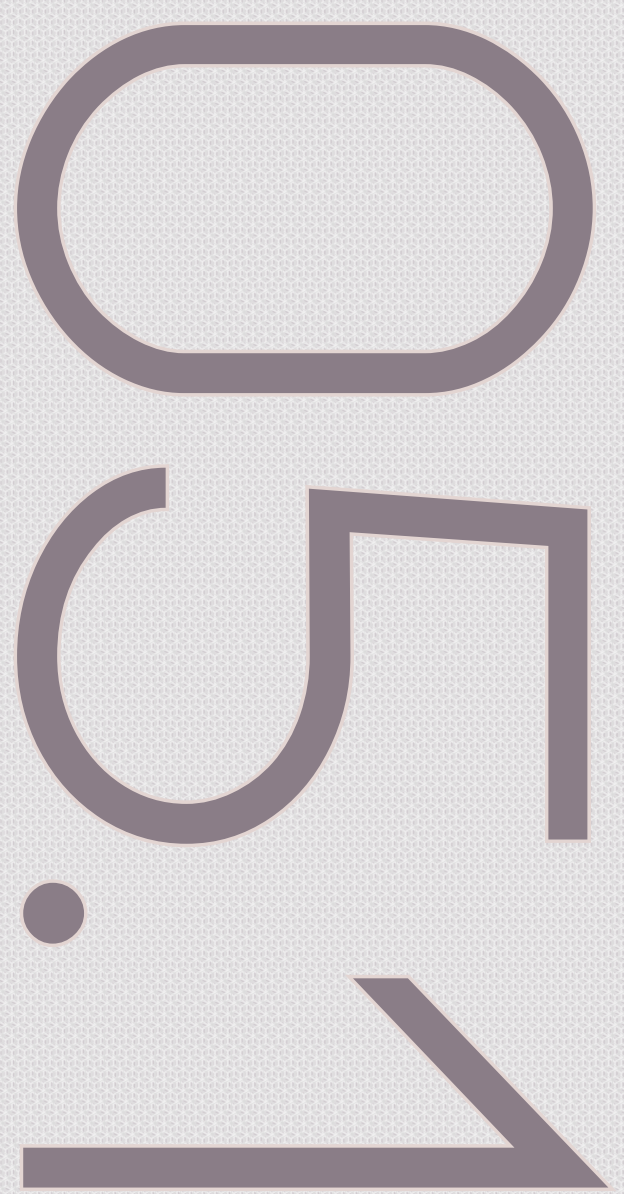


\section{DISCUSSION + OUTCOME}

How can we simplify timber crafts in architecture sustainably, and allow for easy construction at a residential and light industrial scale that is readily available?

As industrialisation has allowed for faster and cheaper production of goods, a sense of craft was lost. Creating a sustainable product that is reusable, repairable and recyclable is essential. Traditional Japanese carpentry techniques has been reviewed as they are renown for their beauty and longevity. These joints are engineered to withstand gravity and lateral loads without the need for metal or adhesive reinforcements, meaning they hold the possibility to be reused, repaired and recycled. With the intent of the produced joints having a circular life cycle, the outcome can be implemented on existing builds through retrofitting.

This investigation has highlighted the importance of the construction tectonics, through the understanding the tectonics, methods of fabricating joinery become easier to comprehend and translate drawings to cuts. The two key tectonics focused on for constructing joinery is through the use of digital information-tools and powered machinetools. This thesis presents two possible ways to produce timber joints that can be quickly and easy produced, either through prefabrication or onsite construction. By using tools that are more accessible, such as a CNC router instead of the robot arm, and portable power tools, it makes well-crafted timber joinery more obtainable to the average consumer.

As discussed by Mackay in Chapter 2.3 - Retrofitting under the subcategory 'As a Trend', a house is where a person's identity can be expressed through personalisation and décor. This creates a sense of achievement as consumers want things that are new, improved and different. To accommodate this, designers and architects as creative professionals, have undertaken a responsibility to preserve the remaining raw materials that are dwindling. Circular design assists designers in finding a method that creates a cycle where a product can be repaired, reused and recycled, which is why timber is important. A 
common construction material in New Zealand, timber is a sustainable material when used and treated correctly.

By producing prefabricated joinery, this allows for kitsets that can purchased to retrofit New Zealand properties. Fabricating joints onsite is a possibility where the local builder can quickly construct, or done as a DIY project. These methods of constructing joints can be applied to residential dwelling, and light industrial structures as a form of retrofitting, which could also be applied to furniture.

\section{LIMITATIONS}

The CNC robot arm was not applicable for use due to time constraints and lack of training on the machine and software, it was recommended not to utilise the CNC robot arm.

As a research-led design thesis, it was initially thought to be a designled research. As this research progressed, fundamental knowledge on processing timber was missing, therefore heavy research was conducted, dictating the design of a method, rather than a design for joinery. This research has emphasised the importance of the construction tectonics.

Due to the workshop closing, this affected the choice in tools available for testing timber joinery.

There is also no way of telling if the methods produced would be efficient enough to reduce costs to make timber joints more accessible.

\section{FUTURE WORK}

To understand the implication of these methods better, more research could be undertaken. Analysis into the follow points could prove to be an advantage to fabricating timber joinery. 
To further this study on simplifying timber crafts for accessibility, the development of only one joint is recommended. This testing can be conducted on various types of tools to deduct which would be the most efficient to fabricate timber joinery.

The structural integrity and seismic resilience of the joints must be tested to prove its viability as a construction kitset and potentials for onsite construction.

By limiting this thesis to reviewing primarily Japanese carpentry has constrained the possibility to apply social identity to these joints. Ornamentation, and cultural elements could be incorporated to produce a narrative, or play.

The use of only using two key tools, the $\mathrm{CNC}$ router and mitre saw has limited the potential that the joints could have been. By expanding the types of tools tested, it allows for a greater number of joints available to prototype and test.

This work process could be applied to a larger scale, and creating larger prototypes. This could work up to the architectural scale for pavilion structures and retrofitting for buildings. 


\section{CONCLUSION}

This research contributes to the reinvigoration of craft in modern construction and addresses the challenges of creating Japanese inspired joints on a building site. Well-made joints can be expensive, no matter which tectonic is used to fabricate them.

Japanese inspired joints that follow the developed method using the CNC router could be applied to the prefabricated joinery, producing kitsets available for purchased to retrofit New Zealand properties. This method of using power tools and jigs could also be used as a construction technique onsite for quick construction, or even a DIY project. These can be applied to existing buildings or a stand-alone structure.

The research aimed to 'create a method of timber construction that has the sense of craft and capability for easy production in the residential and light industrial scale that is readily available'. This has been explored by utilising digital information technologies such as the CNC router and mitre saw. This attempted to create a method of timber joinery construction that has the sense of craft and capability for easy production through prefabrication and onsite construction. However, there is also no way of telling if the methods explored would be costefficient or structurally effective enough to make crafted timber joints more accessible. 


\section{REFERENCE}

Abodo Wood Ltd. (2014, January 11). Timbers: What is Thermally Modified Wood? [Brochure]. Abodo. https://www.abodo.co.nz/ resources/articles/what-is-thermally-modified-wood

Accsys Technologies. (2012, November 5). Benefits [Brochure]. Accoya ${ }^{\circledR}$. https://www.accoya.com/why-accoya/benefits/

Accsys Technologies. (2017, November 1). Accoya and the Circular Economy (C2C) - A Perfect Fit! [Brochure]. Accoya ${ }^{\circledR}$. https://www.accoya. com/sustainability/

Accsys Technologies. (2018, May 24). Acetylation: What is it and what is Acetylated Wood? [Brochure]. Accoya ${ }^{\circledR}$. https://www.accoya.com/blog/ acetylation-what-is-it-and-and-what-is-acetylated-wood/

Aline, L., \& Kuma, K. (2006). A Return to Materials. In Kengo Kuma: Works and projects / Lugi Aline with an essay by Kengo Kuma (pp. 15-28). Phaidon distributor.

Atkinson, N. (2016, March 11). Railways-Housing the workers. Te Ara - the Encyclopedia of New Zealand. http://www.TeAra.govt.nz/en/ railways/page-9

Baden-Powell, C. (2005). Architect's pocket book of kitchen design. Architectural Press.

Balboa, R. A., \& Paklone, I. (2014, January 22). SunnyHills and The Matter of Business: An interview with Kengo Kuma [Transcript]. https://www.academia.edu/5796426/SunnyHills_and_The_Matter_of_ Business?auto=download

Bell, P., \& Southcombe, M. (2012). Kiwi Prefab: Cottage to cutting edge. Balasoglou Books.

Branz. (2011, September 12). Railways cottage. Renovate: The Technical Resource for Industry. https://www.renovate.org.nz/bungalow/other1920s-building-styles/railways-cottage/

Burgess, J., Buckett, N., \& Page, I. (2013). Prefabrication Impacts in the New Zealand Construction Industry (SR 279 (2013); pp. 1-105). BRANZ. https://www.branz.co.nz/cms_show_download. php?id=2935644f1d998595f3a2d8f5e8167dd08a42a179

Design Council. (2019, September 2). What is the framework for innovation? Design Council's evolved Double Diamond. Design Council. 
https://www.designcouncil.org.uk/news-opinion/what-frameworkinnovation-design-councils-evolved-double-diamond

Dubey, M. K. (2010). Improvements in stability, durability and mechanical properties of radiata pine wood after heat-treatment in a vegetable oil [University of Canterbury]. https://core.ac.uk/download/pdf/35463134. pdf

Ellen MacArthur Foundation. (2017). What is the Circular Economy? [Brochure]. The Circular Design Guide. https://www. ellenmacarthurfoundation.org/circular-economy/what-is-the-circulareconomy

Esteves, B. M., \& Pereira, H. M. (2009). Wood modification by heat treatment: A review. 370-404.

Filson, A., France, A. K., \& Rohrbacher, G. (2017). Design for CNC. Maker Media, Inc. https://learning.oreilly.com/library/view/design-forcnc/9781457187414/preface01.html\#idm139695283132880

Frampton, K. (1995). Studies in Tectonic Culture: The poetic of Construction in Nineteenth and Twentieth Century Architecture. The MIT Press.

Garber, R. (2014). BIM design: Realising the creative potential of building information modelling. John Wiley \& Sons, Inc.

Gorai, S. (2016). Advanced retrofitting techniques for reinforced concrete structures: A state of an art review. I-Manager Publications, 5(1), 6-18.

Graham, I. (2019, November 13). Jigs [Personal communication].

Groat, L., \& Wang, D. (2013). Architectural Research Methods (2nd ed.). Wiley Publishing.

Hardwoods Incorporated. (2016, April 27). The History of Thermally Modified Wood [Brochure]. Hardwoods Incorporated. http://www. hardwoodweb.com/wp/the-history-of-thermally-modified-wood/ Helen \& Hard. (2019, July 5). Bjergsted Financial Park, Stavanger. Helen \& Hard. http://www.helenhard.no/projects/bjergsted_financial_park_ stavanger

Kengo Kuma \& Associates. (2009). Department of System Design Engineering, Faculty of Science and Technology, Keio University + Kengo Kuma \& Associates. Kengo Kuma \& Associates.

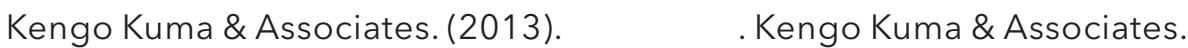
Khor Xin Suan. (2019). Interlocking Timber Joint in Kengo Kuma's Works. https://issuu.com/xinsuan.selectedworks/docs/interlocking-timber- 
joint-in-kengo-

Langlands, A. (2018). Cræft: An Inquiry Into the Origins and True Meaning of Traditional Crafts. Faber \& Faber Ltd.

Lansdown, H. (2019). Digital Modelmaking: Laser Cutting, 3D Printing and Reverse Engineering. The Crowood Press.

MacKay, C. (2010). Kitchen Remodelling in New Zealand - Issues of Sustainability. 1-11. http://www.branz.co.nz/cms_show_download. php?id=f76d0943170ee5480b2555e95abbdc61f2624ef7

Man, V. I. T. (2017). Mereology-A Study of SunnyHill, Minami-Aoyama, Tokyo, Japan, Kengo Kuma [University of Southern California]. https:// issuu.com/vincentip/docs/20170104-ddr-print

Morrison, C. (2012). Home and heterosexuality in Aotearoa New Zealand: The spaces and practices of DIY and home renovation. 68(2), 121-129. Nagyszalanczy, S. (2006). Taunton's Complete Illustrated Guide to Jigs \& Fixtures. The Taunton Press, Inc.

Peters, S. (2011). Material Revolution: Sustainable and multi-purpose materials for design and architecture (Gaines Translations, Trans.). Birkhäuser.

Rail Heritage Trust of New Zealand. (2012, December 12). Railway Housing for New Zealand Operating Staff. Rail Heritage Trust of New Zealand. http://www.railheritage.org.nz/Register/Category.aspx?c=11

Ramage, M. H., Burridge, H., Busse-Wicher, M., Fereday, G., Reynolds, T., Shah, D. U., Wu, G., Yu, L., Fleming, P., Densley-Tingley, D., Allwood, J., Dupree, P., Linden, P. F., \& Scherman, O. (2017). The wood from the trees: The use of timber in construction. 68(1), 333-359.

Ramstad, T. Ø., \& Hallquist, А. (1980). Scandinavian Timber Frame House Construction Technical Design and Future Trends. 410-415. https:// www.irbnet.de/daten/iconda/CIB15170.pdf

Rando, M. (2019, January 14). NZIA: Mario Rando-Visiting Engineer from Norway Degree of Freedom.

Rapp, A. O. (2001). Review on Heat Treatments of Wood. European Cooperation in the Filed of Scientific and Technical Research, 4-66. http://projects.bre.co.uk/ecotan/pdf/Heat_treatment_processes_ Andreas_Rapp\%20.pdf

SAAHA. (2019, November 18). Finansparken Bjergsted. SAAHA. https:// saaha.no/FINANSPARKEN-BJERGSTED

Schrader, B. (2012, June 20). Housing and government-State loans and 
state houses. Te Ara - the Encyclopedia of New Zealand. https://teara. govt.nz/en/photograph/32422/railway-houses-otira

Seike, K. (1977). The art of Japanese joinery (R. M. Davis, Trans.; 1st English ed). J. Weatherhill.

Southcombe, M., \& Charleson, A. (2014). [Re] Cuba: Renegotiating seismic resilience in Cuba Street Wellington. Wellington City Council.

Sturgeon, M. G. (2011, April 5). Innovative LVLApplications in Commercial and Multi-Storey Buildings. http://www.nelsonpine.co.nz/wp-content/ uploads/LVL-presentation-for-WSU-Seattle-April-5th-2011.pdf Tozer, P. (2019, July 14). Craft of Boatmaking [Transcript].

Tunnicliffe Timber Company Ltd. (2016, March 18). ThermoWood ${ }^{\circledR}$ [Brochure]. Tunnicliffe's. https://www.tunnicliffes.co.nz/thermowood-. html

Weinand, Y., \& Buri, H. (2011). The tectonics of timber architecture in the digital age. In Building with timber: Paths into the future (pp. 56-63). Prestel Verlag.

Whiteley, N. (1987). Toward a Throw-Away Culture. Consumerism, 'Style Obsolescence' and Cultural Theory in the 1950s and 1960s. Oxford University Press, 10(2), 3-27.

Williams, G. C. (2018). Engineered Wood Products-Experience and Opportunities. Timber Systems Limited, 8(2). https://www.timberdesign. org.nz/wp-content/uploads/2018/05/Engineered-Wood-ProductsOpportunities.pdf 


\section{BIBLIOGRAPHY}

Accsys Technologies. (2014, May 22). End of Life [Brochure]. Accoya ${ }^{\circledR}$. https://www.accoya.com/sustainability/end-of-life/

Allaf, N. (2018). Improving Integration of Seismic Retrofit and Architecture in Unreinforced Masonry Buildings. Victoria University of Wellington.

Anon. (2016). All Sorts of Carpentry Joints: A Guide for the Amateyr Carpenter on how to construct and use Halved, Lapped, Notched, Housed, Edge, Angle, Dowelled, Mortise and Tenon, Scarf, Mitre, Dovetail, Lap and Secret Joints. White Press.

Bellomo, M., \& Pone, S. (2011). Technological retrofit of existing buildings: Dwelling quality, environmental sustainability, economic rising. TECHNE - Journal of Technology for Architecture and Environment; TECHNE 1 (2011): Beyond the Crisis. http://www.fupress.net/index.php/techne/ article/view/9439/8610

Bickman, L., \& Rog, D. J. (2008). Applied Research Design: A Practical Approach. https://us.sagepub.com/sites/default/files/upmbinaries/23770_Ch1.pdf

Branz. (2015a, September 6). Braced frames. Seismic Resilience. http:// www.seismicresilience.org.nz/topics/superstructure/seismic-designconcepts/braced-frames/

Branz. (2015b, September 6). Timber Structures. Seismic Resilience. http://www.seismicresilience.org.nz/topics/superstructure/commercialbuildings/timber-structures/

Braumann, J., \& Cokcan, S.-B. (2012). Digital and Physical Tools for Industrial Robots in Architecture: Robotic Interaction and Interfaces. 10(4), 541-554. https://doi.org/10.1260/1478-0771.10.4.541

Brown, A. (2013). The Genius of Japanese Carpentry: Secrets of an Ancient Craf (Revised edition). Tuttle Publishing.

Building Performance. (2014, March 1). 3. Single-storey detached buildings not exceeding 10 square metres in floor area. Building Performance. https://www.building.govt.nz/projects-and-consents/ planning-a-successful-build/scope-and-design/check-if-you-needconsents/building-consent-exemptions-for-low-risk-work/schedule-1guidance/part-1-exempted-building-work/3-single-storey-detachedbuildings/ 
Bull, B. (2013). When a traditional detail becomes the facade: Analysing the facade of GC Prostho Museum Research Center by Kengo Kuma. Department of Architecture \& Design, Aalborg University. http://www. bjornbull.com/Work/gc-prostho-museum-research-center.html Clement, D. (2016, November 18). Extending outdoor living. NZME Publishing Limited. https://www.nzherald.co.nz/property/news/article. cfm?c_id $=8 \&$ objectid $=11750756$

Dickson, M. (2015). Sustainable timber design. Routledge.

Ding, D. (2015, May 27). Art of Joinery in Architectural Design. Think Building. https://medium.com/thinking-building/art-of-joinery-used-inrecent-japanese-architecture-5e3d0e5aa4c1

DIY Wood Boats. (2009, April 3). Copper Rivets and Rove. DIY Wood Boats. https://www.diy-wood-boat.com/Rivets.html

Ellen MacArthur Foundation. (2017a). Understand Circular Flow [Brochure]. The Circular Design Guide. https://www.circulardesignguide. com/post/loops

Ellen MacArthur Foundation. (2017b, January 20). New Circular Design Guide launched by the Ellen MacArthur Foundation and IDEO at Davos [Brochure]. Ellen MacArthur Foundation. https://www. ellenmacarthurfoundation.org/news/new-circular-design-guidelaunched

Encyclopædia Britannica, inc. (2010, July 21). Japanese cedar. Encyclopædia Britannica. https://www.britannica.com/plant/Japanesecedar

Encyclopædia Britannica, inc. (2011, May 23). Joint. Encyclopædia Britannica. https://www.britannica.com/technology/joint-carpentry Encyclopædia Britannica, inc. (2013, August 20). Prefabrication. Encyclopædia Britannica. https://www.britannica.com/technology/ prefabrication

Finch, G. (2019). Defab: Architecture for a Circular Economy. Victoria University of Wellington.

Gatley, J. (2014, October 22). Domestic Architecture. Te Ara: The Encyclopedia of New Zealand. http://www.TeAra.govt.nz/en/domesticarchitecture

Gisip, J. (2015). Improvement of Wood-Based Machining Operations on a CNC Router through Extending Tool Life [North Carolina State University]. https://search.proquest.com/docview/1703792737?pq- 
origsite $=$ primo

Halswell Timber. (2009, April 3). Kauril - Fijian. Halswell Timber. https:// www.halswelltimber.co.nz/kauri-fijian.php

Harrod, T., \& Hawksmoor, H. (2009). Smooth and Rough: Creative Sociability in the Studio Craft World. 37 (2), 59-63.

Heesterman, M. (2019). The Robotic Craftsman: Robotic Fabrication of Complex Timber Connections. Victoria University of Wellington.

History.com Editors. (2018a, August 21). Bronze Age. HISTORY. https:// www.history.com/topics/pre-history/bronze-age

History.com Editors. (2018b, August 21). Iron Age. HISTORY. https:// www.history.com/topics/pre-history/iron-age

History.com Editors. (2018c, September 14). Middle Age. HISTORY. https://www.history.com/topics/middle-ages/middle-ages

History.com Editors. (2019a, January 10). Industrial Revolution. HISTORY. https://www.history.com/topics/industrial-revolution/industrialrevolution

History.com Editors. (2019b, March 13). Stone Age. HISTORY. https:// www.history.com/topics/pre-history/stone-age Isozaki, A., Ando, T., \& Fujimori, T. (2007). The contemporary tea house: Japan's top architects redefine a tradition. Kodansha International.

Jamal, H. (2017, July 9). Retrofitting Techniques for Existing Damaged Buildings. AboutCivil. https://www.aboutcivil.org/retrofittingtechniques-for-existing-buildings.html Japanese Guest Houses. (2010, July 25). Japanese Carpentry. Japanese Guest Houses. https://www.japaneseguesthouses.com/japanesecarpentry/

Johansson, D. (2005). Strength and Colour Response of Solid Wood to Heat Treatment [Luleå University of Technology]. https://www. researchgate.net/publication/228338222_Strenght_and_Colour_ Response_of_Solid_Wood_to_Heat_Treatment/figures

Kengo Kuma \& Associates. (2002). Kengo Kuma: Spirit of Nature Wood Architecture Award 2002 (G. Griffiths, Trans.). Wood in Culture Association.

King, A. (1998). Earthquake Loads \& Earthquake Resistant Design of Buildings. International Seminar on Loading Standards for Structural Design, Singapore. http://www.branz.co.nz/cms_show_download. php?id=405a730d9f218fe0b18d4296e28ff5cf7fad52ab 
Laminated Beams Ltd. (2014, March 26). Stratalam. Laminated Beams Ltd. http://www.laminatedbeams.co.nz/technical/stratalam/

Level. (2019, October 3). Minimising waste. Level. http://www.level.org. $\mathrm{nz} / \mathrm{material-use/minimising-waste/}$

Mac Sweeney, N. (2011). Community Identity and Material Culture. In Community Identity and Archaeology (pp. 42-58). University of Michigan Press.

Mayo, J. (2015). Solid Wood: Case Studies in Mass Timber Architecture, Technology and Design (1st ed.). Routledge.

Morton, J. (2018, May 31). NZ's recycling crisis after China ban: 'This situation is not sustainable'. NZME Publishing Limited. https://www. nzherald.co.nz/nz/news/article.cfm?c_id=1\&objectid=12062016 Noever, P. (Ed.). (2003). We were a team: Carlo Scarpa and Saverio Anfodillo. In W. Astelbauer (Trans.), Carlo Scarpa: The Craft of Architecture (pp. 97-100). Ostfildern : Hatje Cantz.

Northmen. (2017, July 7). Timber framing and log building course. Northmen. https://northmen.com/en/courses/timber-framing-logbuilding

NZ Wood. (2008, September 19). Forestry: Disposal of treated wood [Brochure]. NZ Wood. http://www.nzwood.co.nz/forestry-2/disposal-oftreated-wood/

Parker, J. (2015). Timber takes on new forms. BRANZ Ltd, 149, 50-51.

Renmælmo, R. (2009). The skjelter boathouse (Skjelternaustet). In Living Crafts. https://www.academia.edu/4235779/The_skjelter_boathouse Sabelli, R., Roeder, C. W., \& Hajjar, J. F. (2013). Seismic Design of Steel Special Concentrically Braced Frame Systems: A Guide for Practicing Engineers. NEHRP Consultants Joint Venture. https://www.nehrp.gov/ pdf/nistgcr13-917-24.pdf

Sidwell, G. K. (1985). Eccentrically Braced Frames. 18, 355-359.

Sigurðardóttir, S. (1955). Traditional Building Methods (A. Yates, Trans.). Skagfjörður Regional Museum. http://www.glaumbaer.is/static/files/ Skjol/xvi-traditional-building-methods.pdf

Suh, S.-H., Kang, S.-K., Chung, D.-H., \& Stroud, I. (2008). Theory and Design of CNC Systems (1st ed.). Springer London. https://link.springer. com/content/pdf/10.1007\%2F978-1-84800-336-1.pdf

Timber Construction Manual (5th ed.). (n.d.). John Wiley \& Sons, Inc. Ulak, J. (2012, September 11). Japanese architecture. Encyclopædia 
Britannica. https://www.britannica.com/art/Japanese-architecture Ximenes, F., Robinson, M., \& Wright, B. (2006). Forests, Wood and Australia's Carbon Balance. [Melbourne]: Forest and Wood Products Research and Development Corporation. http://www.nzwood.co.nz/wpcontent/uploads/2013/08/ForestsWoodCarbonBalance2.pdf Yasuhara, M., \& Sakiyama, T. (2009). Characterization Of Space Around Japanese Traditional Buildings: Transitions Of Layout Plan And Meaning Of Space Of Darkness Inside Wooden Temple. WIT Press, 109, 47-58. 


\section{FIGURE LIST}

Fig. 01 GC Prostho Museum Research Center Interior.

Ano, D. (n.d.-a). GC50_135 [Photograph].

Fig. 02 Research Method diagram adapted from Groat and Wang's Architectural research methods "a conceptual framework for methods".

Fig. 03 Diagram adapted from Design Council's "Framework for Innovation" diagram.

Fig. 04 Byodoin Temple, Uji City, Japan.

G, J. (2008). DSC21822, Byodoin Temple, Uji City, Japan [Photograph]. https://www.flickr.com/photos/jimg944/2485335064

Fig. 05 Hōryū-ji temple

Arany, S. (2010b). Untitled [Photograph]. https://www.flickr.com/ photos/28203536@N06/4763010240

Fig. 06 Timeline of technology.

Fig. 07 Nara, Japan.

Arany, S. (2010a). Untitled [Photograph]. https://www.flickr.com/ photos/monkist/4762766354/in/album-72157624298546383/

Fig. 08 Timber Stack.

Wright, D. (2011). Roadside Timber Stack [Photograph]. https:// www.flickr.com/photos/dhwright/5916636166/in/photostream/

Fig. 09 Linear economy diagram adapted from Ellen MacArthur Foundation.

Fig. 10 Circular economy diagram adapted from Ellen MacArthur Foundation.

Fig. 11 Ropes tied on brown wooden boat on water.

Hardy, M. (2019). Ropes tied on brown wooden boat on water [Photograph]. https://www.pexels.com/photo/ropes-tied-on-brownwooden-boat-on-water-2568028/ 
Fig. 12 "Hōryū-ji, Nara, Japan", the Golden Hall and the Pagoda.

Pontida, R. (2013). Hōryū-ji, Nara, Japan. https://www.flickr.com/ photos/romainpontida/10226688925

Fig. 13 Diagram of timber cells after modification, adapted from Abodo Wood Ltd "What is Thermal Modification".

Fig. 14 Diagram of thermal modification adapted from "Strength and Colour Response of Solid Wood to Heat Treatment".

Fig. 15 Diagram of thermal modification adapted from WTT Wood Treatment Technology.

Fig. 16 Diagram of thermal modification adapted from Accoya.

Fig. 17 RO\&AD Architecten - Moses Bridge.

Forgemind ArchiMedia. (2012). RO\&AD Architecten-Moses Bridge [Photograph]. https://www.flickr.com/photos/eager/7669585316

Fig. 18 Interior stairway of SunnyHills at Minami Aoyama.

Caruso, E. (n.d.). Sunnyhills7 EDWARD CARUSO [Photograph].

Fig. 19 Railway Cottage on Tarikaka Street, Ngaio.

Fig. 20 CNC modela prototyping joints.

Fig. 21 Use of drill press on joint.

Fig. 22 GC Prostho Museum Research Center street view.

Ano, D. (n.d.-b). GC50_170 [Photograph].

Fig. 23 Cidor joint system.

Fig. 24 Street view of SunnyHills at Minami Aoyama.

Ano, D. (n.d.-c). Sunnyhills1 DAICI ANO [Photograph].

Fig. 25 Jigoku-Gumi joint system. 
Fig. 26 Façade on roof top of SunnyHills at Minami Aoyama.

Guarino, A. (n.d.-a). Sunnyhills11 ALESSIO GUARINO [Photograph].

Fig. 27 Interior of SunnyHills at Minami Aoyama.

Guarino, A. (n.d.-b). Sunnyhills9 ALESSIO GUARINO [Photograph].

Fig. 28 Section of SunnyHills at Minami Aoyama.

Kengo Kuma \& Associates. (2014). 131202_sec_vr4 [Technical Drawing].

Fig. 29 Top image, render of Finansparken Bjergsted.

Rando, M. (2019, January 14). NZIA: Mario Rando-Visiting Engineer from Norway Degree of Freedom.

Fig. 30 Bottom right image, assembly of structure.

Rando, M. (2019, January 14). NZIA: Mario Rando-Visiting Engineer from Norway Degree of Freedom.

Fig. 31 Top left image, exploded isometric drawing of structure.

Rando, M. (2019, January 14). NZIA: Mario Rando-Visiting Engineer from Norway Degree of Freedom.

Fig. 32 Bottom image, mid-construction of the Finansparken Bjergsted. Rando, M. (2019, January 14). NZIA: Mario Rando-Visiting Engineer from Norway Degree of Freedom.

Fig. 33 Railway Cottage with a lattice style porch on Tarikaka Street, Ngaio.

Fig. 34 End Mills.

Blickpixel. (n.d.). Drill Milling Milling Machine [Photograph]. Retrieved 30 July 2019, from https://www.needpix.com/photo/242241/ drill-milling-milling-machine-drilling-drill-bit-set-tool-metalmetalworking-industry

Fig. 35 Process of cutting traditional joints.

Fig. 36 Isometric drawings of selected test joints. From top to bottom, halved dovetail, interlocking tenon joint, mitred double bridle joint, and corner bridle joint. 
Fig. 37 Roughing of joints - pushing joint through band saw fast, leading to wobbly cuts.

Fig. 38 Hand-tool tectonic test joints made of Fijian kauri, disassembled.

Fig. 39 Hand-tool tectonic test joints made of Fijian kauri, plan view and disassembled.

Fig. 40 Hand-tool tectonic test joints made of Fijian kauri, assembled.

Fig. 41 Series of string models iteration one.

Fig. 42 Series of string models iteration two.

Fig. 43 Abstract acrylic models.

Fig. 44 Dogbone fillet internal centred on the corner.

Fig. 45 Interlocking tenon joint soaking in water.

Fig. 46 Cracking on the end grain of the interlocking tenon joint.

Fig. 47 First iteration, bridle joint - major tearing of fibres from the CNC router.

Fig. 48 First iteration, interlocking tenon joint.

Fig. 49 First iteration, corner bridle joint.

Fig. 50 CNC Router profiling joints, iteration one

Fig. 51 Sketch series of jig configuration.

Fig. 52 Close up image of dual bevel sliding mitre saw blade.

Fig. 53 Foam board lap joint.

Fig. 54 Foam board scarf joint. 
Fig. 55 Foam board roughing out of segments.

Fig. 56 Mitre saw.

Goff, P. (2019). Untitled [Photograph]. https://unsplash.com/ photos/3ddULwpBoF4

Fig. 57 Corner bridle joint.

Fig. 58 Angled corner bridle joint.

Fig. 59 Underside of angled corner bridle joint.

Fig. 60 Butterfly Joint.

Fig. 61 Keys for the butterfly Joint.

Fig. 62 Dogbone fillet internal, radius perpendicular to edges.

Fig. 63 Interlocking tenon joint, ripping of fibres.

Fig. 64 Test error, CNC profile cut in Fijian Kauri.

Fig. 65 Angle bridle, comparison of edges.

Fig. 67 Twisting of end mill.

Fig. 68 Mitre saw diagram.

Fig. 69 Lap joint - Iteration one.

Fig. 70 Lap joint - Iteration two.

Fig. 71 Lap joint - Iteration three.

Fig. 72 Lap joint - Iteration four.

Fig. 73 Scarf joint - Iterations. 
Fig. 74 Splicing joint marking diagrams.

Fig. 75 Connection joint marking diagrams 1.

Fig. 76 Connection joint marking diagrams 2.

Fig. 77 Connection joint marking diagrams 3.

Fig. 78 Connection joint marking diagrams 4.

Fig. 79 Connection joint marking diagrams 5.

Fig. 80 Setting height on mitre saw.

Fig. 81 Fixed jigs assisting cuts.

Fig. 82 Cutting joints with mitre saw.

Fig. 83 Isometric call out of joints.

Fig. 84 Marking Diagram of joints.

Fig. 85 Series showing the assembly of the joints.

Fig. 86 Series showing the assembly of the stand.

Fig. 87 Existing pergola at Wellington Central home.

Fig. 88 Existing pavilion at Wellington Central home.

Fig. 89 Existing pavilion at Ngaio home.

Fig. 90 Alternative joints for pergola.

Fig. 91 Alternative joints for pavilion 1.

Fig. 92 Alternative joints for pavilion 2.

Fig. 93 Interlocking tenon joint. 


\section{APPENDIX A}

Title: Craft of Boatmaking

Researcher: Jasmine Tran

Interviewee: Paul Tozer

Date: Sunday 14th July 2019

Transcript Summary

Paul Tozer has been in the industry for 55 year, beginning his apprenticeship at $15 y e a r s$ of age.

\section{Craft x Boat making}

In traditional boat making, the whole process is craft, from drawing scaled plans, to assembly.

The process would usually consist of drawing a scaled plan, a 1:1 scale plan, taking patterns off the plan for the timber, cutting the timber, bending the timber (if needed) and assembling the pieces.

Traditionally an adze is used to cut and shape the timber. Power tools are now used to assist cutting the timber. Machines have decreased manual labour, making life a lit easier.

When Paul Tozer began his apprenticeship, he was taught the wood work, the technical drawings, how to install the motors, and the plumbing. The job required an expertise in all fields except the electrical. The apprenticeships in present time only requires of one element of boat building, such as wither laying fibreglass or joinery.

A lot of the timber is steam bent, with the larger and heavier elements, such as the elements around the keel and stem, are shaped with an adze and tomahawk.

\section{Process}

The whole process consists of craft, the ability to draw it, and to understand requires a lot of skill.

For steel boats :

You draw it all the way out to full size and then you take thin wooden templates $(6 \mathrm{~mm}$ MDF and a hot glue gun have made cutting out patterns for a template a lot easier, however, it creates a lot of waste) of all the 
shapes and you just roll the steel to that shape.

It is the same with wood boat building, you have patterns, you make your frame up to these shapes and then space them out to both distances. And when you bend your plank around them it should be spot on.

Depending on the material, the treatment of the patterns cut out indiviualises each piece making them all unique. (rolling out steel or steam bending timber)

The mass produced fibreglass boats have influenced the boatmaking industry in a postive yet negative way. It has made production a lot less labour intensive, and therefore easier, faster and cheaper to produce. It makes it easier for people to own boats, and there's no maintenance. However this has lead to the loss of craftsmanship in boat making.

Fibreglass $x$ tradition

"they want the good quality, but they don't want to pay for it" "Its just the way life is now. Everything is just mass produced."

Fibreglass catamaran still have to be hand done, they are laid up on big panels on a table, cut to shape, placed on a vacuum table and then it is glassed in the vacuum, it sucks all the air out and shapes the fibreglass (double check). Once its off, you cut out each sections on an assembler. Traditional boats are preferred for the look and aesthetic, which costs a lot of money to build and restore. However with a wooden boat you've got maintenance otherwise they will deteriorate in look and quality.

A well made traditional boat will last a hundred years, whereas fibreglass won't. Fibreglass breaks down, and they easily go out of style, whereas an old wooden boat is a classic, it stays a classic.

Do you think craft will continue in your trade?

"I think it will always continue, but very limited. Some guys just really like old wooden boats."

Tools

The some of Paul Tozer's traditional tools date back multiple generations. "On an old sailing ship over in England, the Cutty Sark, they've got a mueseum in it and all the tools in there are what I use. And that's from like the 1700s, and they are still the same tools some of us use today." "Most of my tools I've got I've had for 55years, you know ive had from my 
apprentace, still got the same hammer, same plane, same everything." Paul Tozer makes a lot of tools that he needs for certain jobs. He would grind down tools to fit to size as he has to make a lot of specific tools for boat building.

A lot of the traditional tools cannot be bought at a local hardware store, instead have to be imported from overseas

Corking a boat is punching cotton between all the wooden planks

"My corking irons were given to me by the old guy that taught me and they were actually his fathers before that. My adze belonged to Griffin's great grandad."

"For a house builder, you don't need half as many tools, its real basic tools for building a house."

Timber boats just got to be hand built. Even with aluminim and that, its still got to draw the plans out, you still got to cut each section of aluminium out, you got to get someone to weld it all, but its basically still boat building the old way, but its not the same.

Dovetail joins?

A lot of our stuff with big heavy stuff, you'd do like a half dovetail to put all the big deck beams etc that are just too big and because of the shape of the deck beams which all curve so you cant use a machine, they've all got to be hand done. A lot of the shaping on wooden boats it all has to be hand done on bandsaws and things like that. You cant just mass produce them.

\section{Rusting boat}

you know a lot of the boats i do still do, like an old one hundred year old boat I'm going to restore for the Historic Trust out in Kaipoi. And those planks, They're like old weatherboards on a house, see how they over lap like that? When you put the nails in, you put a copper nail in it, you punch it in and you get a guy on the outside with a what you call it a dolly, it a heavy lump of metal, that holds one end of the nail, and you go on the otherside and you got like a washer, a raised copper washer, and you punch that over the end of the nail, snip it off then you got a ball peen the rove with a small engineers hammer, and its all done like that, thousands of nails. Its time consuming, but at the end of the day it's the old traditional way of doing it. 
Is there any machines that could help the process (inserting copper nails)?

Theres no machine that can do it like that, theres sort of lots of things like that really that machines cant do like corking a boat, you couldn't do it on a machine. You still got to go along and punch every bit of cotton in by hand.

\section{Material choice}

Yeah you cant get the good kauri anymore.

Now days you cannot get the good kauri easily in New Zealand, we use to get it by the 40 railway wagon at a time of real good quality, but now they're not allowed to mill it and stuff like that so that's another reason people are using rubbish timber instead of the good stuff.

I would shape all this out of hardwood with an adze and a little tomahawk and then you got to lay planks around to you have to lay battens around so it can lay natural, then you cut your planks out to that shape you can do that both in timber.

Steam bending would sometimes take up to 5 hours, especially on the real bendy ones.

If I had planks that I needed to bend, I would take them out and soak them in the creek for a week, you know just got a bit of rope tied around it and leave it soaking. Its just stuff like that you wouldn't do now.

Its all rotten I ended up, this is where all the botlt and everything were all rotten in the timber, and that was all kauri, but that was built in 1911. Its all totally rotten and had big steel frames in it. Every row with bolts in it is rotten.

Did you still use steel frames?

(35.35) No, just use timber frame, I don't know why they had steel frames in this. These bolt they should be half an inch thick but they were only like $2 \mathrm{~mm}$ because they were just eaten away. This is when I started pulling out planks, I had to replace so many planks I could only do the odd one at a time but I ended up rebuilding a whole boat. So that it would keep its shape. If I took the whole lot off it would have lost its shape. What you do with these is, these is where you cork it, you put a little $V$ on the edge of each plank and then you go along with the cotton and spin it so its like rope and then you just drive it in all the way around. And when it 
goes into the water it swells. It will leak for the first week or so.

So you replaced all the timber? (38.17)

Pretty much the whole hull. He thought I was going to be there for 3 weeks and I was there for 3 years. That's one of the new bulk head I put inside, these are new frames I put in where the steel ones were.

Where the frames steam bent as well?

No, cut out of solid timber. It was rotten all over even around here was rotten and all that and had to be replaced, see there ive prety much replaced the whole hull the stem was all rotten so in to cut those big knees out on the bandsaw and bolt all that back together. A lot of the bolts you have to make yourself out of copper. You just get the copper rod and you hand thread it and then you get an engineers hammer and ball peen the head on it.

Why did it rot? Was it age or material?

Materials that is used is very import. For example the repair of the Halswell Junction boat the steel bolts and the steel frame and things like that. If it had been done with wooden frames and copper bolts, it would still be fine.

Was it because of the rusting steel?

Yeah, and then the bolts rust away and starts leaking all the water in. (interior fitting) See I just done it out of Rimu (41.53) because they didn't have, well, let just say cant afford kauri but he wanted rimu he had a whole lot of old hard rimu there, it was beautiful timber but its really not good in a boat. 


\section{APPENDIX B}

Title: Jigs

Researcher: Jasmine Tran

Interviewee: Isaac Graham

Date: Sunday 13th November 2019

A written correspondence interview.

1. Have you had to cut out timber joints on-site? What type? Eg. Lap join, mortise and tenon, bridle joint... If not why?

A common woodworking joint I have used when timber framing would be a Lap joint. It would be used where members need to pass through each other but maintain their structural integrity. I have also used a pocket hole jig for drilling holes into timber particular for furniture and joinery.

Other types of joints such as Mortise and Tenon and Bridle joints are rare if non-existent in commercial and residential timber framing due to the preference to using mechanical fixing such as nails/ screws or steel structural fixings. Joints such as Finger Jointing and Tongue and Groove are however already common in materials such as Fascia board and flooring, although these are factory produced.

2. If you were to create a join (eg. Angled bridle joint), what would be required to create a jig for this? Would this be difficult/time consuming?

As long as the angles and depths are known, making a jig for these cuts would be possible but time consuming. It would however once completed allow for the joint to be created quickly and easily. A cut of the depth needed for the Bridle joint would probably need to be done with a skill saw or drop saw. Setting a drop saw to the correct angle and depth you could take the cut out fairly quickly. If cutting the joint with a router, a plywood jig would be a good option, or anything that can be used to guide the router around the cut.

All this would be far easier and tidier in a workshop with a dimension saw. 
3. Would having a set jig for specific joins make construction easier? Do you think it would be faster?

If those joints were necessary for whatever reason, and it was not an option to get them machined off site, then yes a jig would help speed the process up if you were doing a large number of particular joints.

Currently there are enough products at cost effective prices to allow modern builders to join timbers members together however they wish. The time spent cutting some of the more difficult joints would be saved and be more economic with a steel fixing instead. It is easier to add a higher kN fixing to a design than specify a type of woodworking joint. That being said, if a system is created where joints can be quickly and easily produced, they certainly can help create a stronger and more stable structure.

4. Do you think using set jigs would make specific timber joints more readily available?

If the jig was easy enough to use it would take a lot of the struggle out of cutting certain joints, however a skilled carpenter will typically be able to mark out and cut timber joints with their usual tools. It would have to be specified in the plans for the builder to decide to use a woodworking joint over modern conventional methods during construction, unless they were specifically aiming to use less steel fixings or more historically traditional methods. 